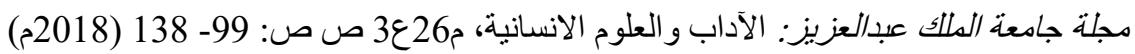

DOI:10.4197/Art.26-3.5

مشروع بعثة الحكومة الفرنسية إلى مكة في عهد الثريف حسين بن علي عام 1334هـ/ 1916م (در اسة تاريخية وثائقية)

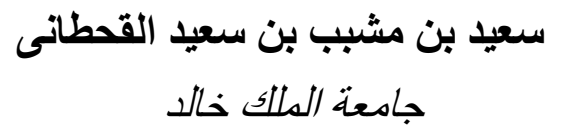

مستخلص. يهدف هذا البحث إلى دراسة مشروع بعثة الحكومة الفرنسية إلى مكة في عهد الثريف حسين بن علي عام 1334هـ/ 1916م (در اسة تاريخية وثائقية)، ولعل أهمية هذا البحث تكمن في محاولة إبراز الدور الذي قامت به الحكومة الفرنسية خلال الحرب العالمية الأولى في محاولة منها للسيطرة على ولاية الحجاز من خلال رئيس بعثتها ابن غبريط الذي أُنيطت إليه مهام البعثة إلى الثريف حسين لبناء خيوط التواصل معه، كما ستوضح الدر اسة لاحقًا، لأنه قد لعب دورًا محوريًا في شر اء نُزل "خان" في مكة من أجل جذب انتباه المسلمين الذين بقعون تحت السيطرة الاستعمارية الفرنسية؛ وتكتسب هذه الدراسة أهمّية عندما نضعها في سياقها التاريخي، ونعلم أن الهدف

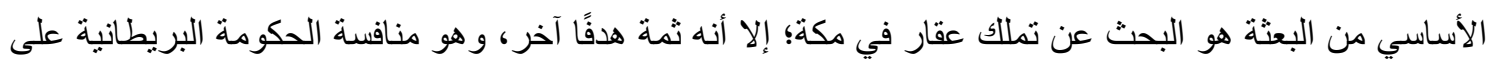
و لاية الحجاز لما لها من أهمية لدى المسلمين. ويزدادُ البحث أهمية عندما يعتمد على الوثائق، موظفا السيّاق التاريخي للنّقد و التحليل، في إطار ما هو مناح من نصوص ووثائق تم الاعتماد عليها لإخر اج در اسة معدقة. الكلمات المفتاحية: بعثة الحكومة الفرنسية ـ الثريف حسين بن علي.

الاستر اتيجي الذي يربط بين الشرق والغرب، ويضم

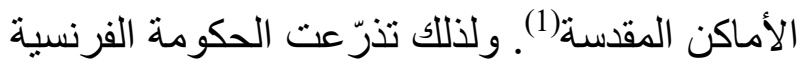
بإنشاء القنصلية الفرنسية في جدة منذ عام 1255هـ/ 1839م؛ وكان ظاهر ها الاهتمام بالثؤون الدينية،

(1) أبو عليه، عبد الفتاح حسن، تاريخ الدولة السعودية الثانية (الرياض: دار

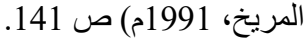

\section{المقدمة}

يركّز البحث على مشروع بعثة الحكومة الفرنسية إلى مكة في عهد الثريف حسين بن علي عام 1334هـ/ 1916 (در اسة تاريخية وثائقية)؛ وتركيزنا ناشىء من طبيعة الموضوع، إذ تطلعت الحكومة الفرنسية إلى شبه الجزيرة العربية لموقعها 
الحجاز، من أجل إكمال حلقات نقص الأحداث التاريخية أثناء الحرب العالمية الأولى معتمدين في التيات

ذلك على الوثائق (4).

سوف نعرض في هذه الدراسة لأهم ما استعرضته البعثة التي جاءت حرصا من الحكومة الفرنسية لتحقيق أهدافها السياسية؛ فكانت سنة 1334هـ/ 1916م سنة محورية في علاقة الحكومة الفرنسية مع ولاية الحجاز من حيث إرسال وفد عالي المستوى يؤمن التبعية الاستعمارية، خاصة بعد إعلان الثريف حسين الحرب على الدولة العثمانية. لذللك اختارت الحكومة الفرنسية ابن غبريط ومعه نخبة من حجاج المغاربة، و أُنيطت بهم مهمة تمثيلها لدى الثريف حسين، غير أن أهم ما يميّز رئيس البعثة ابن غبريط هو طرحه و إبداء رأيه الثخصي لهين وتحليله للأحداث بالقدر الذي يبرز إحاطته الكافية بما يدور حوله من الأحداث. وعلى إثر ذلك تميز ابن غبريط في مهمته ونجح في تنفيذ مشروع الحكومة الفرنسية في شر اء نُزل "خان" في مكان. ويزدادُ البحث أهمية عندما يعتمد على الوثائق، التي في

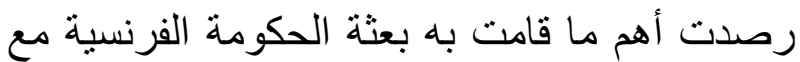
الثريف حسين - موظفا السيّاق التاريخي للنقا و التحليل في إطار ما هو متاح من نصوص ووثنائق تم الاعتماد ـ عليها - لإخر اج در اسة رصينة معمّقة. وقد جرى معالجة الموضوع من خلال نقاط مختلفة تغطي أبرز المحاور التالية: 1- مناقثة مشروع دانه قانون شراء نُزل "خان في مكة داخل البرلمان الفرنسي. 2- عرض المشروع داخل مجلس الثيوخ

و(4)سوقير، المنذر، "العلاقات السعودية الفرنسية من خلال العشرينات

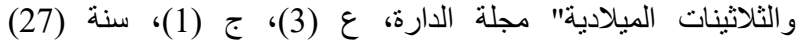

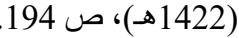

و التجارية (وخاصة أنه يقع تحت سيطرنها بلدان شمال وغرب أفريقيا المسلمة الذين يأتون للحج كل

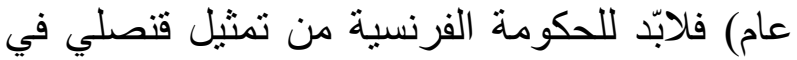

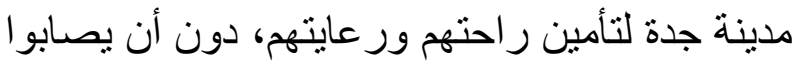

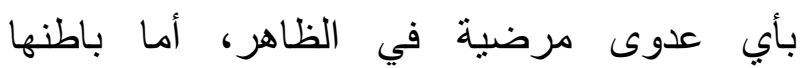

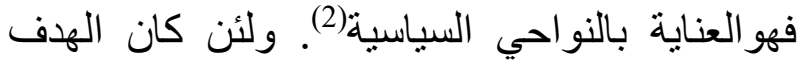

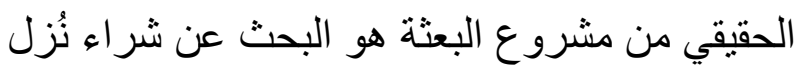

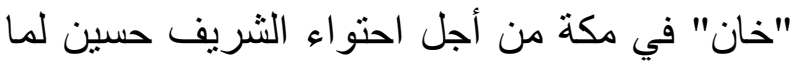
له من أهمية بالغة في قلوب المسلمين في أنحاء

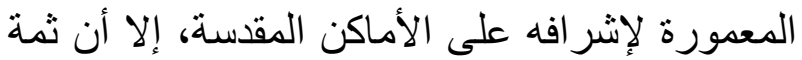

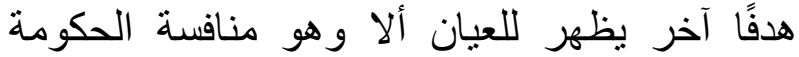
البريطانية على و لاية الحجاز ، التي ازداد نفوذها فيها

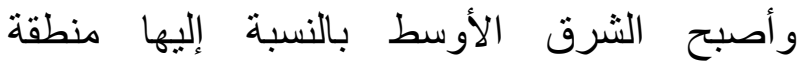

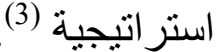
تبلورت مطامع كل دولة أثناء الحرب العالمية الأولى، فأصبحت تقدم لرعاياها المسلمين الواقعين تحت سيطرتها أفضل الخدمات؛ لأن موسم الحج يقدم لران لهما دورًا دعائيًا في البلدان التي ترزئل استعمار ها، إما بتعاطف إسلامي بعدم مناهضة

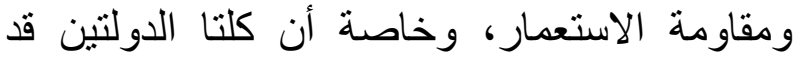

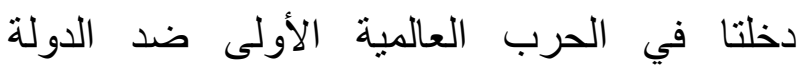
العثمانية. ولذلك قررت الحكومة الفرنسية عدم إثارة أي نزاع مع الحكومة البريطانية لما له من ناثير لهائه

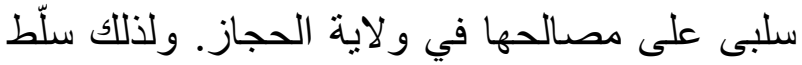
البحث الضوء على جو انب تاريخية مهمة في ولاية

(2)(الأنصاري، عبد القدوس، موسوعة تاريخ مدينة جدة ( د.ن، 1982/م) (1936)

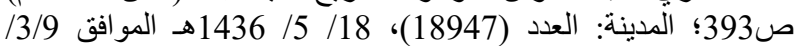
2015

${ }^{(3)}$ Busch, Briton Cooper, Britain India and the Arabs 1914-1921(London: University of California Press, 1971), p.VI. 
و هذا المقترح في الأساس مبنى على مقترح تقرير

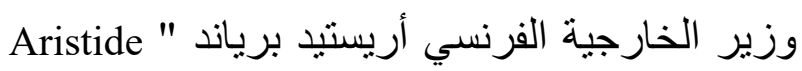

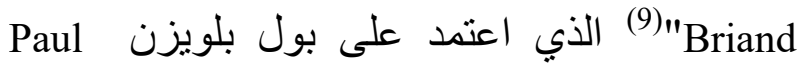
"Bluysen" وافقت على ذلك المشروع(11) الذي اقترحته الإدارة الاستعمارية الفرنسية والمتمثل في شراء نُزل

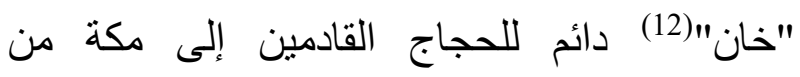

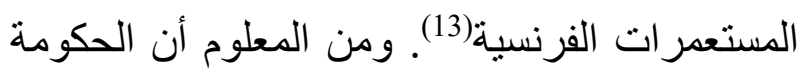
الفرنسية لا تسنطيع العمل بذلك المقترح حتى تأخذ

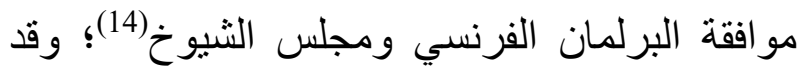
نظرت الحكومة الفرنسية إلى هذه القضية بعين

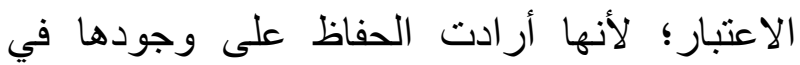
مستعمراتها الإسلامية المنتشرة في شمال القارة الأفريقية والتي كانت تقصد سنويا و لاية الحجاز (15)

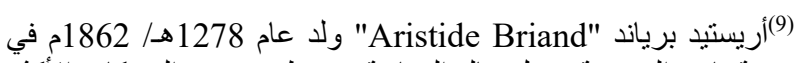

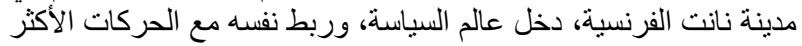

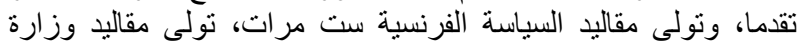

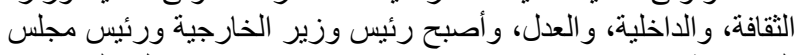

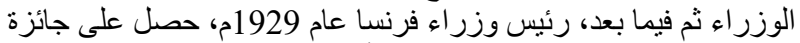

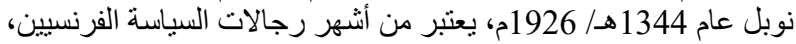

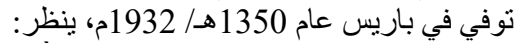
Bellon, Christophe: Àristide Briand, (Paris: Edition CNRS, 2016), P. 382.

(10)بول بلويزن "Paul Bluysen" ولد عام 1861م، صحفي وسياسي

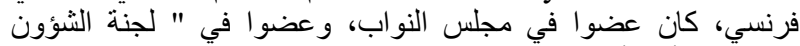

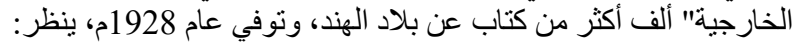
Http://data.bnf.fr/12951347/paul_bluysen.

(11)"Journal Officiel...", 28 December 1915, p, 2287.

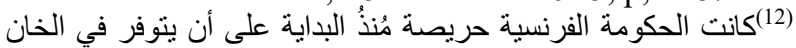

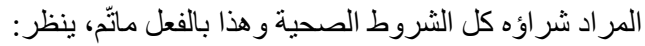

"Rapport Médical sur le local Propose". Mecque, le 11 Octobre, 1916. Ministere des Àffaires Étrangeres, 19151919, "Àrabie-Hejaz", 18. Mission dé M. Cherchali. Serie É. Carton 310. Dossier 2, p. 11.

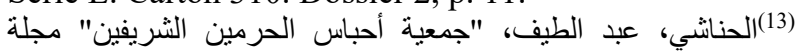

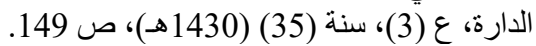
(14)"Journal Officiel...", 28 December 1915, p, 2287.

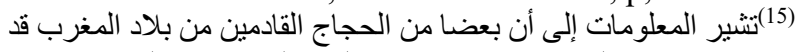

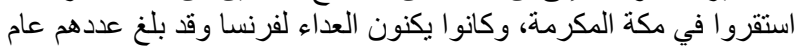

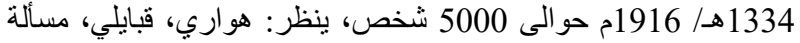

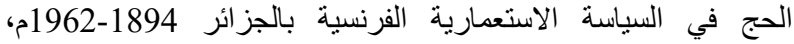

الفرنسي. 3- موقف الحكام الفرنسيين من المشروع. 4- تنفيذ المشروع الفرنسي. 5- اختيار مرشح ووفد لتنفيذ المشروع. 6- موقف الحكومة البريطانية من الششروع. 7- مهام البعثة ونقلهم إلى ميناء جدة. 8مراسم استقبال البعثة الفرنسية من قبل الثريف حسين. 9- المفاوضات حول تنفيذ المشروع. 10مغادرة البعثة، ونتائجها. 11- الخاتمة.

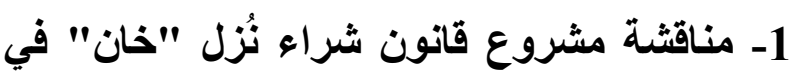
مكة داخل البرلمان الفرنسي: في سنة 1332هـ/ الحكومة الفرنسية بسبب نشوب الحرب العالمية الأولى وفي السنة التي تلتها منعت الحكومة الفرنسية حجّاجها من (شمال وغرب إفريقيا) من الذهاب إلى الى الى

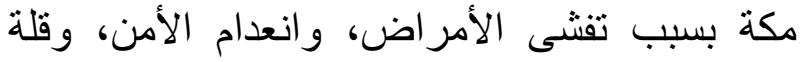

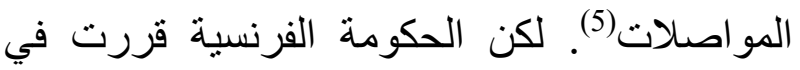
جلسة البرلمان المعقود بتاريخ: 3-11- 1333هـ/ 12-1915-9 (من خلال رئيس مجلس النواب بول

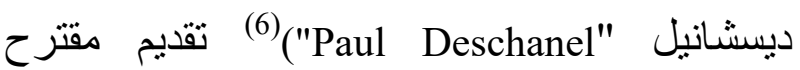
مشروع شر اء نُزل "خان" (7) في مكة المكرمة(8).

(5)"Journal Officiel de la Republique Française, Debats Parlementaires". Chambre des Deputes, 28 December 1915, p, 2287.

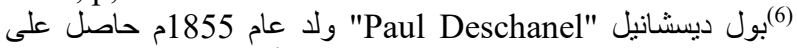

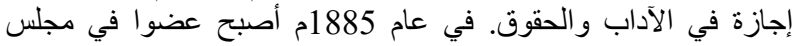

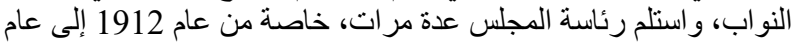

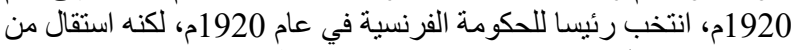

منصبه بسبب المرض، وتوفي عام 1922م، ينظر : Http://www. elysee.fr/Presidence/Paul-Deschanel.

(7) تجدر الإثارة إلى أن نُزل "خان" كان معروفًا في ولاية الحجاز تحت

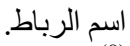

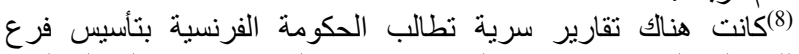

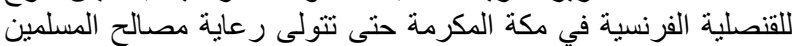

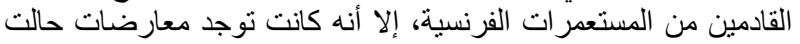

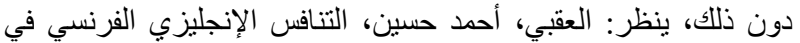

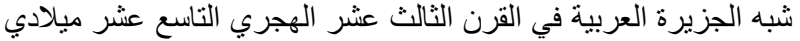

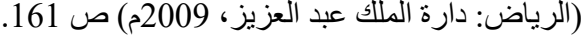


و على إثر ذللك وفي جدول أعمال يوم الثثلاثاء 5-111333هـ/ 1915-9-14م تمت دعوة البرلمان(23) المتخصص لمناقثنة مشاريع القانونيين:(24) الأول يتعلق بتخصص اعتماد مالي قدره خمسمائة ألف الف فرنك لتمويل مشروع شراء نُزل "خان" في مكة، صار مخصصيًا للحجاج القادمين من مناطق السيطرة

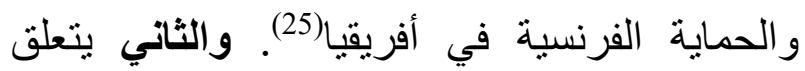
بتسمية مستشارين شرعيين مسلمين لدى "اللجنة

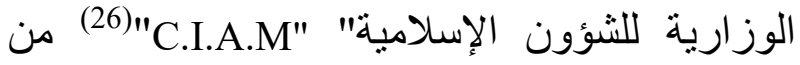

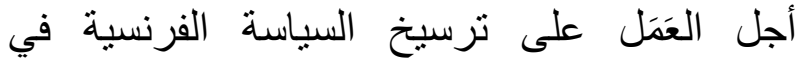
مستعمر اتها في شمال وغرب أفريقيا على أن يكون مقر ها مدينة باريس(27). و إذ لم يكن هناك اعتر اض فئاض

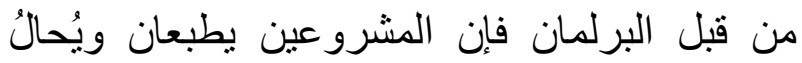

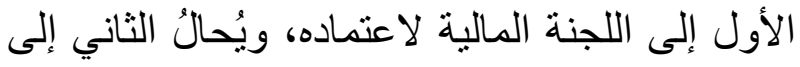
لجنة الثؤية

Guerresmondiales et Conflitscontemporains 2006/1 ( ${ }^{\circ}$ 221), pp. 17-31.

مجلجدر الإثشارة إلى أن البرلمان الفرنسي ينقسم إلى قسمين: الأول

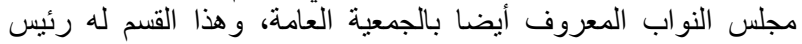

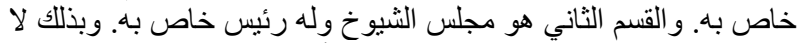

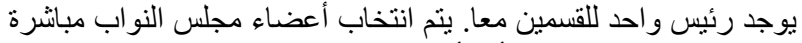

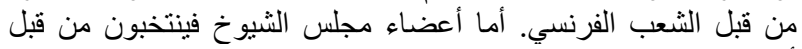
أعضاء مجلس النواب ومن قبل ممثلين عن الددن والبلدات الفرنسية،

Http://www.Assemblee-Nationale.fr/Decouvrir-1assemblee/role-et-pouvoirs-de-l-assemblee-nationale.

(24)"Journal Officiel...", 28 December 1915, p, 2287.

${ }^{(25)}$ Ibid.

Commission " "اللجنة الوزارية للثؤون الإسلامية

"C.I.À.M" Interministerieiie des Àffaires Musulman استحدثت تلك اللجنة عام 1911م برئاسة وزير الخارجية وتضم ممثلًا من ونه

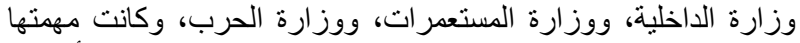

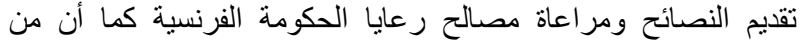

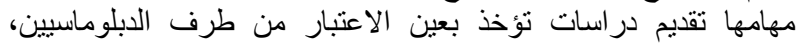

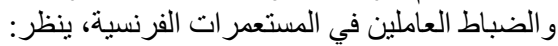

Pautremat, Pascal, La Politique Musulmane de la France au xxe siecle. De l'Hexagone aux Terresd' Islam. Espoirs, Réussites, échecs (Paris: Maisonneuve et Larose, 2003), p.42-43.

(27)"Journal Officiel...", 28 December 1915, p, 2228.
لأداء فريضة الحج(16)؛ ولكن الحكومة ذاتها خشيت على حجاجها من الوقوع في فخ التأثير الديني، وفي فخ السياسة المعادية، مما يؤدي إلى فقدان الحكومة الفرنسية مكانتها وريمنتها على شمال وغرب إنى أفريقيا(17). ولذلك وجدت نفسها مضطرة إلى أن تمنع وهئ المسلمين من أداء فريضة الحج(18) وهذا غير ممكن، وهئ حتى لا بقعوا تحت تأثير القوى المناوئة للحكومة الفرنسية مثل بريطانيا(19) التي امتلكت مميزات في مكة(20) بالإضافة إلى ذلك فقد سعت الحكومة الفرنسية إلى تحسين صورنها في نظر العالم الإسلامي، كما هدفت إلى أن تعمل على مراقبة رعاياها من المسلمين وضبط تحركاتهم وما يفكرون فيه(21)، على اعتبار أنها تدافع عن حقوق المسلمين وحرياتهم الدينية(22).

(الدكتوراة)، جامعة وهران، كلية العلوم الإنسانية والحضارة الإسلامية،

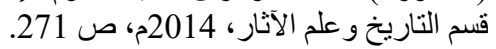

(16"La Depeche Direction des Affaires Politiques et Commerciales, Sous-Diriction Déuropes", du 14 Juin, 1916. Àrchives Dipiomatique de Nantes, Maroc, Dossier, No, 660.

لانه في التركبز على المستعمرات الفرنسية في شمال القارة الأفريقية،

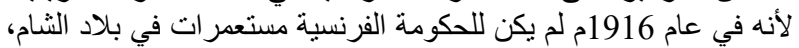

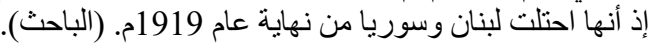

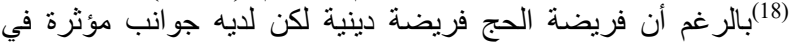

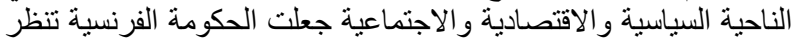

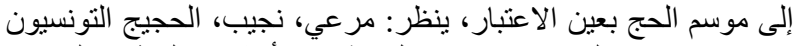

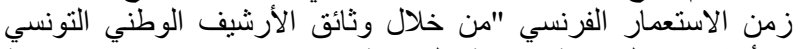

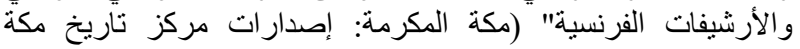
المكرمة، 2014م) ص13 14، 147.

(19)"La Depeche Direction des Affaires...", du 14 Juin, 1916, Maroc, Dossier, No, 660.

${ }^{(20)}$ Telegram Secret From Resident Jedda to High Commissioner Cairo "Arabie Report", 12 July 1917, F.O. 371/6075.

${ }^{(21)}$ Meynier, Gilbert, L Algerie Revellee, Là Guerre de 1914-1918 et le Premier Quàrt du Xxe (Geneva: Publications Libràirue Droze, 1981), p. 536.

${ }^{(22)}$ Pascal, Pautremat, "La Mission du Lieutenantcolonel Brémond au Hedjaz, 1916-1917", Dans 
أمام أعضاء مجلس الثبوخ كتبته اللجنة المالية الموجودة في مجلس الثيوخ وهو مشروع قانون، يتعلق بشر اء نُزل "خان" في مكة، وطلب من رئيس مجلس الثيوخ إعلان الحالة المستعجلة والمناقثة الفورية واعتماد مشروع القانون؛ لأنه قد تأخر إعلان الفرانه تنفيذه(36)، عندها طالب رئيس مجلس الثيوخ من دومر "Doumer" يوم الخميس بتاريخ: 1-201334هـ/ 1915-12-9م أن يتقدم بقراءة التقرير إن لم يكن هناك اعتر اض من مجلس الثيوخ(37) خاصة أن الحكومة البريطانية كانت تطحح إلى تطوير وجودها في شبه الجزيرة العربية(38. و على إثر ذللك قال دومر "Doumer": قُدِّمَ لمجلس الثشيوخ تقرير باسم اللجنة المالية المكلفة، ومعها تقرير من جوستين غودارت "Justin Godart" تقريت

وزيرا للمالية من 1921م إلى 1922م، وزئل وفي عام 1925م أصبح رئيسا

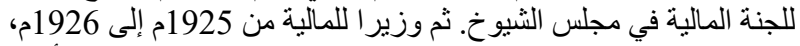

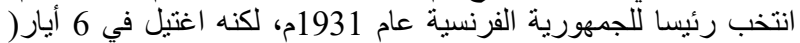
مايو ) عام 1932م في مدينة باريس، ينظر : لإنس

Chauvin, Jacques, Doumer, Paul, le Président Àssassine, (Paris: Les Editions du Pantheon, 1994), p. 217; Http://www.elysee.fr/la-presidence/paul-doumer.

(36)"Journal Officiel de la Republique Française, Debats Parlementaires". Chambre des Deputes, 20 January 1916, p, 14.

${ }^{(37)}$ Ibid.

1918)التميمي، عبد الجليل، دراسات في التاريخ العربي العثماني 1453-

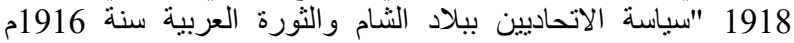

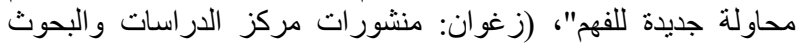

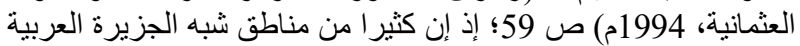
كانت تخضع للحكومة البريطانية، ينظر : سوقير ، "العلاقات السعودية...."

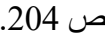

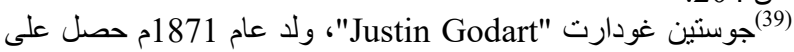

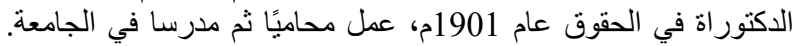

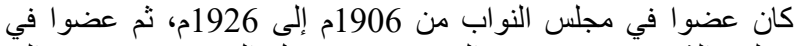

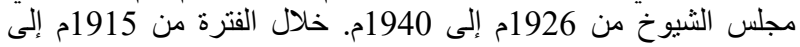

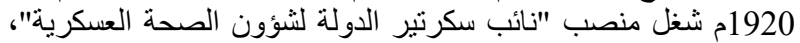

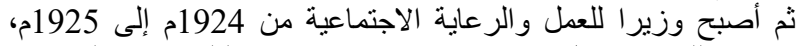

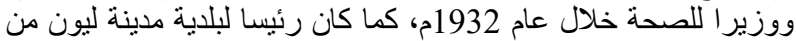
1944م إلى 1945م، ونوفي عام 1956م، ينظر:
و المستعدرات(28). وبعد عرض القانونيين بدأ رئيس المجلس بطلب من الحضور التصويت على المادة الوحيدة التي تم الاجتماع من أجلها(29)، وقال: "أود إعلام المجلس بأن "اللجنة الوزارية للشؤون الإسلامية" "C.I.A.M" لمراقبة الحجاج تقترح عليكم تعديل اسم القانون إلى: "مشروع قانون للمو افقة على صرف مبلغ خمسمائة ألف فرنلك لشر اء نُزل "خان" في مكة"(30). ثم طرح رئيس المجلس فئس

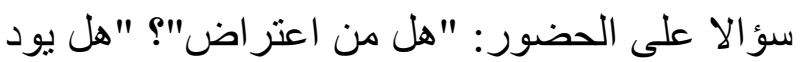
أحد مناقشة المادة الوحيدة في مشروع الأهو القانون"(31)؟ عندها أعلن رئيس المجلس عرض المشروع للتصويت. فلم يجد أي اعتر اض. وحينئذ أعلن رئيس المجلس أن يُعتمد اقتراح تعديل اسم القانون لأخذ الصبغة القانونية بموافقة كافة أعضاء البرلمان الفرنسي(32). بشرط أن يُحال مشروع القانون إلى مجلس الثيوخ لدر استه و إبداء الر أي(33). 2- عرض المشروع داخل مجلس الشيوخ القرنسي:

سادت فكرة "الحماية الرحيمة" و "المهمة النبيلة" داخل مجلس الثيوخ الفرنسي على المستعمرات الفرنسية في شمال وغرب أفريقيا(34) و على إثر ذلك تقدم بول دومر "Doumer Paul"(35) بقر اءة تقرير

${ }^{(28)}$ Ibid.

${ }^{(29)}$ Ibid.

${ }^{(30)}$ Ibid.

${ }^{(31)}$ Ibid.

${ }^{(32)}$ Ibid.

${ }^{(33)}$ Ibid.

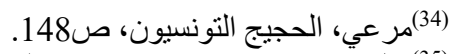

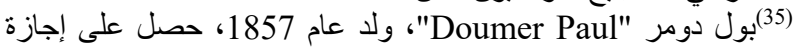

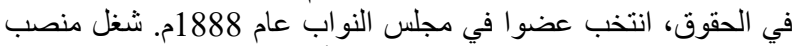

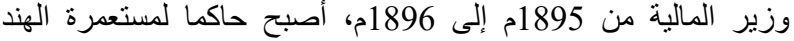

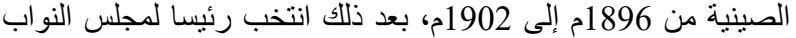
في عام 1902م، وفي عام 1912م أصبح عضوا في مجلس الثيوخ. ثم الثر 
أكد دومر "Doumer" لمجلس الثيوخ بأن نوصية مجلس البرلمان و "اللجنة الوزارة للثؤون الإسلامية" "C.I.A.M" أكّدنا بأنه في كل عام لهام يتوجه جمع غفير من المسلمين إلى الأماكن المقدسة

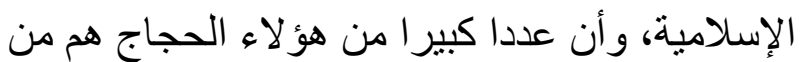

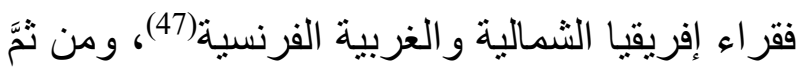
فإن تدفق جموع الحجاج قد أدى إلى ارتفاع كبير في

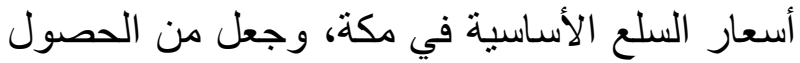
على مأوى أمر ا صعبا إن لم يكن مستحيلا(48)، لذلك الكاسل كان القنصل الفرنسي في مدينة جدة بول ليبيسيييه "Paul Lepissier" 1328هـ/1910م على "اللجنة الوزارية للثؤون الإسلامية" "C.I.A.M" تأسيس مشروع شراء نُزل "خان" دائم للحجاج القادمين من المستعمرات لاتين الفرنسية(49) على غرار ما فعلته الإمبراطورية

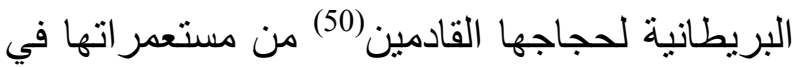
بلاد الهند(51)، والتي قد سخرت لهم دور ضيافة في

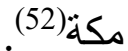

لذلك عُرض المشروع على "اللجنة الوزارية للثؤون الإسلامية" "C.I.A.M" (في الجلسة التي عقدت بتاريخ: 1330-18هـ/12-129-1911م من

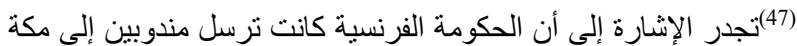

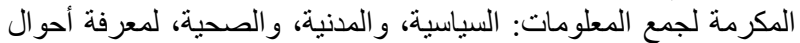

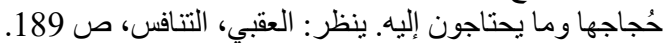
(48)"Journal Officiel...", 20 January 1916. p, 16.

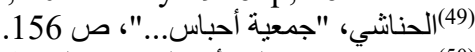

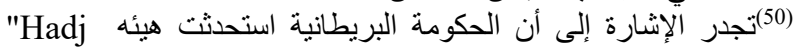
"Committee"

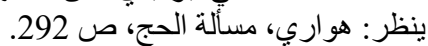

${ }^{(51)}$ Telegram Secret From Resident Jedda to High Commissioner Cairo "Arabie Report", 12 July 1917, F.O. 371/6075.

${ }^{(52)}$ Pautremat, La Politique Musulmane, p. 196.
نائب سكرتير الدولة لشؤون الصحة العسكرية بدراسة مشروع قانون اعتمده مجلس البرلمان، يتعلق بالموافقة على صرف مبلغ خمسمائة ألف أف فرنك لمشروع شر اء نُزل "خان" ب(40). وعندها سنحت الفرصة، وبرز نجم دومر "Doumer" مجلس البرلمان يوم الثلاثاء بتاريخ: 19-111333هـ/ 1915-9-28م قد أصبح مؤكدا، و أضاف: إن ذللك المشروع هو بمثنابة "أخوة بستحقها آلاف المسلمين المقاتلين(41) تحت راية فرنسا أثناء الحرب بمنابه العالمية الأولى الذين بذلو ا أرو احهم وضحو ا بأنفسهم

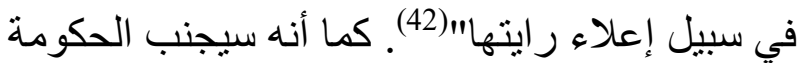
الفرنسية مشكلات الانتفاضات و المقاومة المسلحة و غير المسلحة(43)، للاقطار الإسلامية التي رزحت

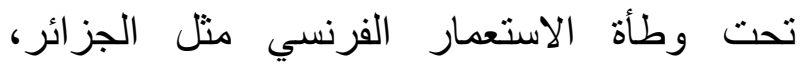
و المغرب وتونس(44)، من خلال شر اء نُزل "خان" منان

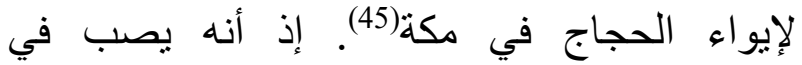
مصلحتها من خلال سهولة متابعة رعاياها من

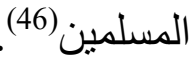

$\mathrm{Http} / / /$ fresques.ina.fr/rhone-alpes/fichemedia/Rhonal00368/justin-godart.html.

(40)"Journal Officiel...", 20 January 1916. p, 14.

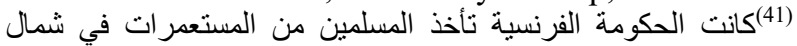

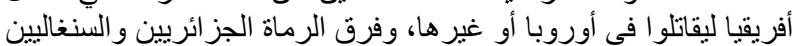

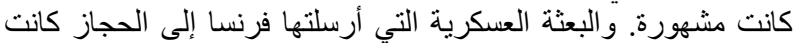

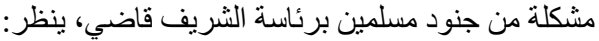
Http://orientxxi.info/l-orient-dans-la-guerre-1914-1918. (42)"Journal Officiel...", 20 January 1916. p, 15.

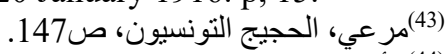

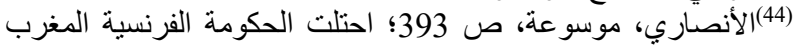

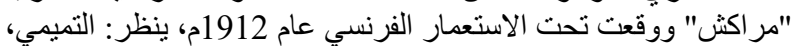

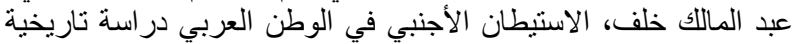

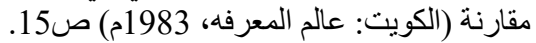

(45)"Journal Officiel...", 20 January 1916. p, 15.

${ }^{(46)}$ Ibid. 
فكرته تدور حول شراء نُزل "خان" في مدينة جدة،

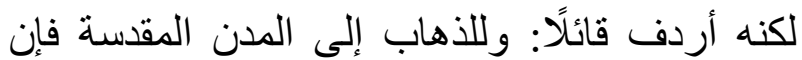
أغلب قو افل الحج تسلك طريق ميناء جدة أو طريق ميناء ينبع(60)، التي تعتبر ميناء المدينة المنورة(61). وكان المخطط آنذالك استنجار بيت في مدينة جدة، وتجهيزه بكل وسائل الراحة الضرورية، ووضعه

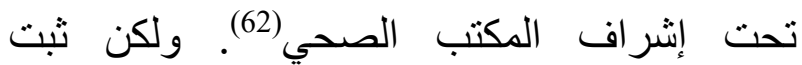
للحكومة الفرنسية أنه لا يمر في ميناء جدة إلا جزء من قو افل الحجاج، فأغلبها تسلك طريق ينبع هذا من ناحية(63)، ومن ناحية أخرى سيكون لخط الحديد الحجازي(64) الذي دشن قسم منه في تاريخ: 4-81326هـ/ 1-908-9 1908، نتائج سلبية على موانئ البحر الأحمر (65). وأخيرًا أكد دومر "Doumer" بأن مولن مينائي جدة وينبع ليسا إلا محطتين يقضي فيهما الحجاج أقصر وقت ممكن(66). ولهذه الأسباب تم التخلي عن ذلك المشروع الأولي، إذْ يجب استقبال

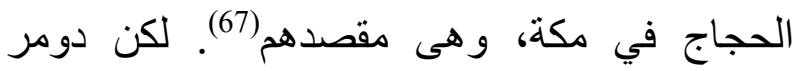

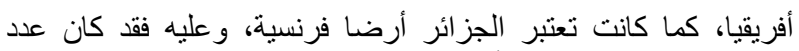

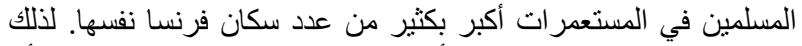

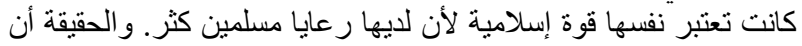

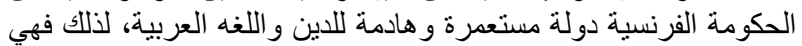
ليست بقوة إسلامية. (الباحث).

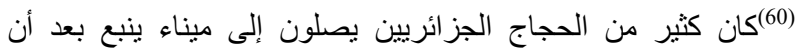

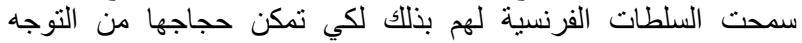

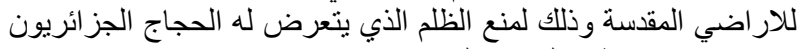

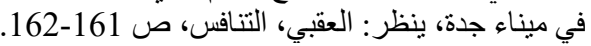
(61)"Journal Officiel...", 20 January 1916. p, 17.

(62)(ألن كل التقارير تؤكد أن موسم الحج تنتشر فيه الأوبئة من الكوليرا،

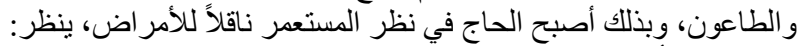
هو اري، مسألة الحج، صاعل 13.

(63)"Journal Officiel...", 20 January 1916. p, 19. (64) لمزيد من المعلومات حول سكة الحديد في عهد السلطان عبد الحميد

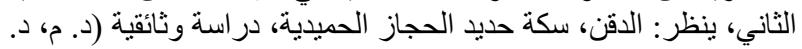

(65)"Journal Officiel...", 20 January 1916. p, 15.

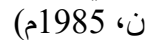

${ }^{(66)}$ Ibid.

${ }^{(67)}$ Ibid.
قبل قنصل(53) الحكومة الفرنسية في مدينة جدة ليبيسييه "Lepissier")(54) لحل مشكلة حجاج شمال وغرب أفريقيا (55). ذلك لأن الحكومة الفرنسية كانت تسعى لإيجاد رؤية سياسة إسلامية إفريقية فرنسية ف "Islam Made in France" فرض مزيد من السيطرة على المستعمرات الإسلامية(56)، لكن تم التخلي عن المشروع من قبل الحكومة الفرنسية لسببين الأول: لأسباب مالية، إذ أن خزينة الحكومة الفرنسية كانت تمر بضائقة مالية(57)، والثاني: لأن الحكومة الفرنسية واجهت مشكلة امتناع علماء الدين والسياسة في ولاية الحجاز لبيع الأراضى المقدسة للفرنسيين المسبحصين (58) أكد دومر "Doumer" أنه في أعوام سابقة تداولت "C.I.A.M" "اللجنة الوزارية للثؤون الإسلامية" هذا المشروع، كونها قوة إسلامية(59) والذي كانت الإسله

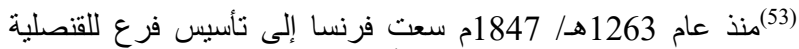

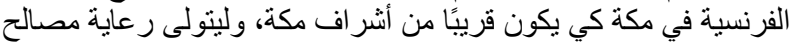

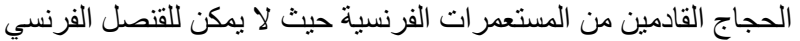

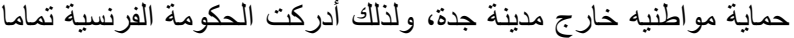

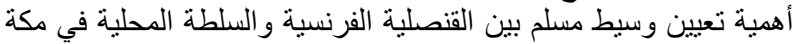

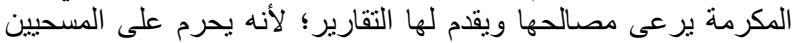

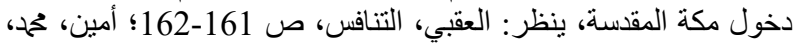

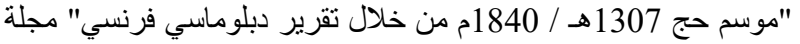

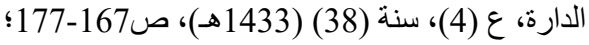
"Arabian Report" N. S, 23 September 1916, F.O.17/177. (54)تجدر الإشارة إلى أن القنصلية الفرنسية كانت تقدم العديد من الخدمات

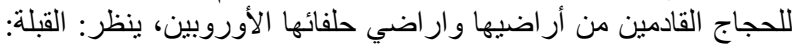

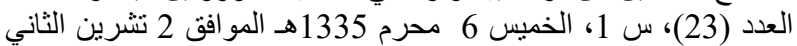
(نوفمبر) 1916م، صد3 (23)

(55)"La Depeche le Consul de France a Djeddah a Son Excellence Poincare Prisident du Conseil" Service Historiqué de la Defence, 20 Fevrier 1912, Dossier, 57.

${ }^{(56)}$ Pautremat, La Politique Musulmane, p. 40.

(57)"La Depeche le Consul de France...", 13 Fevrier 1912, Dossier, 58.

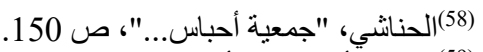

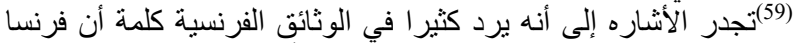
"قوة إسلامية" على اعتبار أنها تستعمر دولاً إسلامية كثيرة في شئ شمال 
(وخاصة من البلدان التي تسيطر عليها الحكومة

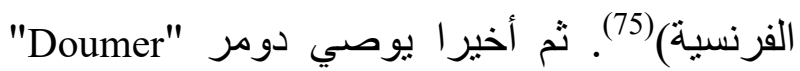

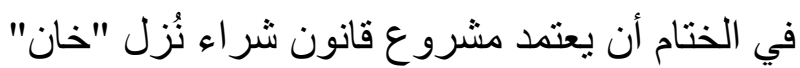
في مكة، الذي سبق وتم التصويت عليه و اعتماده من فن فئرن

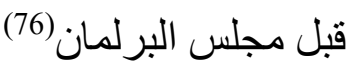

بعد ذللك العرض، أعلن رئيس مجلس الثيون المو افقه على المشروع؛ لأنه قد تلقى طلبا موقعا من عشرين عضوا (أثناء جلسة مجلس الثنيوخ) يطلبون لنان

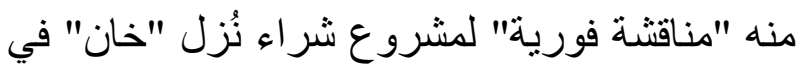
مكة، وعليه تم عرض المشروع للتصويت حول إعلان "الحالة المستعجلة للمناقثة الفورية" (77)، و التي تنص على الآتي: "يُسمح لوزارة الخارجية بصرف مبلغ خمسمائة ألف فرنك، لشراء وتجهيز بناء نُزل "خان" في مكة للحجاج الفقراء القادمين من مناطق السيطرة الفرنسية" (78). ولذا نم اعتماد مشروع القانون(79) نهائيا بتاريخ: 14-334-133هـ/ 1916-1-20م (80) وبذلك ستضمن الحكومة الفرنسية خضوع واستكانة شعوب شمال أفريقيا و إفريقيا الغربية ومن ثمَّ يصبح المستعمر "حاميا للبلاد" ودافعا من دوافع النهوض(81). كما أن

(75)"Journal Officiel...", 20 January 1916. p, 17.

${ }^{(76)}$ Ibid.

${ }^{(77)}$ Ibid.

${ }^{(78)}$ Ibid.

${ }^{(79)}$ Ibid.

${ }^{(80) " L a ~ D e p e c h e ~ l e ~ C o n s u l ~ d e ~ F r a n c e . . . ", ~} 13$ Fevrier 1912, Dossier, 58.

$$
\text { (81) مر عي، الحجيج التونسيون، ص147. }
$$

"Doumer" أكد لمجلس الثيوخ بأن هناك عقبةً تقف : في طريق المشروع، إذ يحظر على الأجانب حيازة أملاك عقارية في المدن المقدسة(68). ثم أكد دومر "Doumer" لمجلس الثيوخ بأنه بمكن للحكومة الفرنسية إدارة مشروع نُزل "خان" في مكة المكرمة باختيار مندوب جدير من إحدى الطرق(69) الدينية في شمال وغرب أفريقيا(70)، ويكفي لضمان إنان مشروع شر اء نُزل "خان" أن تصرح فرنسا بالهدف منه(71). بعد ذلك قام دومر "Doumer" بلقت انتباه مجلس الثيوخ إلى عدم التحدث عن ذلك المشروع؛ لأن شراء عقار في مكة سيثير حساسية الأهالي، لذلك يجب وضع الرأي العام أمام الأمر الواقع بالاتفاق مع الثريف حسين(72). وفي النهاية أوضح دومر "Doumer" لمجلس الثيوخ بأن نجاح مشروع شر اء نُزل "خان" في مكة سيكون علامة جيدة على اهتمام فرنسا(73) بأولئك فئك المسلمين(74) الذين يُظهرون لها الولاء و الإخلاص

${ }^{(68)}$ Ibid.

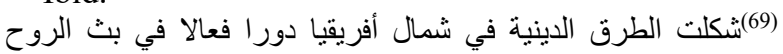

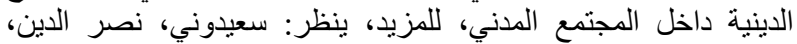

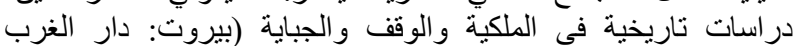

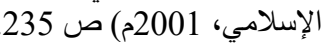

(70)"Journal Officiel...", 20 January 1916. p, 16.

${ }^{(71)}$ Ibid.

(72)"Lettre de President du Conseil", Ministre des Àffaires Étrangeres a Monsieur Mustapha Cherchali Charge de Mission au Hedjaz. Paris, le1mai, 1917. Ministere de Àffaires Étrangeres , 1918- 1919. "ArabieHejaz", 18. Mission de M. Cherchali. Serie É. Carton 310. Dossier 2. p. 48.

ود3نست الحكومة الفرنسية إلى إقرار المشروع لكسب عطف المسلمين

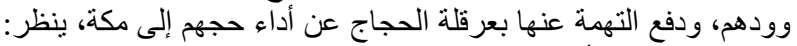

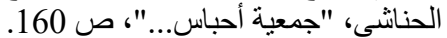
أن (74)تجدر الإثارة إلى أن الحكومة الفرنسية كانت تعلم أن العقار لا بمكن

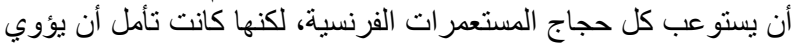

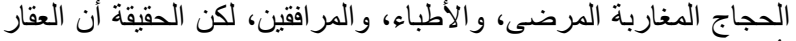

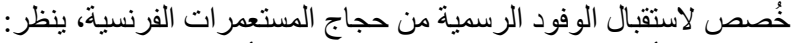
هو اري، مسألة الحج، ص 80؛ الحنانثي، "جمعية أحباس..."، ص الع الرنة 151. 
المشروع من قبل مجلس الثشيوخ الحكومة الفرنسية عليه يعتبر مناقضا لقانون عام 1323هـ/ 1905م لقام القاضي بفصل الدين عن الدولة(90)، كما أكّد بأن مشروع شراء نُزل "خان" في الأماكن المقسة الانس

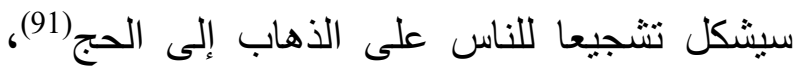
و هذا بطبيعة الحال يتعارض مع سياسة الحكومة الفرنسية التي قضت بفصل عامة الناس وتجهيأهم بالدين (92).

Hubert " ثانيا: المقيم العام في المغرب هو بير ليوتي

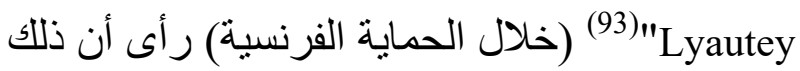
المشروع غير مناسب؛ لأن الحكومة الفرنسية تخوض غمار الحرب العالمية الأولى، وتعتقد بأن هذا المشروع هو أفضل وسيلة للتقرب إلى سكان شبه الجزيرة العربية(94)، ثم أكد بالقول: "أما فيما يخص التدخل عن طريق فرقة التيجانية(95)" فهى لئي

عام (89)

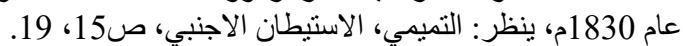
(90)"La Depeche le Consul de France...", 20 Fevrier 1912, Dossier, 60.

${ }^{(91)}$ Ibid

${ }^{(92)}$ Ibid.

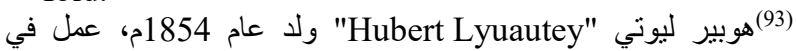

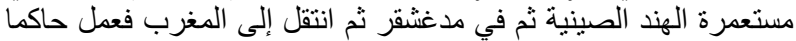

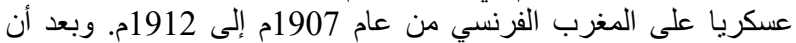

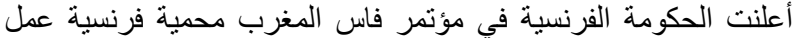

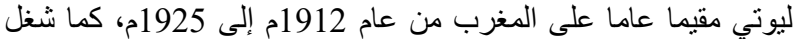

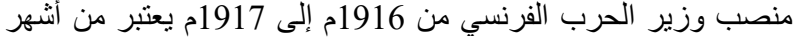

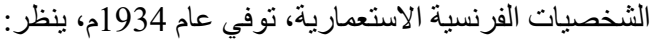
Hoisington, William, Lyautey and the French Conquest of Morocco (Palgrave, Macmillan, 1995), p. 76.

(94)"Commissaire Resident General, Relative a la Creation Hotolleries la Mecque", Rabat, le 23 Juin 1916, Àrchives Diplomàtique de Nantes. Commission Interministerielle aux Àffaires Musulmanes, Carton, 2 Mi 101, vol, 5e.

ف95)(التيجانية: فرقة صوفية، أسّّها أبو العباس أحمد التيجاني، في مدينة

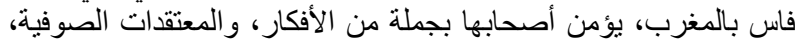
انتشرت في بلاد شمال أفريقيا، وفي الهند، وباكستان، ينظر : الباكستاني، الإنيا

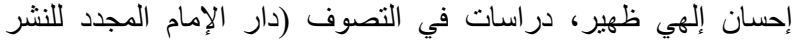

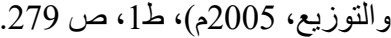

الحاج(82) سيتخلى عن فكرة الجامعة الإسلامبة ويقبل السيطرة الفرنسية(83) بعد تلك المناقشات، تقدمت وزارة الخارجية الفرنسية بطلب إلى مجلس البرلمان تطلب فيه فتح اعتمادٍ مالي يُدرج في ميزانيتها نفقات البعثة ووفد حجاج المغرب(84) وبالفعل تم اعتماد مبلغ مالي وقدره ثلاثنة ملايين وخمسمائة ألف فرنك لتغطيه المصساريف(85) إذ أن سياسة الحكومة الفرنسية كانت تهدف إلى اتباع ذللك الإجراء التقليدي لبلوغ غايتها وهو كسب الحرب العالمية الأولى باستماله الثعوب الإسلامية إلى جانبها بتنظيم رحلات مجانية لموسم حج 1334هـ/ 1916م بعد انقطاعه لأعو ام سابقة(86). 3- موقف الحكام الفرنسيين من المشروع: أرادت الحكومة الفرنسية أن تستطلع أراء حكومات شمال أفريقيا التي تسبطر على تلك الأماكن المسلمة آنساء أثناء فترة الحماية (87) والتي تباينت آراؤها:

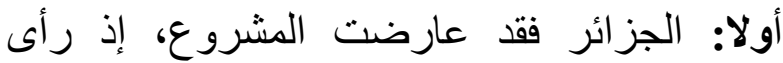

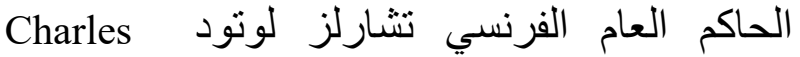
"(88)"Lutaud" في الجز ائر (89) بأن المو افقة على ذونى ذلك

(82) يتميز الحاج بمكانه اجتماعية مرموقة بعد أداء فريضة الحج، فيعتبر

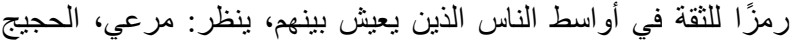

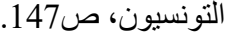

(83)Julien, Charles Àndres, Histoire de Lalgrie Contemporàine (Alger: Edition Casbah, 2010). P. 171.

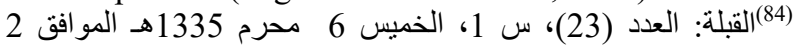

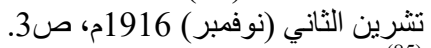
(85)

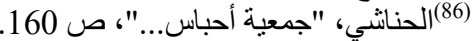

(87)"La Depeche le Consul de France...", 14 Fevrier 1912, Dossier, 59.

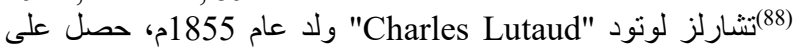

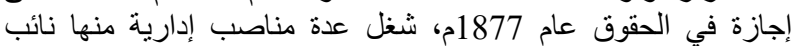

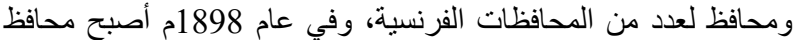

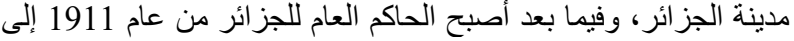

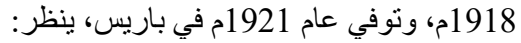
Https://en.wikipedia.org/wiki/Charles_Lutaud. 
نُزل "خان" قد لقي ترحيبا في أواسط التونسيين(103) المحبين للاولة العثمانية(104) أكثر من سكان الجزائر و المغرب(105)، ثم أكد أن المبلغ المرصود للمشروع منه غير كاف، إذ يحتاج إلى مزيد من الدعم المالي (106)

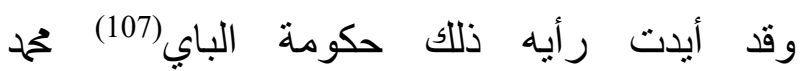
الناصر (108) في تونس(109)، و التي أكدت "بأنه يجب أن تتهج فرنسا نفس سياسة الحكومة البريطانية التي

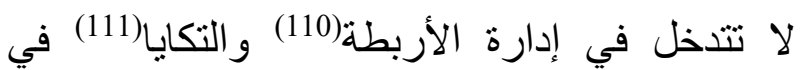

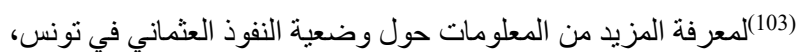

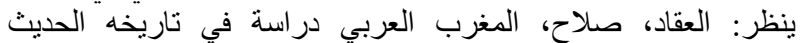

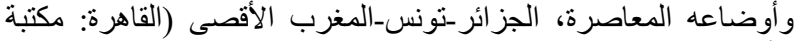

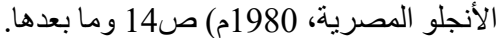
${ }^{(104)}$ Elder, Dan, "French Policy Towards Hussyn Sharif of Mecca", An Annual Publishe by Frank Cass, Middel Eastern Studies, London, Vol, 26, No, 3 (July 1990), p. 336.

(105)"Commissaire Resident General...", Rabat, le 23 Juin 1916, Carton, 2 Mi 101, vol, 5e.

${ }^{(106)}$ Ibid.

(107)|المقصود بكلمة باي تونس لقب تركي شرفي كان يطلق على حكام تونس في عهز الدولة العثمانية.

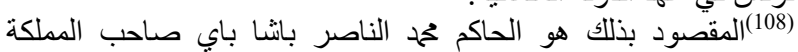

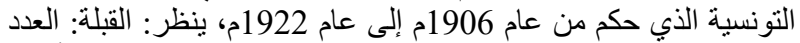
(14)، س 1، الخميس 1 الخي ذي الحجة 1334هـ الموافق 29 أبلول

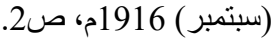
(109)"Commissaire Resident General...", Rabat, le 23 Juin 1916, Carton, 2 Mi 101, vol, 5e.

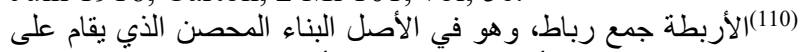

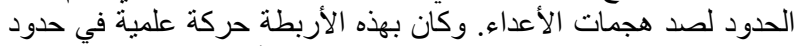

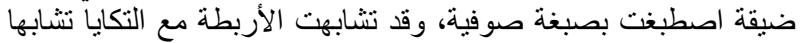

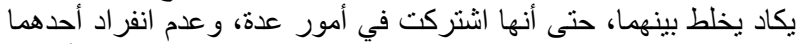

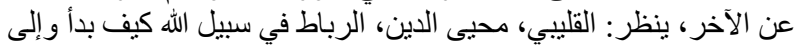

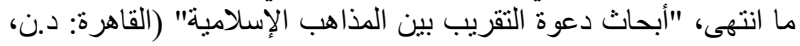

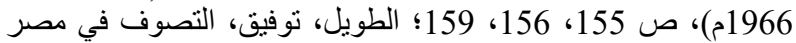
في العصر العثماني (القاهرة: الهيئة الدصرية العامة للكتاب ، 1988م)،

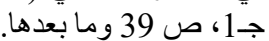
(111)التكية: كلمة تركية تطلق على نُزل "خان" للحجاج المسافرين، وهي

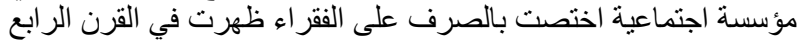

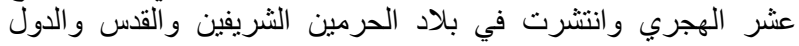

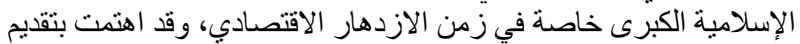

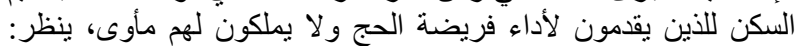

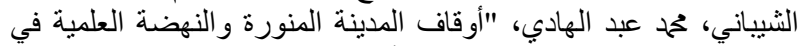
رحابها" بحوث المؤتمر الثالث للأوقاف الإسلامية بالمانية المملكة العربية

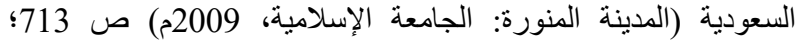
حيزوم، عبد الرحيم محم، "الوقف ودوره في تمويل المرافق الخدمية عند
فكرة غير جيدة وغير محمودة العواقب(96). ثم أكد بأن مشروع شر اء نُزل "خان" في مكة لا يمكن للحكومة الفرنسية تطبيقه؛ لأنها دولة مسيحية (97)، لذا يقترح أن يوضع المبلغ المرصود للمشروع تحت

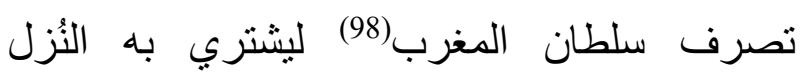

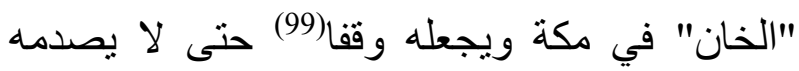
المسلمون بالاعتر اض فئهان.

ثالثا: أما المقيم العام في تونس غابرييل ألابيتيت "Gabriel Alapetite" لر أى الحاكم العام الفرنسي في الجزائر (102)، وللمقيم العام في المغرب، إذ أشار إلى أن مشروع شراء

(96)"Commissaire Resident General...", Rabat, le 23 Juin 1916, Carton, 2 Mi 101, vol, 5e.

${ }^{(97)}$ Ibid.

(98)الرقصود بذلك الإيالة الثريفية في عهد السلطان عبد الحفيظ، ينظر:

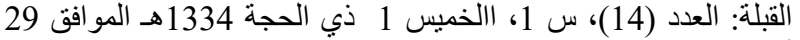

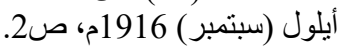

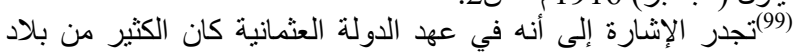

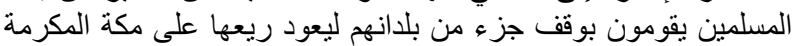

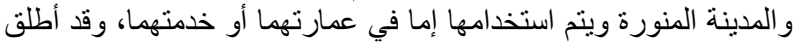

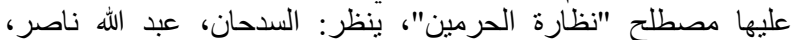

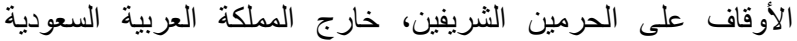

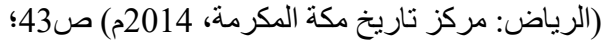

Guler, Mustafa, Osmanli Devetinde Haremeyn Vakhflari, Xvii (Istanbul, 2002), p. 218.

(100"Commissaire Resident General...", Rabat, le 23 Juin 1916, Carton, 2 Mi 101, vol, 5e.

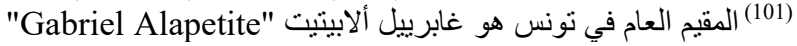

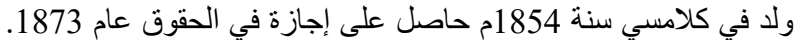

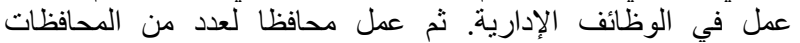

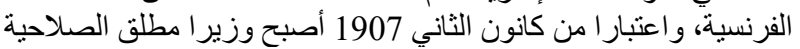

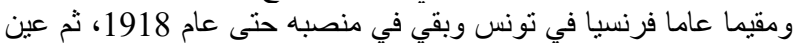

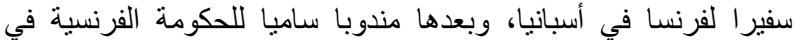

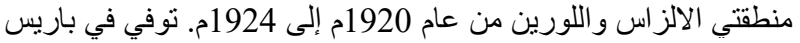
عام 1932م، ينظر : ع الالز

Arnoulet, Francois, Residents generaux de France en Tunisie ces mal-aimes, ed. (Marseille: Narration, 1995), p. 83-109.

(102)منذ أن احتلت الحكومة فرنسا الجزائر عام 1830م اعتبرتها قضيه

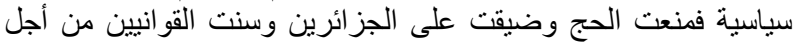

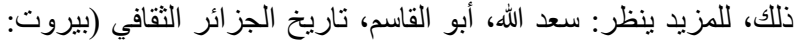

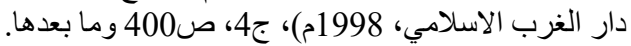


لإثبات نواجدها في هذه الولاية عبر استخدام سياسة

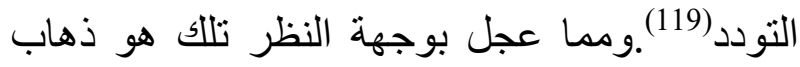
قيصر ألمانيا فيلهلم الثاني "Wilhelm II")

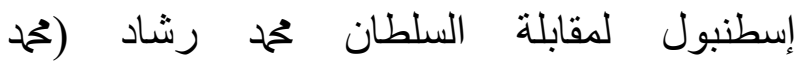
الخامس)(121)، من أجل الاستعداد لإعلان الجهاد(122) المقس ضد الحلفاء(123) بعد تناغم ألمانيا وادعائها الصداقه الحميمة مع الدولة العثمانية والعالم

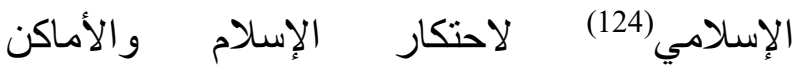
المقدة'(125.) وبذللك نلاقت أهداف ألمانيا مع الدولة العثمانية فخشيت بريطانيا وفرنسا من تتامي الرابطة

Elder, French Policy, p. 337.

${ }^{(119)}$ Leclerc, C, Àvec T.E. Lawrence en Arabie. La Mission Militaire Francaise au Hedjaz 1916-1920 (Paris: Lharmattan, 1998), p. 43.

(120) ولا عام 1859م درس في جامعه بون، ركز الهتمامه على تسليح

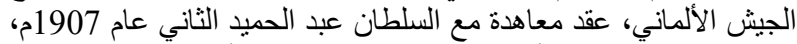

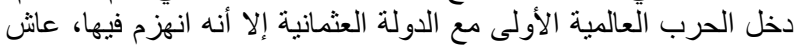

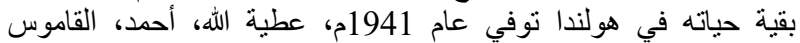

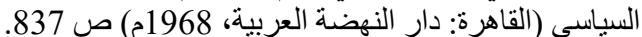

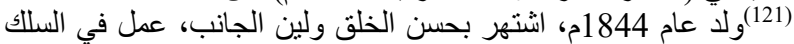

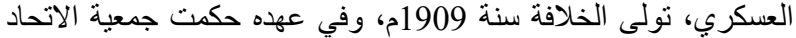
و الترقي البلاد، ينظر: فريد، تحمد، تاريخ الدولة العثمانية (هنداوي،

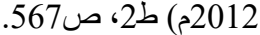

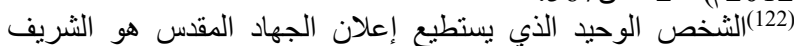

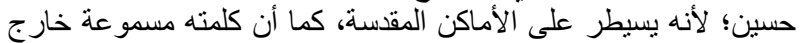

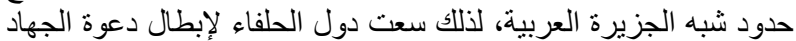

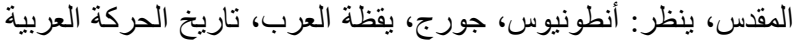

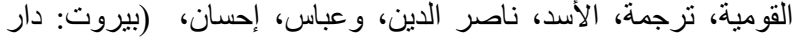

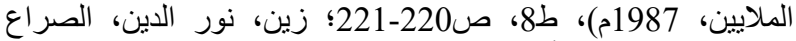

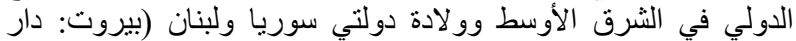

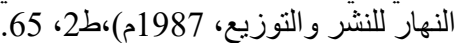

${ }^{(123)}$ Malcolm, Edward Yapp's, The Making of the Modern Near East 1792-1923 (London: Forth Impression, 1990), p. 272؛

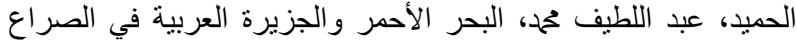

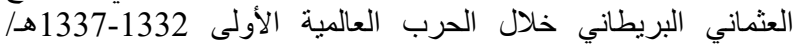

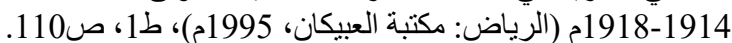
${ }^{(124)}$ Hurbert Lucien, L Islam et Guerre (Paris: Chcllamel Editeur, 1918), p. 38.

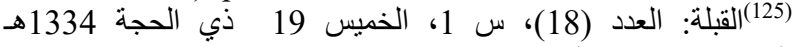
المو افق15 تثرين الثناني (نوفمبر) 1916م، صن3.
مكة" إلا في حالة وجود صعوبات مالية لا تستطيع

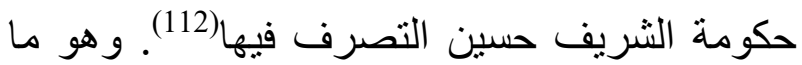
ينبغى أن يكون لحكومة فرنسا(113).

\section{4- تنفيذ المشروع الفرنسي:}

جاءت الخطوة التنفيذية التالية باختيار ممثلين لذلك التفاوض بشأن الموضوع لا سيما وأن عدم ثبات السياسة الفرنسية في ولاية الحجاز (114) وموقفها من ثورة(115) الشريف حسين كانت تحتاج إلى موقف صارم(116)، لكسر تفرد الحكومة البريطانية بالثريف حسين وبمنطقة الثرق الأوسط(117). لذلك يبدو جليا أن الحكومة الفرنسية قد سعت إلى مد نفوذها السياسي(118) على ولاية الحجاز لكونها خطوة

عجز الميزانية العامة للاولة" بحوث المؤتمر الثالث للأوقاف الإسلامية

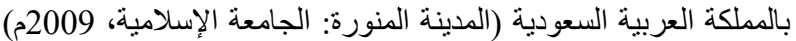

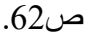
(112)"Commissaire Resident General...", Rabat, le 23 Juin 1916, Carton, 2 Mi 101, vol, 5e.

(113)"Telegramme Affaire Etrangeres, Reponse a letter", No, 878, du 15 Juin, 1916. Àrchives Dipiomatique de Nantes, Arab-Hedj, E-Lev.18-40.

مان (114)نظر الوجود معاهدة عام 1801م بين فرنسا والدولة العثمانية و التي

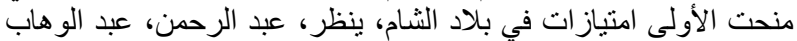

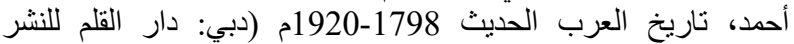

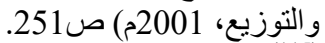

(115)قرر الثريف حسين القيام بثورة ضد الدولة الثبام العثمانية، في ولاية

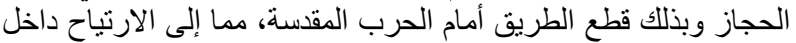

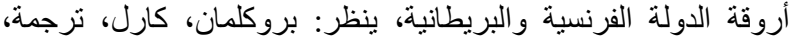

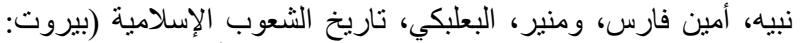

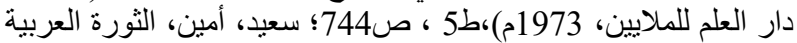

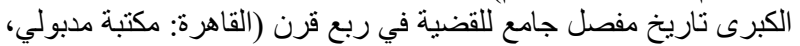

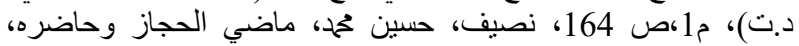

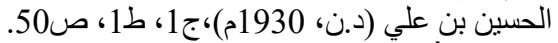

(116)"La Depeche, Diplomat a Paris", Àrchives Diplomatique de Nantes, du 13 Juin, 1916, Rabat No, 977.

الكرى (117)فريحات، حكت عبد الكريم، السياسة الفرنسية تجاه الثورة العربية

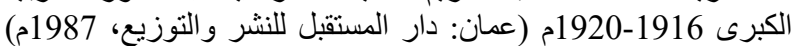

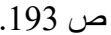

(118) تجدر الإثارة إلى أن الحكومة الفرنسية كانت تسعى إلى تحقيق

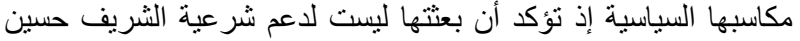

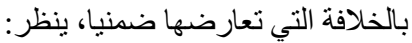


بإرسال بعثة رسمية إلى الثريف حسين في موسم حج عام 1334هـ/ 1916م، وهي عبارة عن قافلة حج(133) مكونة من سبعمائة حاج مغربي(134)، يرافقهم وفد سياسي يقوم بالمهمة الرسمية التي مني اختيرت بعناية من قبل الحكومة الفرنسية تتميز فيها بعض الثروط لعل من أهمها أولا: 1- أن يتكون الوفد من شخصيات(135) دينية مرموقة في بلاد المغرب(136). 2- أن بتميز الوفد بالولاء و الإخلاص دئه دئه

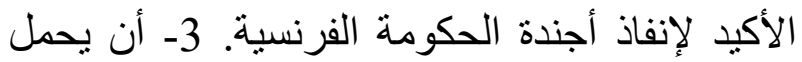
الوفد معه هدايا وإعانات للثريف حسين في

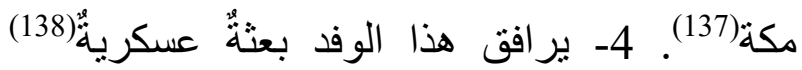
بقيادة الضابط العربي الفرنسي "شريف بن العربي قاضي"(139). ثانيا: المهمة الرئيسية للبعثة العسكرية

(133)قررت الحكومة الفرنسية مساعدة حكومة الشريف حسين بفتح باب

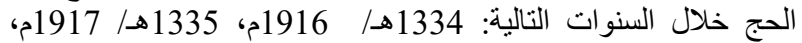

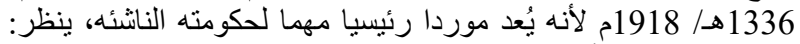

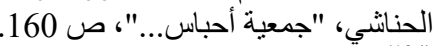

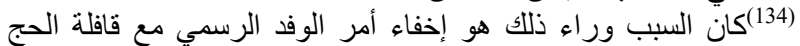
خوفا من انكثاف أمر الحكومة الفرنسية أمام الحكومة البريطانية، ينظر : Meynier, L Algerie Revellee, p. 539.

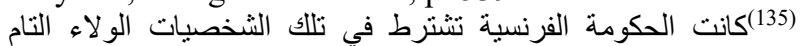

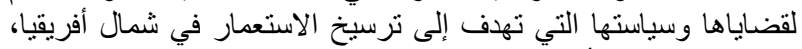

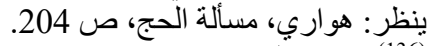

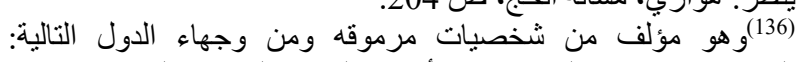
الجزائر، وتونس، و المغرب ومن أفريقيا الغربية الفرنسية التي كانت تحت التهب

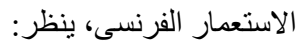

Éxcelsior, Paris, Ànnee 7, N 2191, 10 Novembre 1916, p. 4.

${ }^{(137)}$ Leclerc, Lawrence en Arabie, p. 43.

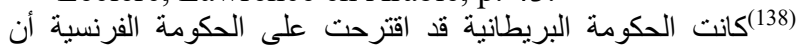

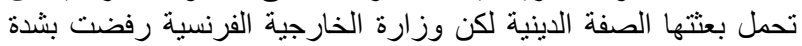

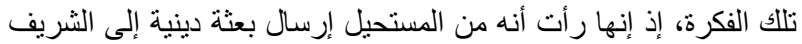

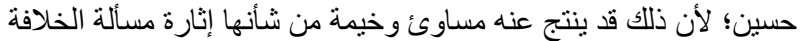

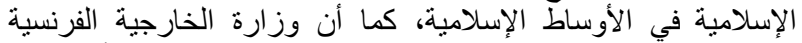

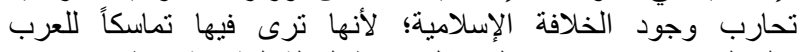
و المسلمين، و هذا قد يؤدي إلى فثل إسقاط الدولة العثية العثانية، ينظر : "Telegramme, Ministere des Affàires Etrangeres", Paris, du 3 Septembre 1916. Àrchives Diplomatiques de Nantes, "Londres, Ambassade Fonds K, 378Po/K 382". (139)"شريف بن العربي قاضي"، ولد عام 1867م في سوق أهراس

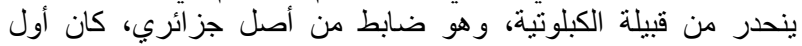

الإسلامية(126)، فقد أوردت وزارة الخارجية الفرنسية بأن مشرو عها في شراء نُزل "خان" في مكة سيكون دليلا على أن فرنسا ليست من أعداء الإسلام، وأنها تساند الثريف حسين للقيام بثورته ضد الدولة العثمانية التي تعتبر من أكثر الأحداث أهمية(127)، لهنية وهو نفس الموقف الذي اتخذته الحكومة

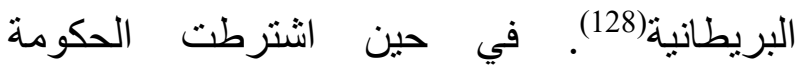
البريطانية على الحكومة الفرنسية أن لا يحمل مبعوثها للشريف حسين أي صفة عسكرية أو رسمية(129)؛ لأنها تخشى أن تسقط مكانة الثريف

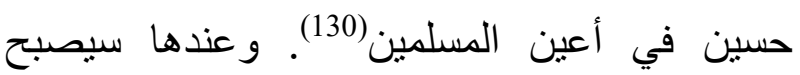
ثائرًا(131) و غير مؤتمن على الأماكن المقدسة وهذا قد يؤدي إلى فثل الثورة العربية(132). لذا أصدر رئيس وزراء فرنسا برياند "Briand"

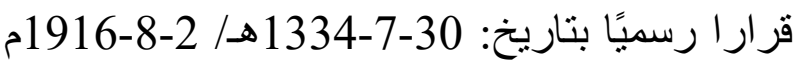

(126)"La Depeche le Consul de France...", 13 Fevrier 1912, Dossier, 60.

(127)"Proces-Verbal de la Seance de la Commission Interministerielle des Àffaires Musulmanes", Àrchives Diplomatique de Nantes, du 2 Decembre, 1915, Carton, 2 Mi 101, vol, 6e.

ذللك الإجراء من قبل الحكومة الفرنسية كان الهدف منه إضعاف وإحباط الإنها

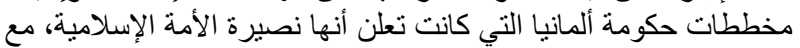
محاولة استغلال الخلاف العربي العثماني وتوظيفه لصالح الصنالح دول الحلفاء

ينظر:

La verite sur la Question Syrienne, Commandement de la IvmeArmée (Tanine, 1916), p. 168.

(128)"La Depeche le Consul de France...", 20 Fevrier 1912, Dossier, 60.

(129) تجدر الإشارة إلى أن وزارة الخارجية رفضت وبثدة فكرة أن تحمل

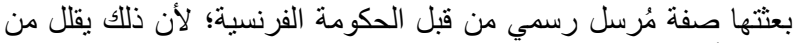

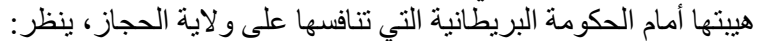
"Lettre de President du...", le 1mai, 1917, Carton 310. Dossier 2. p. 46.

${ }^{(130)}$ Memorandum on British Commitments to Cairo, Political Intelligence Department, F.O. 1916, L/PS/10/1089.

${ }^{(131)}$ Elder, French Policy, p. 336.

${ }^{(132)}$ Statement of Lord Grey Regarding Mission to Mecca, 1916, F.O. 371/2479. 
السياسية في التعامل مع القوى العربية(147.) و أنه من الأهمية بمكان الإشارة إلى أن الحكومة الفرنسية قداندان

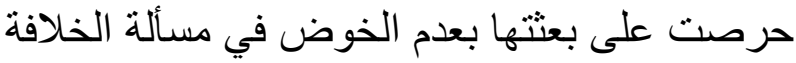

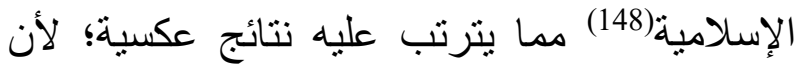
رعاياها المسلمين في شمال و غرب أفريقيا ما زالوا يعترفون بالخليفة العثماني ويكنون له الاحترام خاصة في و لاية تونس (149). ولهذا قررت الحكومة الفرنسية بعد موافقة مجلس تلس الثيوخ على أن تعمل "اللجنة الوزارية للثؤون لثانه الإسلامية" "C.I.A.M" في باريس بكل إخلاص على تأمين وتخصيص مبلغ خمسمائة ألف فرنك لشر اء نُزل "خان" في مكة، إذ أن غايتها جذب انتباه المسلمين في البلدان التي تقع تحت سيطرتها،

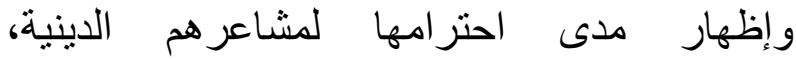
ومصالحهم المادية من خلال ضمان حقوقهم في

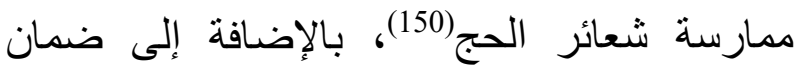

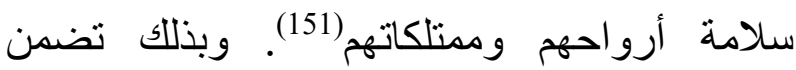

الإسلامية وباللغة العربية، وبعد خدمته في ولاية الحجاز عينته الحكومة

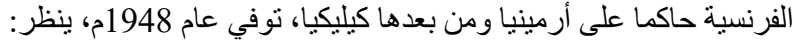
Pascal, "La Mission du Lieutenant...", pp. 17-31.

${ }^{(147)}$ Leclerc, Lawrence en Arabie, p. 43; "La Depeche, Diplomat...", du 13 Juin, 1916, Rabat No, 977.

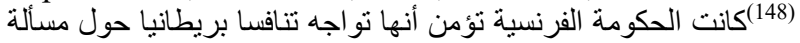

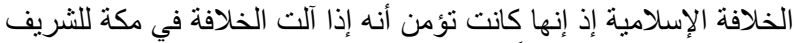

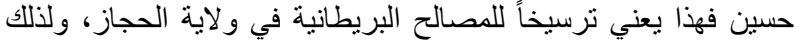

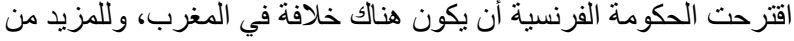

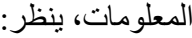

Elder, French Policy, p. 331, 329; Hubert, lucien, Une Politique Colonel, le Salut par les Colonel, Une Politique Colonel: le salut par les Colonel / Lucien Hubert (Paris: Librairie Felix Alcan, 1918), 97.

${ }^{(149)}$ Elder, French Policy, p. 336.

(150) تجدر الإشارة إلى أن ذلك الإجر اء من قبل الحكومة الرنسية يخالف

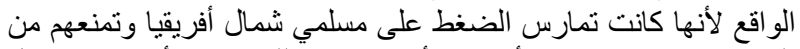

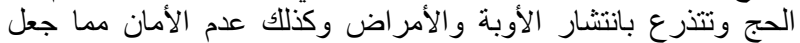
سياسة الحج السري تنفشى في مجتمعات شمال أفريقيا، ينظر : "Journal Officiel...", 28 December 1915. p, 22.

(151)"Telegramme Affaire Etrangeres...", No, 878, du 15 Juin, 1916, Arab-Hedj, E-Lev.18-40.
تتكون من أربعة أمور: 1- توفير الاحتياجات

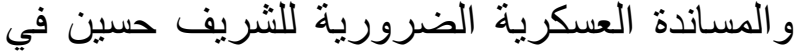
مكة(140). 2- الحصول على معلومات عن مشروع

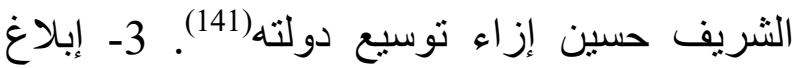
السلطات الفرنسية في حال حدوث أيّ سوء تفاهم يخص سياسة الحكومة الفرنسية مع بريطانيا في شبه

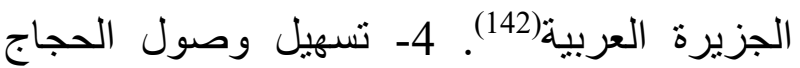
المغاربة(143) إلى و لاية الحجاز (144)؛ لأن الثريف حسين قطع صلاته بالدولة العثمانية؛ لارتكابها أخطاء بحق العرب(145). وإزاء تلك التطورات ألقت الحكومة الفرنسية مسؤولية التنسيق بين البعثتين السياسية والعسكرية على عاتق الكولونيل إدوارد بريموند Colonel" " ${ }^{(146) E d o u a r d ~ B r e m o n d " ~}$

جزائري يدرس في مدرسة البوليتكنيك في فرنسا، كان متخصصا في في الجيا

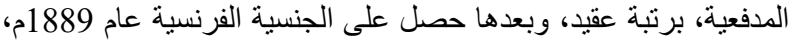

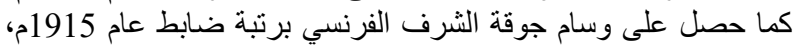

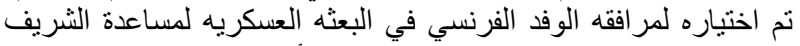

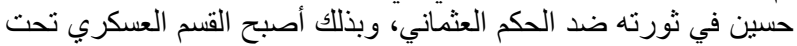
قيادته، نوفي عام 1939م، فينظر :

Bertrand-Cadi, Jean-Yves. Le Colonel Cherif Cadi: Serviteur de l'Islam et de la République. [Colonel Sharif Cadi: Servant of Islam and the Republic], (Paris: Maisonneuve \& Larose, 2005).

${ }^{(140)}$ Leclerc, Lawrence en Arabie, p. 43.

(141)"Lettre de President du...", le 1mai, 1917, Carton 310. Dossier 2. p. 49.

${ }^{(142)}$ Ibid.

(1433) تجدر الإشارة إلى أن الحكومة الفرنسية قد تكفلت بمصاريف حجاج

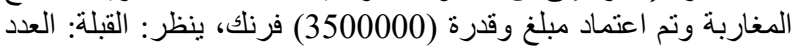

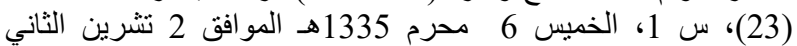

(نوفمبر) 1916م، صن الخير)

${ }^{(144)}$ Leclerc, Lawrence en Arabie, p. 43; "La Depeche, Diplomat...", du 13 Juin, 1916, Rabat No, 977.

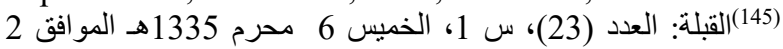

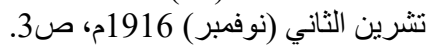

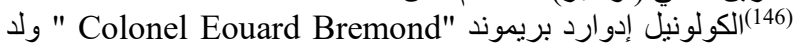

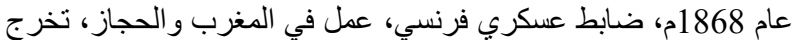

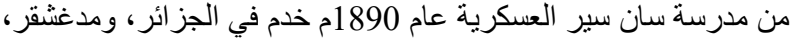

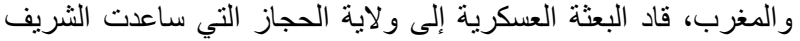

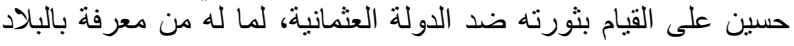


1334-10هـ/11-11-1916م الذي تشاور بدورهـ مع وزير الحرب الفرنسي ليوتي "Lyautey") وبعد مداولات طويلة اتفقا على أهمية ترشيح شخص مناسب لشغل منصب رئيس بعثة فرنسا إلى حكومة الثريف حسين؛ لأنه سيكون بين أعظم القوى السياسية المؤثرة في ذللك الوقت. لذلك اقترح الأخير عدة أسماء رشحها لرئيس الجمهورية الفرنسية في باريس ريموند بوينكار "Raymond Poincare"

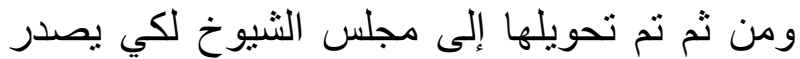
قرارا باختيار رئيس البعثة من بين ثلاثة أثخاص قدمتها له وزارة الداخلية وهم على النحو الآتي (161): 1- عبد القادر سي قدور بن غبريط(162) رئيس التشريفات لدى سلطان المغرب(163) ومستشار

للاخلية من عام 1914م إلى 1917م، واخيرا ألى أصبح عضوا في مجلس النواب مرة ثنانية من عام 1924م إلى عام 1940م توفي عام 1949م،

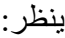
Http://gw.geneanet.org/deverdiere?lang-fr\&p-louis\&nmalvy. (160) حصل على إجازة في الحقوق، في عام 1893م انتخب عضوا في مجلس النواب، كما أصبح عضوا في مجلس الثبوخ، شغل منصب وفي وزير التعليم والثقافة، المالية، وفي عام 1912م أصبح رئيسا لمجلس الوزراء أهب ووزيرا للخارجية، وفي عام 1913م انتخب لرئاسة الجمهورية الفرنسية، ثم أصبح مرة ثانية رئيسا للمجلس من عام 1922م إلى 1924م، ثم أصبح رئيسا للمجلس مرة ثالثة ومن 1926م إلى 1929م. استقال من منصبه عالأسباب صحية، وتوفي في باريس عام 1934م، ينظر: البعلبكي، منير، معجم

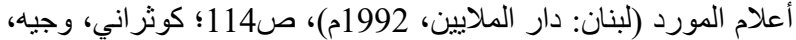

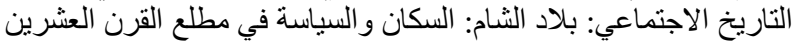

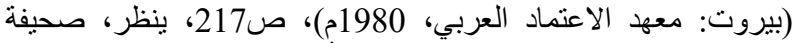

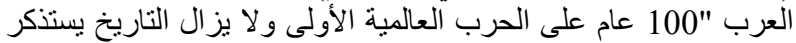
الكارثه الأوروبيه"، ع (9465)، سنة (36) (2014م)، ص 6. (161)"Journal Officiel de la Republique Française", Lois Decrets, 14 November 1916, p, 9820.

162)

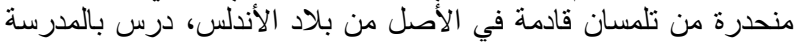

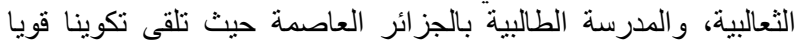

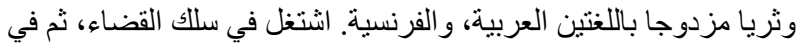

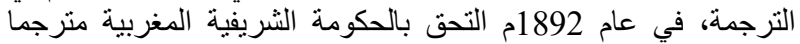

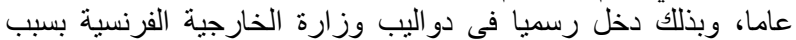

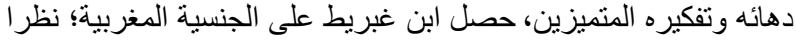
لقدرنه على التفاوض مع القبائل المغربية المتمردة التي جعلته رجل التيل
الحكومة الفرنسية خضوع واستكانة البلدان التي تقع تحت استعمار ها(152). وبتلك الخطوات تحقق فرنسا أمنا دينيا داخل المجتمعات الإسلامية التي تستعمر ها(153). بالاضافة إلى ذللك حرصت الحكومة الفرنسية على ألا تصول الحكومة البريطانية وتجول وحدها في و لاية الحجاز (154). إلا أن مجلس الثيوخ كان قد اشترط خمسة شروط على الحكومة الفرنسية لتسليم مبلغ خمسمائة ألف إلف فرنك أولا- يجب أن يرسل المبلغ إلى الثريف

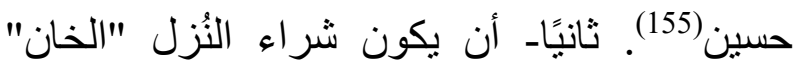
تحت إثر اف ناظر (156)، يتميز بالاخلاص و الولاء

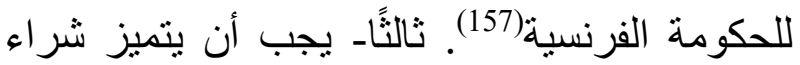

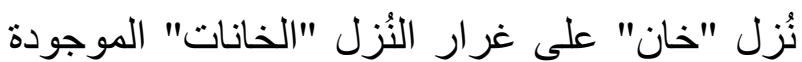
في ولاية الحجاز (158).

\section{5- اختيار "المرشح والوفد" لتنفيذ مشروع الحكومة الفرنسية لاى شريف مكة:}

من خلال قراءة الوثائق الفرنسية بتضح أن المراسلات السرية بين أطراف الحكومة الفرنسية (ووزير الداخلية مالفي "Malvy" (159) بتاريخ: 14-

100(152)مرعي، الحجيج التونسيون، ص147؛ هواري، مسألة الحج، ص

${ }^{(153)}$ Foreign Office Memorandum, 14 August, 1916, F.O. 371/6074.

(154) فريحات، السياسة الفرنسية، ص 193.

(155)"Proces-Verbal de la Seance...", du 3 Decembre, 1915, Carton, 2 Mi 101, vol, 6e.

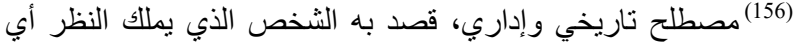

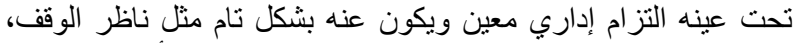

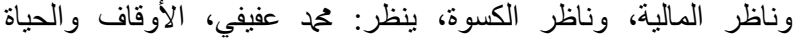
الاقتصادية في العصر العثماني (القاهرة: الهيئة الهصرية العامة للكتاب،

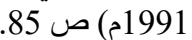

${ }^{(157)}$ Pascal, "La Mission du Lieutenant...", pp. 17-31. ${ }^{(158)}$ Ibid.

عام (159)مالفي"Malvy" ولد عام 1875م، حصل على دكتوراه في الحقوق

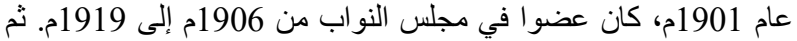
في عام م1913 شغل منصب وزير التجارة، وبعد ذلك عمل وزيرا 
يوسف، منرجم قضائي في (ولاية قسنطينة)، لايه سجل حافل بالعمل والخدمة مع الحكومة الفرنسية لمدة ثلاثين عاما في الجزائر (167). وبعد مشاور ات رأت الحكومة الفرنسية أن ترسل إلى الى الثريف حسين في مكة ابن غبريط من أجل إنفاذ مشروع الحكومة الفرنسية بكل نجاح، وذللك لعدة التهن

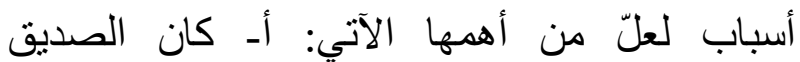

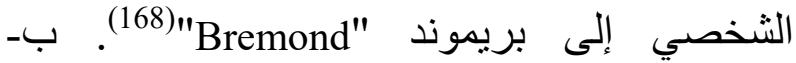

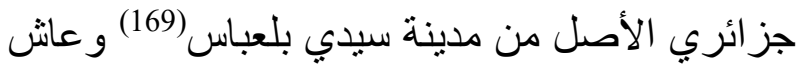

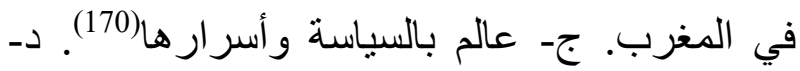
كان بمثابة حجر الزاوية في مشروع فرنسا السياسي الهادف إلى إحياء سلطة الأشر اف المغاربة(171). هـــ كان مترجما لدى مفوضية الحكومة الفرنسية في طنجة ورئيسا للمر اسم الثريفية بالمغرب (172). لتلك فئ فئ الأسباب السابقة نم اختبار سي قدور بن غبريط من

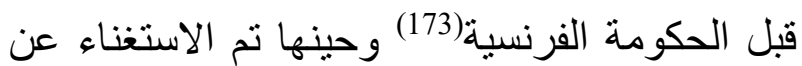
المرشحين الآخرين دون إقفال ملفاتهم، إذ أكد وزير الاستياه الداخلية الفرنسي بأن الحكومة الفرنسية قد تستعين بأحدهم في أي وقت على حسب ما تحتاج إليه مصلحة الحكومة(174).

${ }^{(167)}$ Ibid; "Traduction en Francais dé Constitution...", Carton 310. Dossier 2, P. 18.

(168)"La Depeche, Diplomat...", 10 September, 1916, Rabat No, 977.

(169)مدينة سيدي بلعباس تقع بالسهول الداخلية الغربية للجزائر وهي

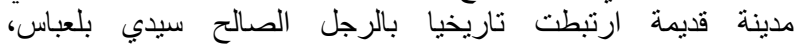

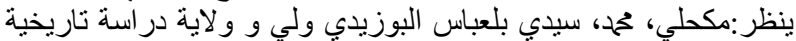
أنتروبولو جية (ماجستير)، جامعة أبي بكر بلقايد تلمسان كلية الآداب، قسم تارئ

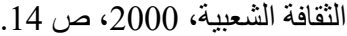

(170)"La Depeche, Diplomat...", 10 September, 1916, Rabat No, 977.

${ }^{(171)}$ Ibid.

${ }^{(172)}$ Ibid.

${ }^{(173)}$ Ibid.

${ }^{(174)}$ Ibid.
الحكومة المغربية، وقائد برتبة ضـابط وحاصل على سام جوقة الشرف منذ عام 1325هـ/ 1907م(164). 2- سي الحاج مصطفى بن أحمد شرشالي(165) المدرس الثرفي في مدرسة الجزائر، برنبه فارس و هو القاضي والكاتب بالعدل في (ولاية الجزائر)، وله تاريخ مشرف في خدمة فرنسا، إذ عمل ما يقرب من خمسة عشر عاما ونصف في خدمة الحكومة الفرنسية في بلاد الجزائر (166). 3ـ قسوس حمح بن

السياسة القبلية. اعتبرته الحكومة الفرنسية من أهم الشخصيات النافذه التي

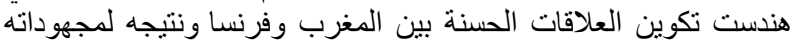

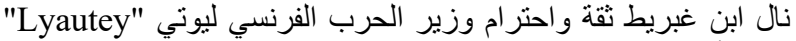

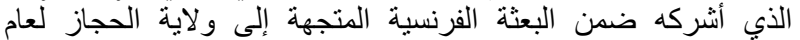

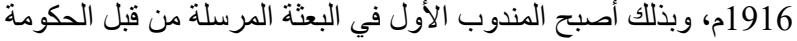

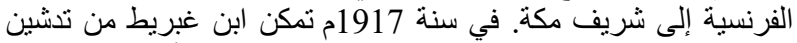

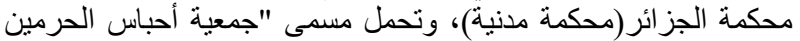

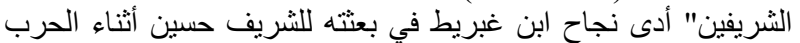

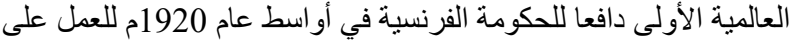

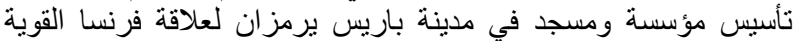

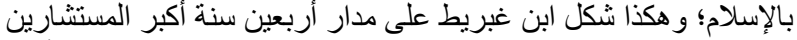

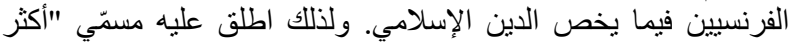

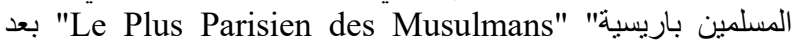
وفاته منحته الحكومة الفرنسية ميدالية جوقة الثرف الفرنسي، ودفن في في

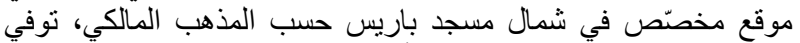
1954م وكان عمره 82 سنة بعد أن صارع المرض لفي لفترة من الزمن،

Gouvion, Edmond, Kitab Àayane el-Marhariba, Tome,1, (Paris: Fontana Freres, 1920), p.1; Sbai, Jalila, Ben Ghabrit Abdelqader (Sidi Bel Abbes, Algerie, 1868-1954) Dictionnàire des Orientàlistes de Làngue Francaise (Paris: Editions Karthala, 2012), p. 86; Pautremat, La Politique Musulmane, p.565; "Journal Officiel...", 14 November 1916, p, 9820;

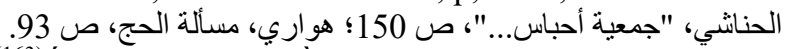
(163) Éxcelsior, Paris, Ànnee 7, N 2191, 10 Novembre 1916, p. 4.

(164)"Journal Officiel...", 14 November 1916, p, 9820.

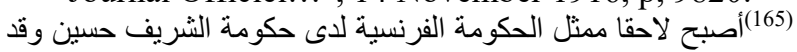

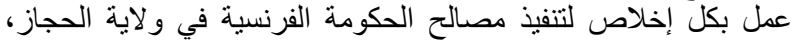

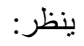

"La Depeche, Diplomat...", du 13 Juin, 1916, Rabat No, 977; "Traduction en Francais de Constitution de Societe Civile". Ministere des Àffaires Étrangeres, 1918- 1919. "Àrabie - Hejaz", 18. Serie É. Carton 310. Dossier 2, P. 18.

(166)"Journal Officiel...", 14 November 1916, p, 9820. 
بالوكالة تشارلز هاردينغ "Lord Harding") لسفير الحكومة الفرنسية في لندن بول كامبون "Paul Cambon" بأن مشروع شراء مُزْل "خان" في مكة سيثير مشاكل مع الحكومة البريطانية(183)؛ لأنه إن قدر للمشروع الفرنسي النجاح(184) فإن الحكومة البريطانية ستجد نفسها مضطرة لتقليدها بإرسال بعثة من مستعدراتها في الهند(185) إلى الثريف حسين(186)، ومن جهة أخرى كانت ردة فعل المندوب السامي البربطاني في مصر هنري ماكماهون "Sir Henry McMahon" (187)

(181)اللورد نشارلز هاردينغ "Lord Harding" ولا عام 1858م، بدأ

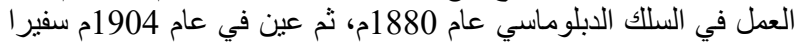

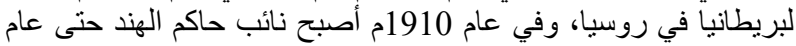

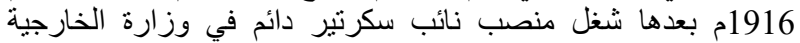
البريطانية. وفي عام 1920م عين سفير البريطانيا في فرنسا. فئ وني أحيل إلى الى التقاعد عام 1922م، وتوفي عام 1944م، عام، بنظر :

Https://fr.wikipedia.org/wiki/Charles Hardinge.

(182)بول كامبون "Paul Cambon" ولد في باريس عام 1843م حاصل على دكتور اه في الحقوق. عمل في مناصن في في في إدارية عديدة، وفي

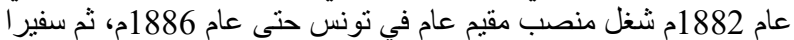

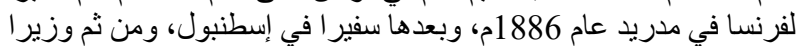
لفرنسا في لندن من عام 1890م إلى 1824، 1920م، وتوفي في في باريس عام

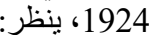

Https://fr.wikipedia.org/wiki/Paul_Cambon.

(183)"La Depeche Ministere des Affaires Etrangeres", Paris, du 5 Aout, 1916. Archives Diplomatiques de Nantes, "Londres, Ambassade Fonds K, 378Po/K 381". (184)تجدر الإشارة إلى أن المشروع الفرنسي في مكة فد نجح بشهادة

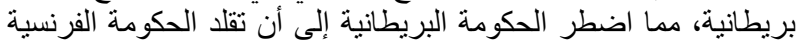

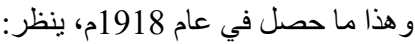

Telegram Secret From Resident Jedda to High Commissioner Cairo "Arabie Report", 11 August 1918, F.O. 371/6075.

(185)تجدر الإشارة إلى أن بلاد الهند اعتبرت أن الخطوات التي اتبعتها

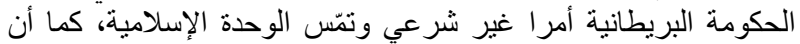

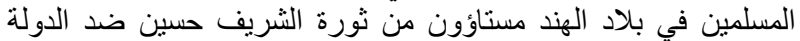

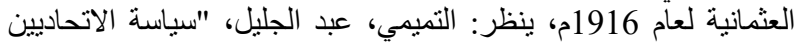

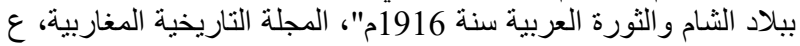

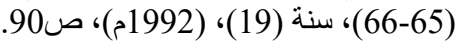

(186)"La Depeche Ministre des Affaires..." du 5 Aout, 1916, "Londres, Ambassade Fonds K, 378Po/K 381".

(187) هنري مكماهون "Sir Henry McMahon" ولدعام 1862م كان

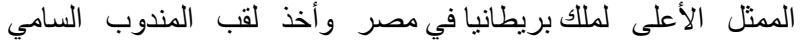

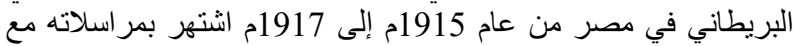

كما قررّت الحكومة الفرنسية إسناد ثلاثة أمور إلى ابن غبريط هى: أـ ترسل البعثة باسم رئيس

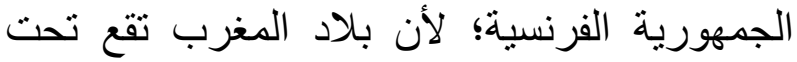
الحكم الفرنسي(175). بـ مُنحت البعثة بلاد مبلغا ماليا،

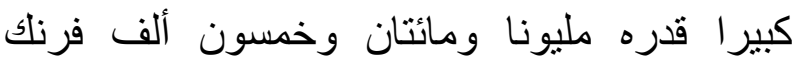

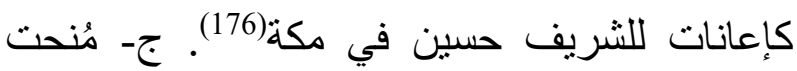
البعثة مبلغا ماليا قدره تسعمائة ألف فرنك لشراء

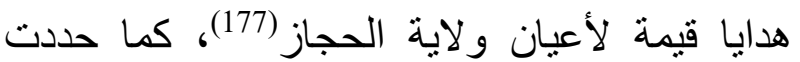
وزارة الخارجية الفرنسية إلى ابن غبريط السياسة الانه

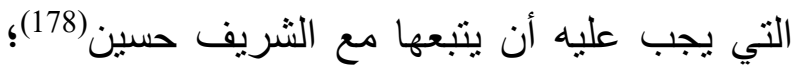
لأن الحكومة الفرنسية أدركت الخطورة التي يشكلها الحج على رعاياها ومصالحها الاستعمارية(179). 7- موقف الحكومة البريطانية من المشروع: تباين موقف الحكومة البريطانية من مشروع البعثة الفرنسية(180)؛ لأن الأصل أن تتكاتف الجهود بين فرنسا وبريطانيا لفصل ولاية الحجاز عن الدولة العثمانية أثناء الحرب العالمية الأولى، إلا أنه مما لإلها

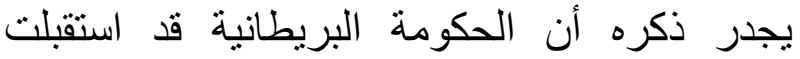

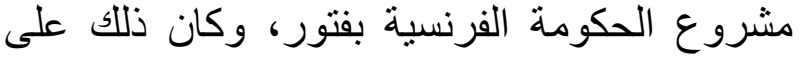
غير المتناد، إذ أوضح وزير الخارجية البريطانية

(175)"La Depeche, Diplomat...", 10 September, 1916, Rabat No, 977.

${ }^{(176)}$ Hubert, Une Politique, p. 97.

(177)"La Depeche, Diplomat...", 10 September, 1916, Rabat No, 977.

(178)"Lettre de President du...", le 1mai, 1917, Carton 310. Dossier 2. p. 46.

(179)"Journal Officiel...", 14 November 1916, p, 9820. دانية إقترحت الحكومة البريطانية على الحكومة الفرنسية أن تكون بعثتها

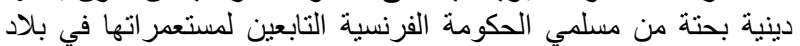

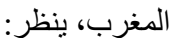

Memorandum on British Commitments to Cairo, Political Intelligence Department, F.O. 1916, L/PS/10/1089. 
بأن مشروع شر اء نُزل "خان" في مكة (193) قد ترك انطباعات غير جيدة لدى الحكومة البريطانية التي لم تكن ترغب أن يقيم شريف مكة علاقات مع بلدان

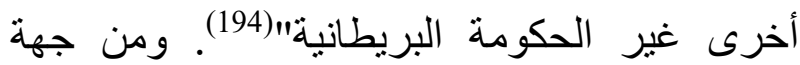
أخرى، كانت الحكومة البريطانية تؤمن بأن تحالفها

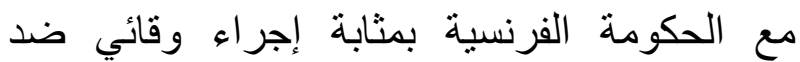
الحكومة الألمانية(195). لكن الشريف حسين أدرك بأن السلطات الفرنسية ترغب في التعاون معه، فرحب بتعزيز علاقته معها بغرض استخدامها ورقة ضغط في مواجهه النفوذ البريطاني المتزايد في في

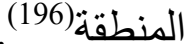

وبدون ريب تتأكد تللك الانطباعات في رسالة وزير "McMahon"الخارجية البريطاني إلى ماكماهون و التي أكد فيها قوله: "لقد صرحتُ للسفير الفرنسي في لندن بأن الوقت غير ملائم، وعلى الحكومة الفرنسية أن تتوخى العواقب غير المحمودة"(197). ومما كانت تأمله الحكومة البريطانية من الحكومة الفرنسية وتُعول عليه هو الالتز ام بمعاهدة سايكسبيكو (198) التي وقعت بين البلدين في عام 1334هـ/

(193) كانت الحكومة البريطانية تدرك أن معنى البعثة العسكرية الفرنسية

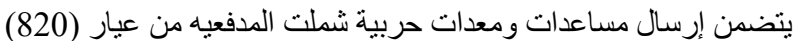
وبندقية (2400) و(8) فرق رشاثات هو تثكينز ، و غير ها، ينظر : Pascal, "La Mission du Lieutenant...", pp. 17-31.

(194)"La Depeche Ministere des Affaires..." du 12 Aout, 1916, "Londres, Ambassade Fonds K, 378Po/K 381". (195)"Arabian Report" N. S, 16 July 1916, F.O.17/177. ${ }^{(196)}$ Ibid.

${ }^{(197)}$ Memorandum on British Commitments to Cairo, Political Intelligence Department, F.O. 1916, L/PS/10/1089.

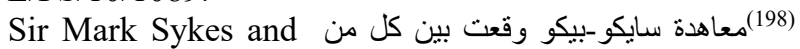
Georges Pico

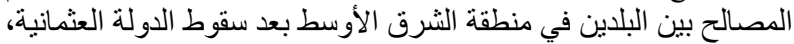

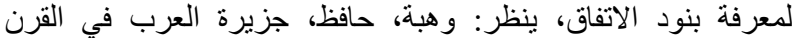

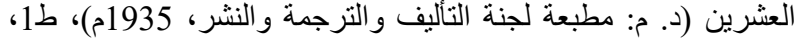

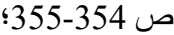

دون المأمول إذ أعرب لسفير فرنسا في القاهرة

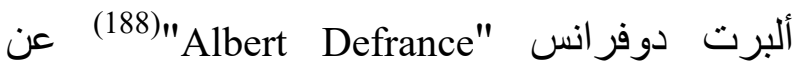
مخاوفه من انعدام الأمن في الطريق بين ميناء جدة ومكة(189). لكن الحكومة الفرنسية أكدت حرصها لإن فيناه على أن ألا يتعرض حجاجها لأي مضايقة أثناء سفرهم من جدة إلى مكة أو أثناء إقامتهم في مكة، لإئا كما حرصت أن توفر لهم وسائل النقل المناسبة(190). إذ أن الحكومة الفرنسية قد علمت من خلال اتصالها بالثريف حسين على أن أول اهتمامات حكومته هو توطيد الأمن الذي عاثت فيه القبائل البدوية(191). و على الرغم من تلك الملاحظة الثانوية على الاهن المشروع الفرنسي، والرد غير المُكترث عليه من

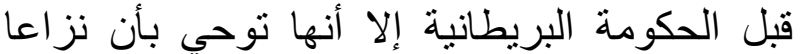

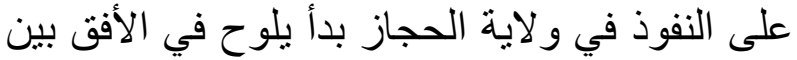

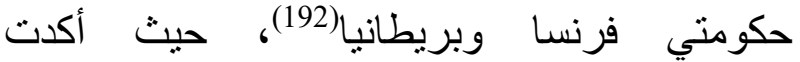
المعلومات بأن دوفر انس "Defrance" قد أبرق إلى وزير الخارجية الفرنسية برياند "Briand" موضحا

الثريف حسين بن علي بين عامي 1915مو 1916م خلال الحرب العالمية الأولى. ونوفين عام 1949م، ينظر : Https://ar.wikipedia.org/wiki/Henry-McMahon.

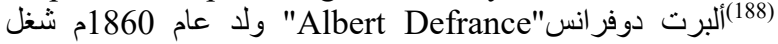

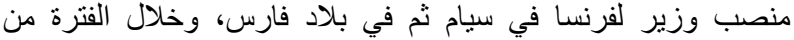

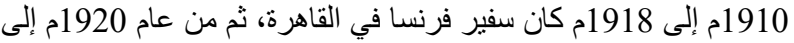
1923م سفير لفرنسا في مدريد، ينظر :

Denechere, Yves, Femmes et Diplomatie: France au XXe Siecle. (Presse: Universitaires Europeennes Bruxelles, 2005), p. 28.

(189)"La Depeche Ministere des Affaires..." du 9 Aout, 1916, "Londres, Ambassade Fonds K, 378Po/K 381".

(190)"Lettre de President du...", le 1mai, 1917, Carton 310. Dossier 2. p. 48.

${ }^{(191)}$ Journal Le Matin, N 11946, 11 Novembre 1916, P, 1

(192)"La Depeche Ministre des Affaires..." du 12 Aout, 1916, "Londres, Ambassade Fonds K, 378Po/K 381". 
التطورات عينت وزارة الخارجية البريطانية، في عام 1334هـ/1916م الكولونيل أرنولد ويلسون "Colonel Arnold Wilson" ممثلا لها سياسيا في ولاية الحجاز، وكانت مهمته تتمثل في تقديم المشورة العسكرية ولعب دور الوساطة(206) ونقل وله ولهن طلبات الثريف حسين(207) إلى الحكومة البريطانية من أجل كسب الحرب العالمية الأولى (208). وعلى غرار البعثة العسكرية الفرنسية، ألحقت الحكومة البريطانية بمكتب الحج بعثة عسكرية أخرى بقيادة الضابط نيوكومب "Newcombe" البريطاني (209). وبذلك اشتا مجال التنافس الاستعماري بين فرنسا وبريطانيا، إلى درجة ألّا تدع إحداهما المجال للأخرى تعمل منفردة في ولاية الحجاز (210). وقد

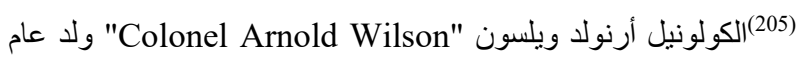

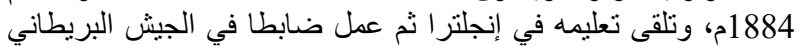

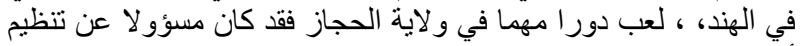

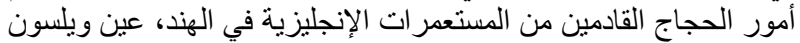

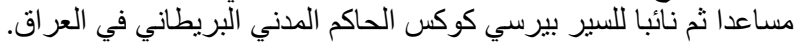

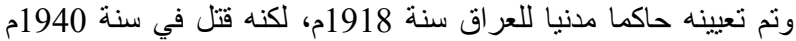
خلال معركة جوية في شمال فرنسا ودفن في مدينة أرينجهم الفرنسية،

Https://ar.wikipedia.org/wiki/Arnold-Talbot-Wilson.

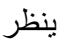

${ }^{(206)}$ Political Resident to the Secretary to the Government of India in the Foreign and Political Department, 24 Septembre 1916, F.O. 371/2476.

والكورة (207)قد تعدت الحكومة البريطانية للثريف حسين- إذا أعلن الحرب

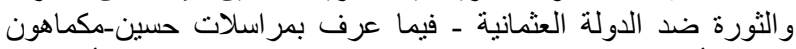

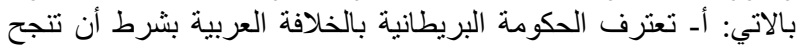

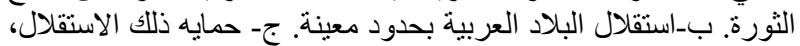

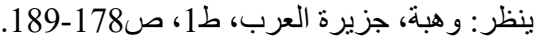

${ }^{(208)}$ Records of the Hashimite Dynastics, A-twentieth Century Docuementary History "The Hashimite Leadership of the Arab Revolt" (London: Archive Editions, 1995), vol, 5, p. 489.

${ }^{(209)}$ Political Resident to the Secretary to the Government of India in the Foreign and Political Department, 24 Septembre 1916, F.O. 371/2476.

${ }^{(209)}$ Ibid.

$$
\text { (210)فريحات، السياسة الفرنسية، ص } 193 .
$$

1916م(199) إذ كانت الحكومة البريطانية تؤمن بأن الثريف حسين على اطلاع عام، وغير دقيق على اتفاق بريطانيا مع فرنسا(200)، لذلك فمن المرجح أن يسأل الثريف حسين عنه، "و على الحكومة الفرنسية إخباره بأنها ليس لديها إلا القليل من المعلومات"، ولكنها على استعداد لإرسال طلب استفسار إلى الحكومة البريطانية حتى تتخذ الأخيرة التدابير المناسبة لإقناع الثريف حسين بعدم مصداقيه الاتفاق المبرم بين الحكومتين(201). لكن وبتلك الصورة كانت الحكومة البريطانية تؤمن بأنه يجب إخماد وتثبيط كل محاولة للتد خل في شؤون ولاية الحجاز سواء كانت من قبل الحكومة

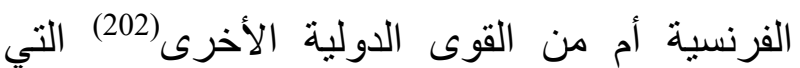
تنافس الحكومة البريطانية في شؤون شبه الجزيرة العربية(203). كما عكس ذللك الإجراء خفاء أو تجليا في الثقة بين الحكومة البريطانية و الحكومة الفرنسية في وقت حرج بين الدولتين(204). و وإزاء تلك

Riley, Carroll, Historical and Cultural Dictionary of Saudi Arabia (New Jersey: Scarecrow Press, 1972), p. 111.

${ }^{(199)}$ Hurewitz, J. C, Diplomacy in the Near and Middle East: A Documentary Record: 1914-1956, (London: D.Van Nostrand Company, 1956).vol. 2. p. 20.

مكانبة النج، محا، الدولة العثمانية و الثرق العربي 1980) 1514-1914م (القاهرة:

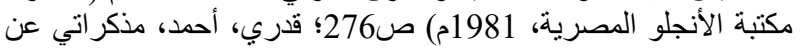

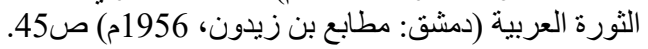

(201)"Lettre de President du...", le 1mai, 1917, Carton 310. Dossier 2. p. 51.

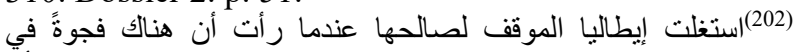

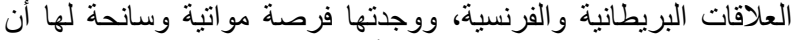
تعين مندوبا لها في ولاية الحجاز من أجل حماية مصالح الحبة الحباج الليبيين

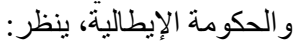
Italian War Aims and Claims in regard to Arabia, 1916, F.O. 371/11448.

${ }^{(203)}$ Foreign Office Memorandum, 14 August, 1916, F.O. 371/6074.

${ }^{(204)}$ Political Eastern Arabia, 1916, F.O. 371/11447. 
بلاد الهند(219)، لما لذلك من أهمية للحكومة البريطانية في كسب تعاطف العالم الإسلامي بعدم مناهضة الاحتلال(220). وعلى إثر ذلك علينت

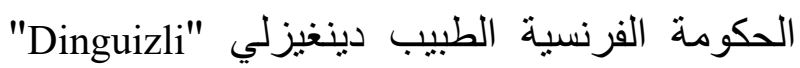
و الطبيب حدو "Haddou"(221). كما خصنصت الحكومة الفرنسية مستوصفا وأسست صيدلية

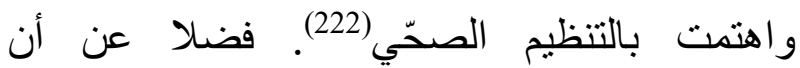
الحكومة الفرنسية وجهت بإنشاء مستشفى عسكري ميداني من أجل خدمة الحجاج(223).

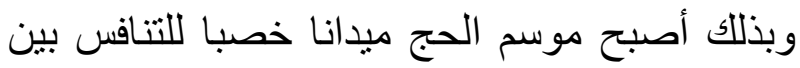
الحكومة الفرنسية و البريطانية فيما يتعلق بالخدمات التي تقدمها كل دولة لرعاياها، وهذا يعطي دورا إيجابيا لكلا الدولتين بتعاطف العالم الإسلامي معهما،

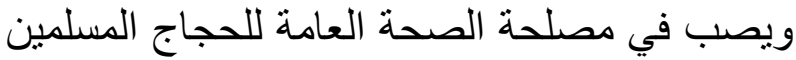

ونتيجة لما طر أ على المشهد السياسي من تغير؛ أصبح "مكتب الحج" بمثابة الجهاز السياسي الئي

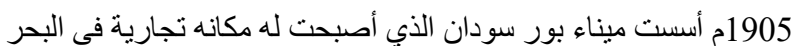

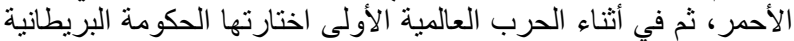

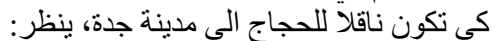
Clayton, Gilbert Falkingham, An Arabian Diary, (Press: University of California, 1969), p 91-92.

${ }^{(219)}$ Political Resident to the Secretary to the Government of India in the Foreign and Political Department, 24 Septembre 1916, F.O. 371/2476.

(220)"Notes on the Mission of French to Sherif Husein ruled Mecca", Arab Bureau, 16 Octobre 1916, F.O. 6074; Telegram from Resident Aden to Sir Mcmahon Cairo, 15 October 1916, F.O. 2487.

(221)"Lettre de President du...", le 1mai, 1917, Carton 310. Dossier 2. p. 48.

${ }^{(222)}$ Ibid.

${ }^{(223)}$ Pascal, "La Mission du Lieutenant...", pp. 17-31.

${ }^{(224)}$ Under Secretary of State Foreign Office to India Office, Political Turkey, 1916, F.O. 371/2799.
تفطن الثريف حسين لذلك التنافس بين الدولتين(211) و عمل على استغلاله لإنجاح ثورته وتوسيع ممتلكاته وتأمينها(212).

لكن كان من أهم التحديات التي واجهت الحكومة البريطانية؛ كيفية تلافي شكوك العرب وبقية دول الحلفاء مع المحافظة على عدم زعزعة ثقتهم بها، وخلق تتاغم بينها وبين العرب؛ ولهذا فقد استخدمت الحكومة البريطانية سياسة المكر والخداع فبدلا من منح ويلسون "Wilson" لقب "قنصل" في ولاية الحجاز منحته لقب "ضابط الحج"(213)، و عينت معه عددا من الموظفين المسلمين(214)، وطبيبا(215) مكلفا بإنشاء مستشفى ميداني مُنتقل (216)، ومعهم موظفون وطئ من ممرضين ومخبريين، بالاضافة إلى الأدوات اللازمة(217)، كما عينت الحكومة البريطانية مندوبا "Gellatly Company" لشركة جيلاتلي كومباني (218) لبتولى مسائل نقل الحجاج من مستعمر اتها في

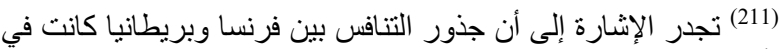

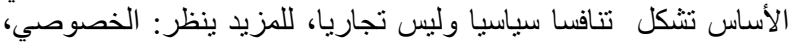

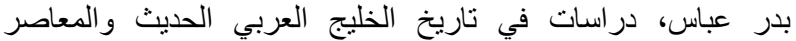
(الكويت: منشورات ذات السلاسل، داريخ 1984م)، ج1، صل العربي 12 وما بعدها. (212)"Arabian Report" N. S, 10 August, 1916, F.O.17/178

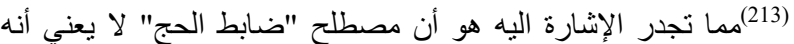

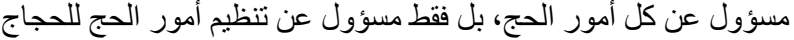
القادمين من المستعمر ات البريطانية وخاصة من الهن الهند. (الباحث)

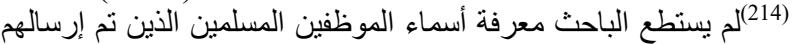

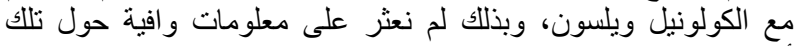
ألاسماء في المصادر والمر اجع المع المتاحة (الباحث).

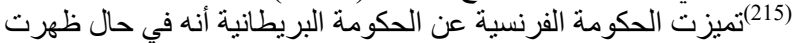

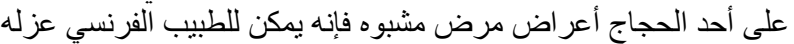

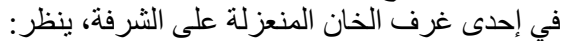

"Rapport Medical sur...", Carton 310. Dossier 2, p. 11.

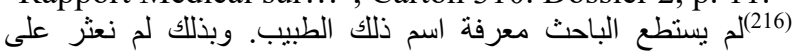
معلومات و افية حول اسمه في المصادر و المر اجع المتاحة (الباحث).

${ }^{(217)}$ The Arab Builetin of The Arab Bureau in Cairo, 1916-1919, (London: Archive Editions, 1986) Vol, 2, 28, p. 398.

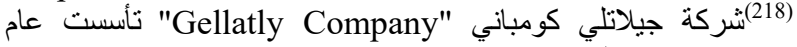
1862م وكانت لها تجارة كبيرة بين مدينتي سواكن وجدة، وفي عام 
ومن خلال استقراء الأحداث، نجد أن الحكومة الفرنسية قد شددت في خطابها للحكومة البريطانية مؤكدة أن الهذف من إرسال بعثثها إلى شريف مكة

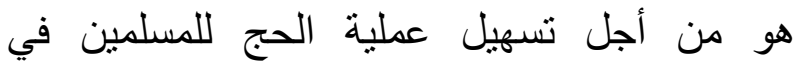
مستعمر اتها و البلدان الو اقعة تحت سيطرتها، ولن يتم ذللك إلا بمساعدة صديقتها الحكومة البريطانية(231)، كما أن الحكومة الفرنسية كانت تعترف لبريطانيا

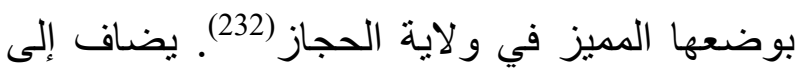
ذللك أن الحكومة الفرنسية أوضحت أنها لن تقوم بأي خطوة في ولاية الحجاز إلا بعد الاتفاق التام مع الحكومة البريطانية(233)، بحجة أن فرنسا لا ترغب لإنب

في التدخل بالثؤون الداخلية لو لاية الحجاز (234). وعلى إثر ذلك اتسم عمل ويلسون "Wilson" في ولاية الحجاز بالليونة وتسهيل تنقلات البعثة

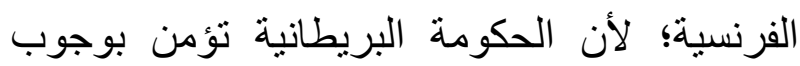
التودد والتقرب للعرب المحيطين بمكة لتأليبهم على لتى بلى الدولة العثمانية(235)، وفي الوقت نفسة تراعي

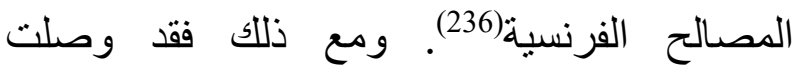
معلومات لفرنسا تؤكد أن الموقف البريطاني لم يتغير

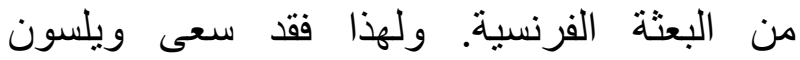
"Wilson" إلى تقديم البعثة الفرنسية للشريف حسين على أنها بعثة مدنية وعسكرية فرنسية ـ إسلامية

العوا(لقبلة: العدد (181)، س 1)، الخميس 19 ذ ذي الحجة 1334هـ

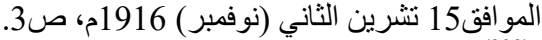

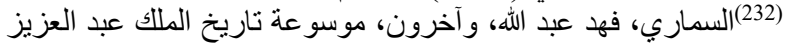

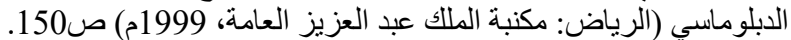
(233)"Lettre de President du...", le 1mai, 1917, Carton 310. Dossier 2. p. 49.

(234)"Arabian Report" N. S, 16 July 1916, F.O.17/177.

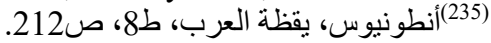
(236)بروكلمان، تاريخ الثُعوب الإسلامية، ط5 ، ص745.
البريطاني في ولاية الحجاز (225) إذ إن الحكومنين البريطانية والفرنسية تدركان أهمية ولاية الحجاز

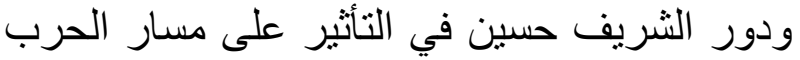

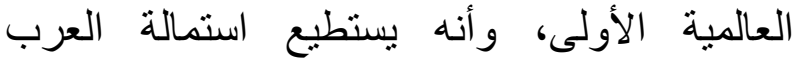

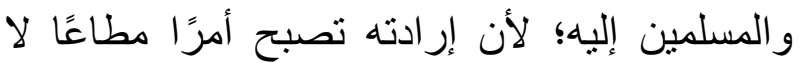

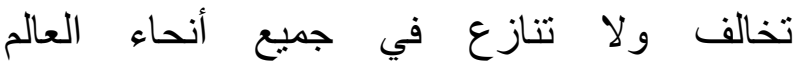

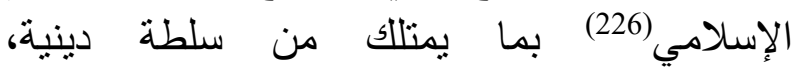
وزمنية(227).

تصاعدث أحداث الحرب العالمية الأولى، وتبدل الموقف البريطاني بهدف الإبقاء على التحالف(228) بين الحكومتين البريطانية و الفرنسية متماسكا إذ إذبي خلقت بعض صور للتفاهم فيما بينهما أسهمت في تلاشي حدّة الصراع على ولاية الحجاز. و وعلى إثر ها، التزمت وزارة الخارجية البريطانية بتقديم ما بوسعها لإنجاح وتسهيل وصول البعثة الفرنسية إلى ولاية الحجاز، عملا على ما بحقق مصلحة بلادهم، وفي إثر ذللك طلبت الحكومة البريطانية من مندوبها في مصر تقيم المساعدة إلى بريموند

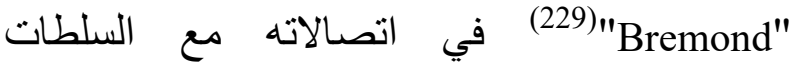
العسكرية للشريف حسين(230).

${ }^{(225)}$ Political Resident to the Secretary to the Government of India in the Foreign and Political Department, 24 Septembre 1916, F.O. 371/2476.

(226)(القبلة: العدد (1)، س 1، الاثثين 15 شو ال 1334هـ المو افق 15 آب

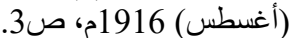
1919 غراييه، عبد الكريم، مقدمة في تاريخ العرب الحديث (1927)

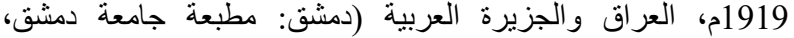

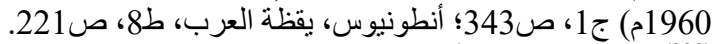

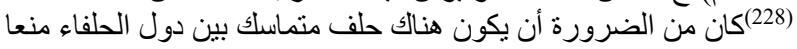
للخلاف، وكانت الحكومة البريطانية هي المهندس الرئيس فئس في إيجاد

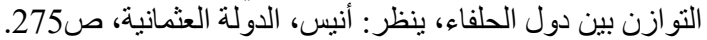
(229) نظر الارنباط بعثة الحجاز ببعثة الحكومة الفرنسية في مصر.

${ }^{(230)}$ Telegram from the Resident, Cairo to the Secretary of State for the Colonel, 28 Augest 1916, F.O. 882/10. 
حسين في مكة عن دعم الحكومة الفرنسية له و أنها تقف بجانبه في ثورته ضد الحكومة دمة العثمانية(244).

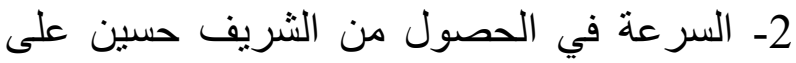

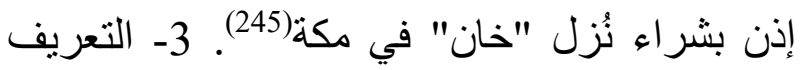
بالإسلام السياسي الفرنسي الجديد الذي سيخدم مصلحة الثريف حسين(246). 4- إعطاء نوجيهات بشأن العلاقات التي تربط ابن غبريط برئيس البعثة

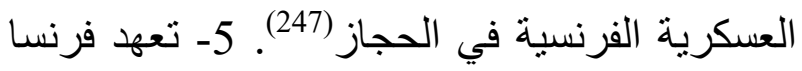
تسهيل وتأمين طرق القو افل للحج(248) كما أن ثمة معلومة وردت تؤكد أن الحكومة الفرنسية

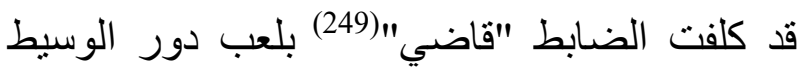
بين بريموند "Bremond"(250) و الثريف حسين (251) وكان من وراء هذه الوساطة أربعة أهداف: أولا:

(244)"Lettre Ministre des Affaires Etrangeres", Paris, du 4 Septembre 1916. Àrchives Diplomatiques de Nantes, "Londres, Ambassade Fonds K, 378Po/K 382".

${ }^{(245)}$ Ibid.

${ }^{(246)}$ Ibid.

(247)"Lettre de President du...", le 1mai, 1917, Carton 310. Dossier 2. p. 46.

${ }^{(248)}$ Sellam, Sadak, La France et ses Muslmans (Alger: Casbah, 2006), p. 176.

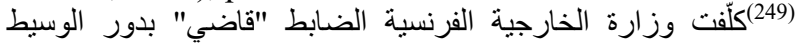
اللبعثة الفرنسية التي أرسلت إلى الحجاز ؛ لأنها كانت كانت مؤلفة من قسمين:

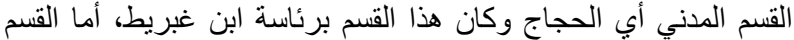

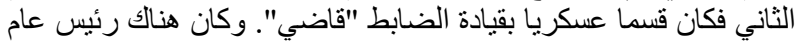

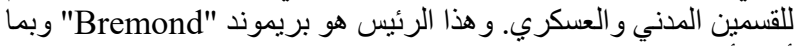

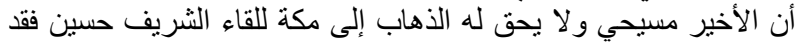

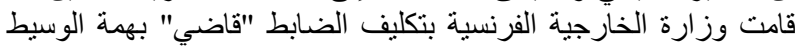
بين الكولونيل بريمو ند و الثريف حسين. (الباحث).

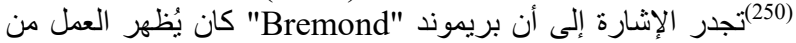

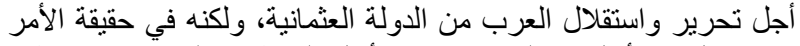

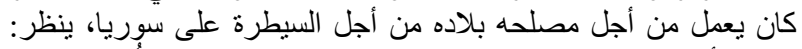

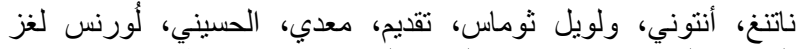

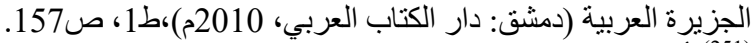

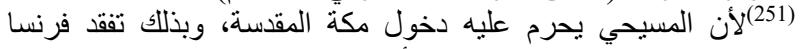

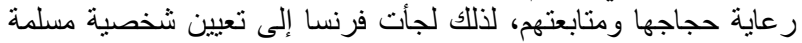
تقوم برعاية حجاجها من المستعمرات الفرنسية، ينظر: أمين، "موسم

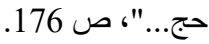

(237). كما أنه قد تم العثور على معلومات في الأرشيف البريطاني تدعم الرأي الفرنسي، إذ إنه بالفعل قد تم تقديم البعثة الفرنسية للشريف حسين على أنها بعثة سياسية لبس لها أهداف عسكرية(238). وقد لاحت بو ادر إقامة كيان سياسي خاص بالحكومة الفرنسية تظهر في الأفق من خلال تصرفاتها تجاه الثريف حسين بمكة، (بالر غم من نفيها أنه لا توجد لها أي مصالح سياسية أو تجارية في ولاية الحجاز)(239)، وأنها لا تسعى للحصول على امتيازات دينية في شبه الجزيرة العربية، بل هي على العكس تمتنع عن التدخل في شؤون المسلمين الدينية(240). لكن من خلال الأحداث التاريخية يتضح أن الحكومة الفرنسية كانت تسير باتجاه تحول الدعم المعنوي إلى مشاركة عسكرية سياسية(241) حتى لهي تتمكن من مد نفوذها وتوسعها في ولاية الحجاز، وفي شمال شبه الجزيرة العربية(242). 8- مهام البعثة ونقلها إلى ميناء جدة: ممَّا يبدو من المعطيات التاريخية أنه قد أُعطيت للبعثة الفرنسية المتجهة إلى ولاية الحجاز الصفة السياسية و الدينية(243)، وحُددت أهدافها ومُنح ابن إنه غبريط عدة أمور تحدد الطابع و الغرض من مهمتة كان من أبرزها ما يأتي: 1- الإعراب للشريف

(237)"La Depeche, Diplomat...", 24 September, 1916, Rabat No, 977.

${ }^{(238)}$ Telegramme from Political Resident to the Secretary to the Government of India in the Foreign and Political Department, 29 Augest 1916, F.O. 371/6096.

(239) (السماري، موسو عة تاريخ، ص160.

${ }^{(240)}$ Journal Le Matin, N 11946,11 Novembre 1916, p, 1. (241)فريحات، السياسة الفرنسية، ص 101.

(242)"Traduction en Francais de Constitution...", Carton 310. Dossier 2, P. 16.

صنس233) 
السفر بحر|(261)، وكانو| نخبة مختارة من مسلمي شمال أفريقيا على النحو الآتي: (293) حاجا جزائريا و (191) حاجا نونسيا و (216) حاجا

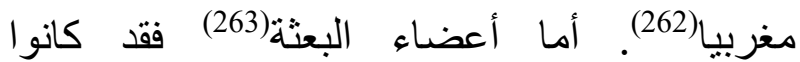
متو اجدين في مدينة باريس وقد التقوا بوزير الداخلية الفرنسي وتم إعطاؤ هم المعلومات وتوجيههم بالعمل لمصلحة الحكومة الفرنسية والاجتهاد في إنجاح المهمة التي أرسلوا من أجلها(264)، وقد نقلوا على ظهر البارجة "أستريه" التي غادرت من ميناء مرسيليا "Marseille" الفرنسي في يوم الأربعاء 81334-11 هـ/6-9- 1916م لمقابلة الشريف حسين من أجل شراء نُزل " خان " في مكة(265)، كما حرصت الحكومة الفرنسية أن يصحبهم بريموند "Bremond" كل من الكابتن كوس "Cousse" من طابور المشاة رقم (314) ورئيس المدفعية الثقيلة رقم (113)، كوني "Cuny"، و ستركير "Streiberg" كاتم أسرار

(261)"Lettre de President du...", le 1mai, 1917, Carton 310. Dossier 2. p. 48.

(262)"La Depeche, Diplomat...", 25 September, 1916, Rabat No, 977.

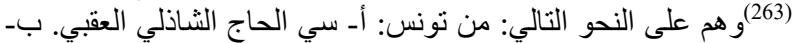

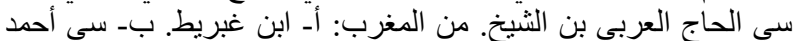

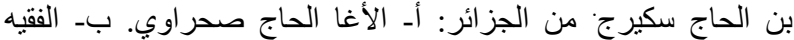

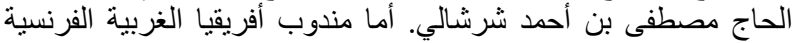

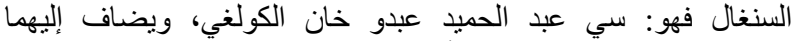

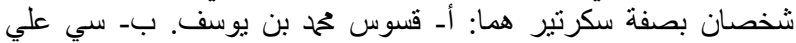

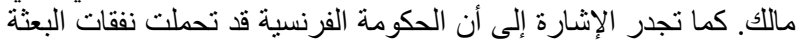

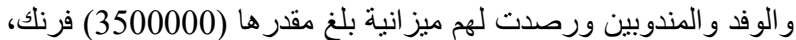

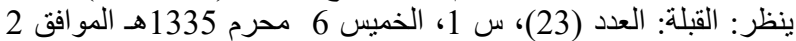

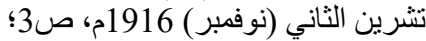

"Notes on the Mission of French to Sherif Husein ruled Mecca", Arab Bureau, 16 Octobre 1916, F.O. 6074.

(264)"Lettre Ministre des Affaires...", du 6 Septembre 1916, "Londres, Ambassade Fonds K, 378Po/K 382". ${ }^{(265)}$ Ibid;

القبلة: العدد (23)، س 1، الخميس 6 محرم 1335هـ الموافق 2 تشرين الثاني (نوفمبر) 1916م، صن3.
تسهيل عملية حج المغاربة إلى مكة(252). ثانيا: تسهيل مهمة ابن غبريط(253). ثالتا: تقديم المشورة العسكرية للشريف حسين في مكة في أثناء ثورته(254) ضد الدولة العثمانية من خلال تقديم الاستشار ات و التقنيين المختصين لضباط العرب . رابعا: إن هدف البعثة الفرنسية هدف سياسي بحت لا دخل له بشؤون الخلافة(256) الإسلامية(257). وفي ضو ء ما سبق قامت الحكومة الفرنسية باستئجار السفينة لورينوك "L'Orenoqué"

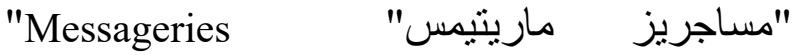
"259(Maritimes" لنقل الحجاج من مستعمر اتها في شمال أفريقيا إلى مكة(260)، وذلك لضمان سلامة

(252)"Lettre Ministre des Affaires...", du 4 Septembre 1916, "Londres, Ambassade Fonds K, 378Po/K 382".

${ }^{(253)}$ Ibid.

(254)القد حرصت الحكومة الفرنسية على عدم تقويه جيش ثورة الثريف

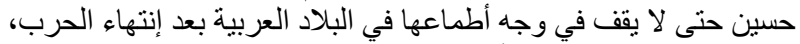

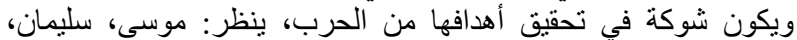

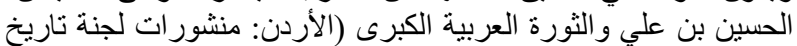

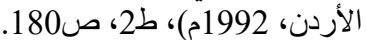

(255)"Lettre de President du...", le 1mai, 1917, Carton 310. Dossier 2. p. 50.

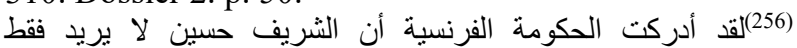

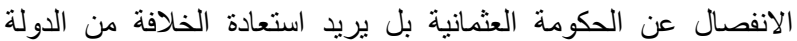

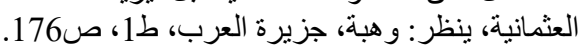
${ }^{(257)}$ Elder, French Policy, p. 337.

(258) حرصت الحكومة الفرنسية على أن تنوفر في السفن التي تنقل

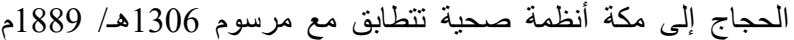

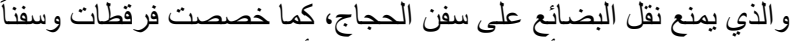

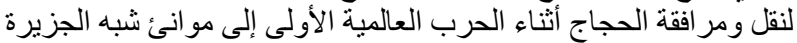

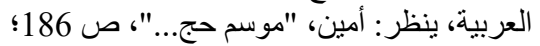
Journàl Lé Màtin, N 11946,11 Novembre 1916, p, 1. عام (259) شركة "ميساجري ماريتيم" "Messagerie Maritime" تأسست

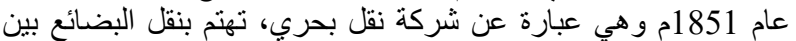
أوروباو آسبا، للمزيد من المعلومات ينظر المقالة التالية:

Berneron-Couvenhes, Marie-Françoise, La Compagnie des Messageries Maritimes: Initiatives privees et subventions publiques a l'origine d'un grand Armement Commercial Français au XIXe siecle, (in Revue d'histoire maritime, no 5, 2006), p. 55.

(260)"La Depeche, Diplomat...", 24 September, 1916, Rabat No, 977. 


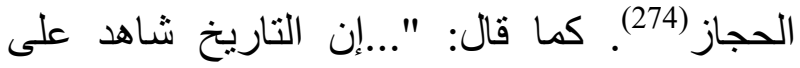

العواطف الكريمة التي أظهرتها الأمة الفرنسية

$$
\text { للإسلام و المسلمين..." (275). }
$$

9ـ مراسم استقبال البعثة الفرنسية من قبل الشريف

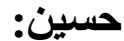

أرسلت وزارة الخارجية الفرنسية رسالة إلى دوفرانس "Defrance"، أكدت فيها على منى منابعة البعثة الفرنسية المتجهة إلى الثريف حسين في مكة و أن تنقل لها كافة التفاصيل، وأن تتحرى في مر اسيم التيم الاستقبال التي أعدت للبعثة كما أكدت على متابعة شؤونها(276)، لأنها كانت حريصة على أن تظهر بعثتها بالمظهر اللائق أمام الحكومة البريطانية المنافسة(277) لها في و لاية الحجاز (278). ومن الأهية بمكان الإشارة إلى أن الثريف حسين

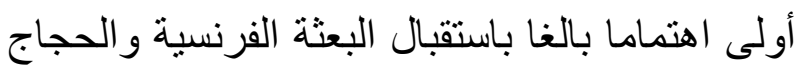

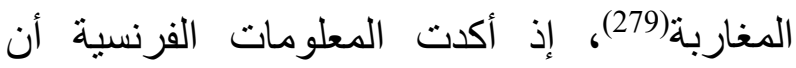
الثريف حسين في عشية يوم الجمعة 17-111334هـ/ 15-916-912 استحوذت عليه فكرة

(274)(القبلة: العدد (18)، س 1، الخمبس 19 ألى ذي الحجة 1334هـ

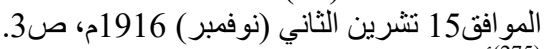

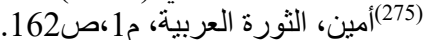

${ }^{(276)}$ Telegramme de Francais au Ministere des Àffaires Étrangeres Francais, No, 40, du 4 Octoper, 1916, Àrchives du Ministere des Àffaires Étrangeres: ÀrabieHedjaz. Carton, 78.

قبر الجزيرة تسنطع الحكومة الفرنسية زعز عة مكانة الحكومة البريطانية في

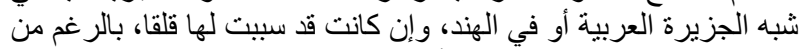

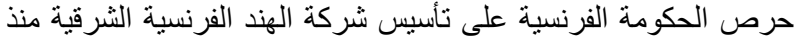

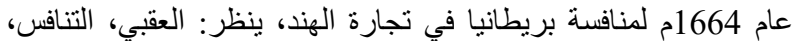

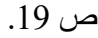

${ }^{(278) " L e}$ President du Conseil Ministre des Affaires Etrangeres a Monsieur de Fleuriau Charge d Affaires de la Republique Francaise a Londres", Paris, Service Historique de là Defence, du 22 Octobre 1916.

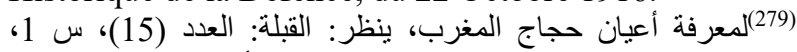

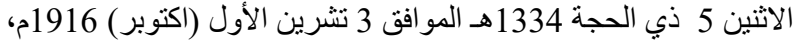

البعثة(266)، و الكمندور كادي Cadi" رفيد" والنقيب "رحو حمح ولا علي"(268) وقد وصلوا جميعًا إلى ميناء مدينة جدة يوم الأربعاء بتاريخ: 22-

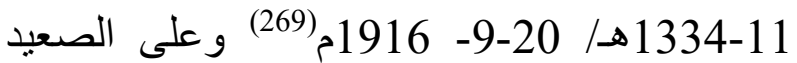
الأخر فقد وصلت سفينة الحجاج المغاربة(270) المذكورة إلى بحر مدينة جدة في يوم الاثنين بتاريخ:

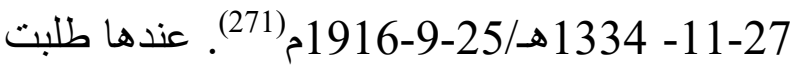

وزارة الخارجية الفرنسية من ويلسون "Wilson" البريطاني في الحجاز أن يساعد بعثتها(272) ويسهل

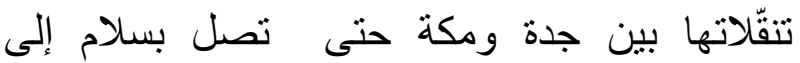
الثريف حسين في مكة، وهذا ما تم بالفعل(273). هذا وقد أكدت المعلومات أن الثريف حسين قد أرسل تلغر افا إلى رئيس الجمهورية الفرنسية بوينكار "Poincare" بوصول البعثة الفرنسية إلى مكة كما شكر فيها الأمة الفرنسية على اهتمامها بالإسلام و عن مدافعتها عن إلى من الحقوق المدنية للشعوب وفي مقدمتها ولاية

(266) القبلة: العدد (12)، س 1)، الخميس 24 ذي القعدة 1334هـ الموافق

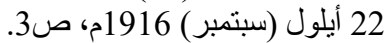
(267)"Arabian Report" N. S, 23 September 1916, F.O.17/177.

${ }^{(268)}$ Pascal, "La Mission du Lieutenant...", pp. 17-31.

(269)"La Depeche, Sairt Aulaire, Ministre Plenipotentiaire Delegues", du 9 Octoper 1916. Àrchives du Ministere des Àffàires Étrangeres, Àfrica II, 169-1.

(270)لقد وجد مشروع إرسال سفن مجانية لموسم حج عام 1916 1334هـ/

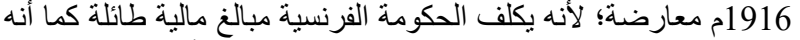
يشجّع الناس على الذّارئ لأهاب إلى مكة، وهذا يخالف أهداف الاستعمار Pautremat, La Politique Musulmane, p. 198. الفرنسي، بنظر : (271) الحناشي، "جمعية أحباس..."، ص 160. (272)"Arabian Report" N. S, 23 September 1916, F.O.17/177.

${ }^{(273)}$ Ibid. 
وفي صباح يوم الأربعاء: 30-11-1334هـ/28-91916م غادرت البعثة الفرنسية مدينة جدة، واتجهت

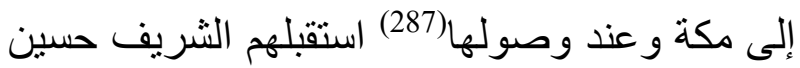
بنفسه استقبالا رسميا لائقا بهم (288)، إذ حيَّو هُم بمئة الفئة

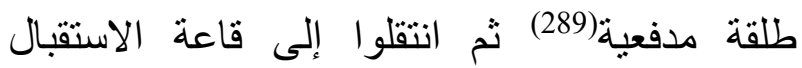
الرسمي(290) وكان بصحبة الثريف حسين أثناء الاستقبال الضابط "قاضي" وبقية الضباط بلباسهر

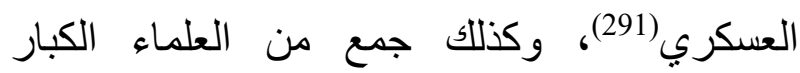
بمكة(292) وأعضاء مجلس الثورى و الوجهاء، ثم بعد

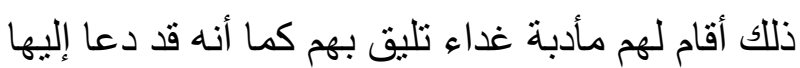
كبار رجال العيئات الدينية، والمستشارين، وكبار

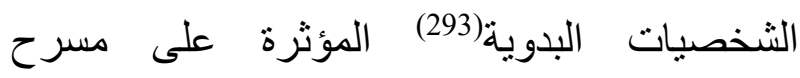

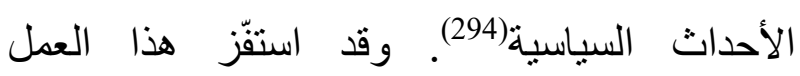
الحكومة البريطانية التي كانت تؤمن بأن الثريف

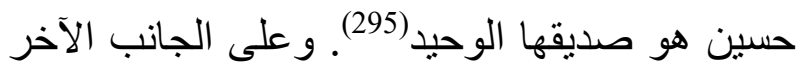
رحبت ولاية الحجاز بالبعثة الفرنسية في أراضيها وليها

${ }^{(287) " L e ~ P r e s i d e n t ~ d u ~ C o n s e i l ~ M i n i s t r e . . . ", ~ d u ~} 22$ Octobre 1916.

${ }^{(288)}$ Ibid.

${ }^{(289)}$ Journal Le Matin, N 11946,11 Novembre 1916, p, 1 ; القبلة: العدد (14)، س 1، الخميس 1 ذي الحجة 1334هـ المو افق 29

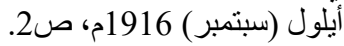

$$
\text { (290) المرجع نفسه. }
$$

(291)"Le President du Conseil Ministre...", du 24 Octobre 1916.

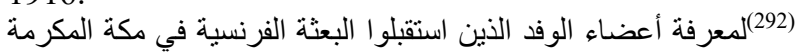

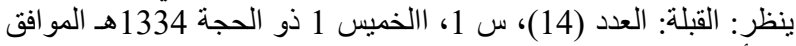

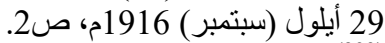

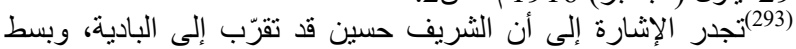

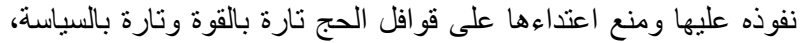

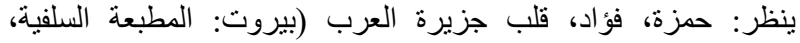

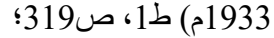

Baker, Randel, King Husain and the Kingdom of Hejaz (Cambridge:Oleander Press, 1979) p, 22.

(294)"Lettre Ministre des Affaires...", du 2 Octoper 1916, "Londres, Ambassade Fonds K, 378Po/K 382".

${ }^{(295)}$ Telegram from the Secretary to the Government of India in the Foreign and Political Department, 1916, L/PS/10/1175.
التحضير لاستقبال يليق بالبعثة الفرنسية والحجاج

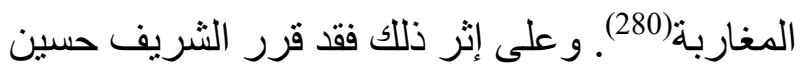
إيفاد وفد (281) من أعيان مكة لاستقبال البعثة في يوم وصولها على ظهر البارجة القادمين عليها في مياه

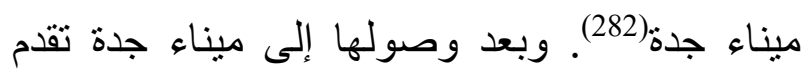

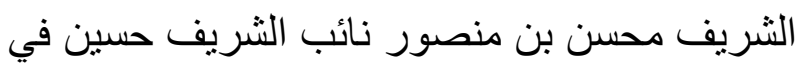
مدينة جدة وكان معه رئيس بلدية مدينة جدة ومدير الأمن العام، وكذلك المعتمد البريطاني في مدئ مدينة جدة(283)، و أطلق ترحيبا بالبعثة الفرنسية (21) مدفعا من البر الحجازي. وكانت علامة على الصداقة و السلام، ثم بعد ذلك ركبو ا الخيول، و اتجهو ا إلى دار الحكومة. وقد عملت لهم مأدبة غداء حافلة، تسودها

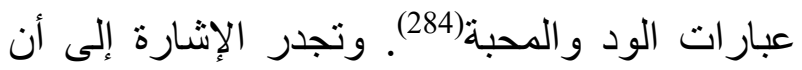
رئيس الجمهورية الفرنسية بوينكار "Poincare" أرسل تلغر افا إلى الثريف حسين شكره فيها على

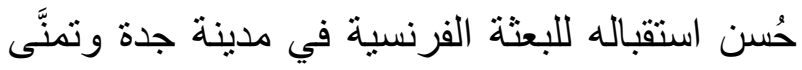
أن يكون النصر حليفه(285) في حين كانت الحكومة في فئهة البريطانية نراقب عن كثب كل تحركات البعثة

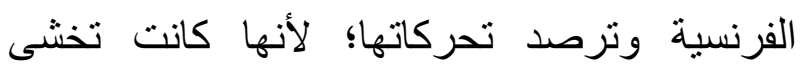
منافسه فرنسا لها في ولاية الحجاز (286).

(280)"Le President du Conseil Ministre...", du 22 Octobre 1916.

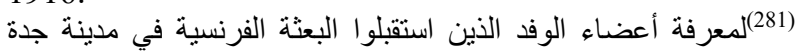

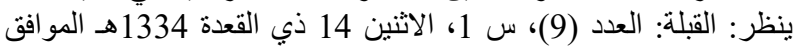

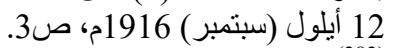

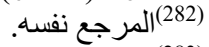

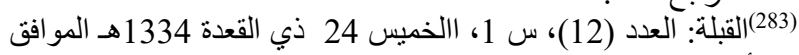

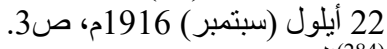

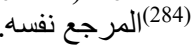

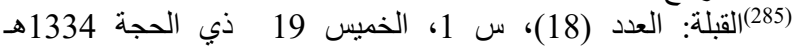

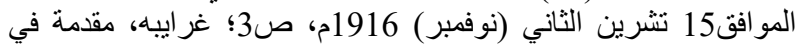

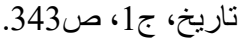
(286)"Arabian Report" N. S, 23 September 1916, F.O.17/177. 
حسين لاسترجاع الكر امة العربية. ي- أكد أن مسلمي

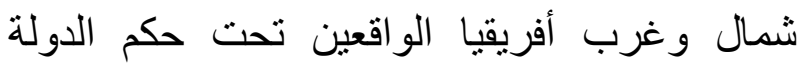

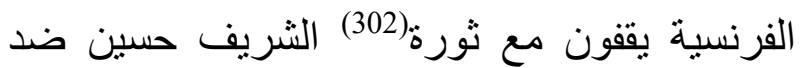
الدولة العثمانية(303). و ـ- أكد أن النصر حليف

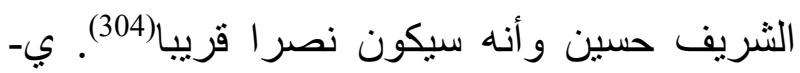
أكّد دعم الحكومة الفرنسية على تأسيس دولة عربية مستقلة(305). عند ذلك ارتجل الثريف حسين خطبة ردا على ابن غبريط، ومن أهم ما جاء فيها على النحو الآتي: أـ

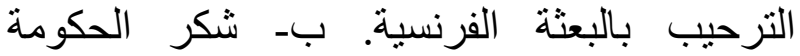

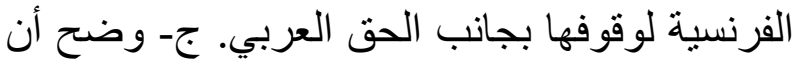
الهذف من ثورة العرب(306) ليس من أجل مطامع ومكاسب دنيوية و إنما الهدف هو إظهار الحق، و المحافظة على الكيان الديني و القومي للأمة العربية و الإسلامية. دـ أظهر محاسن الأمة الفرنسية بوقوفها ومؤازرتها للإسلام و المسلمين. ي- شكر سكان بلاد المغرب وحُكامها على عنايتهم واهتمامهم بتوثيق أواصر المحبة والمودة مع و لاية الحجاز (307). بعد ذللك قدم ابن غبريط للشريف حسين الهدايا التي جُلبت من فرنسا ومن مستعمراتها في شمال

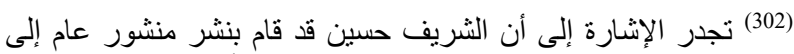

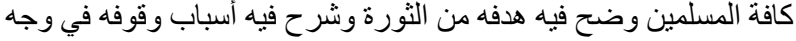

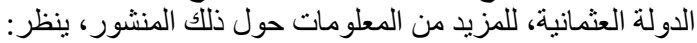

The King of Hedjeaz and Arab Independence, (London: Hayman Lilly Ltd, 1917) p.1.

(303)القبلة: العدد (14)، س 1، الخميس 1 ذي الحجة 1916 1334هـ الموافق

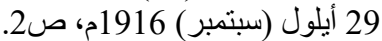
(304) المرجع نفساه. (305) المرجع نفسها.

(306)تجدر الإشارة إلى أن السوريين كان لديهم خبر اتصال الثريف حسين

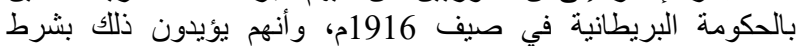

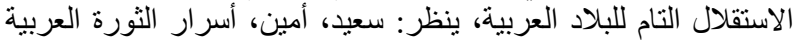

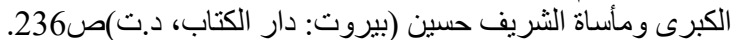

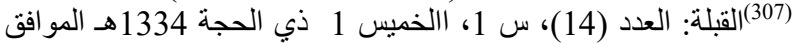

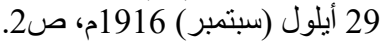

لاعم قوتها على أرض الو اقع للوقوف في وجه الدولة

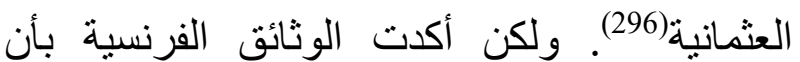
الاستقبال الحجازي للبعثة الفرنسية يخفي سببا أبعد بكان عمقا، يتجسد في رغبة الحكومة الفرنسية باحتو ائها

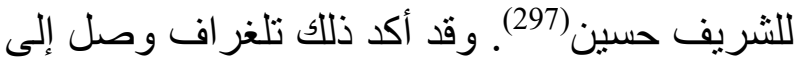
"Poincare" الشريف حسين من الرئيس بوينكار يشكره فيها على إخباره بوصول البعثة الفرنسية إلى لى لئي

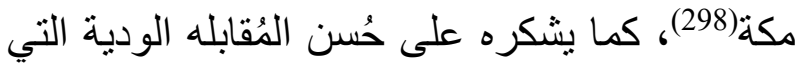
استقبلت بها البعثة (299). ثم في نهايه رسالتة طمأن الشريف حسين وأكد له بقوله: "...أن الحكومة الفرنسية تتمنى بمنتهى الإخلاص النصر المبين

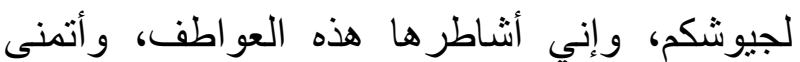

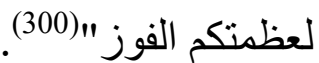
وعلى المشهد الآخر، وبعد مراسم الاستقبال تقدم رئيس البعثة ابن غبريط و ألقى خطبة أمام الثريف التيف حسين، ولعل أهم ما جاء فيها على النحو الآتي: أـ امتدح الثريف حسين؛ لأنه جمع بين السياسة الدينية

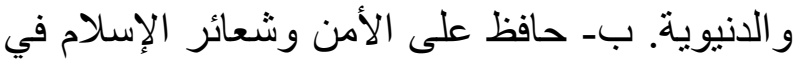

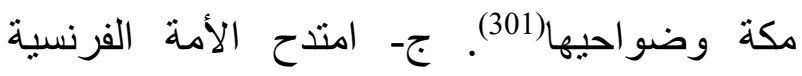
صاحبة المدنية الإنسانية. دـ أكد أنه جاء مندوبا من الن الهن

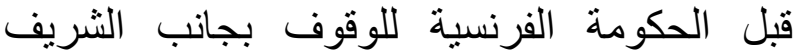

${ }^{(296)}$ Ibid.

${ }^{(297)}$ Tiegramme du Conseil Ministres dés Àffaires Étrangeres Francais, No, 39, du 17 Octoper, 1916, Àrchives du Ministere des Àffaires Étrangeres: ÀrabieHedjaz. Càrton, 77.

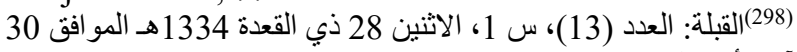

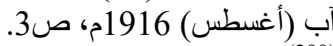

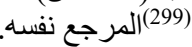

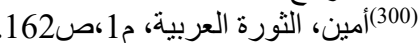

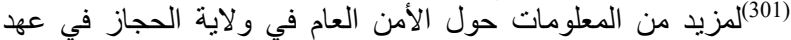

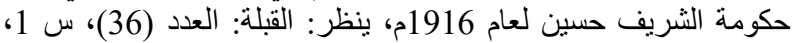
الاثنين 22 صفر 1335هـ الموافق 18 تثرين الثاني (نوفمبر) 1916م، لئ، 
أحمد سر اج(316) وبعد التفاوض تم شر اء العقار بمبلغ قدره مائة وخمسة وعشرون ألف فرنلك، قَدرَّنةُ اللجنة(317) التي قامت بزيارة تفصيلية للعقار، ولهن وأوضحت بأن البناء يتميز بعدة مميزات لعل من بن أهمها الآتي: أــ قربه من إحدى الساحات الكبيرة للحرم(318)، بـ قربه من الكعبة المشرفة؛ فباب الحميدية على بعد حو الى مائة مثر. ج- مخازن الدار تتسع للمؤن، د- صهريج يوفر الحاجة من الماء. و المبنى تتوفر فيه النظافة(319)، وبناء على تلك دونى المواصفات اشترى ابن غبريط العقار (320) بأموال الدولة الفرنسية بعد دفعه عربونا قدره ألفا فرنكاتك(321). لكن الثريف حسين ومعه الثيخ سي أحمد أفندي لهيد باناجه قد واجها بعض الصعوبات الناتجة عن خوفهما من ضغط الر أي العام في مكة الر افض لبيع أي عقار (322) في أنحاء مكة لدولة غير مسلمة، عند

(316)"Àmbassadeur Francais au...", Carton, 529, p. 12.

(317)"Proces-Verbal de la Seance...", du 14 Decembre, 1915, Carton, 2 Mi 101, vol, 8e; Pascal, "La Mission du Lieutenant...", pp. 17-31.

ينظر ملحق رقم (1) (18)

(319)"Note Redigee p ar M. le Commandant Cadi au Sujet" d'un Immeuble Visite par M. Benghabrit qui Pourrait Servir d'hotellerie Destinee aux Perlerins de la Mecque Ministere de Àffaires Étrangeres, 1918- 1919, "Àrabie-Hejaz", 18. Mission de M. Cherchali. Serie É. Carton 310. Dossier 2.

(320) شر اؤه من قبل ابن غبريط، بنظر الفئر

"Àmbassadeur Francais au...", Carton, 529, p. 1-12.

(321)"Lettre de President du...", le 1mai, 1917, Carton 310. Dossier 2. p. 46.

(322)تجدر الإشارة إلى أن العقار الذي اثنترته الحكومة الفرنسية في مكة

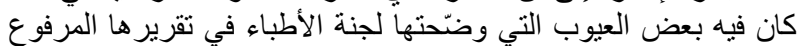

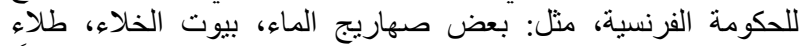

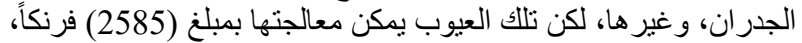

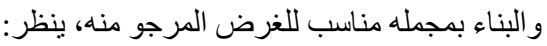

"Rapport Medical sur..."Carton 310. Dossier 2, p. 12.
أفريقيا(308). كما قدّم الإعانة الفرنسية التي أقرها مجلس الثيوخ الفرنسي(309). وتجدر الإشارة إلى أن الحكومة الفرنسية كانت تهدف من ور اء ذلك إلى دفع مخصصات البدو ورواتب الجنود النظاميين ورواتب

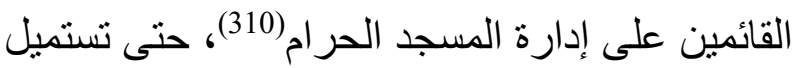
كافه أطياف المجتمع الحجازي إلى جانبها(311). 9ـ المفاوضات حول تنفيذ المشروع: حقق ذلك التلاحم و التحالف بين و لاية الحجاز و البعثة الفرنسية في موسم حج 1334هـ/ 1916م اجتماع

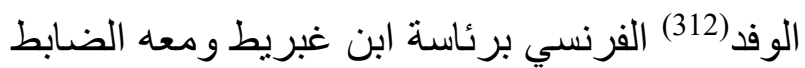

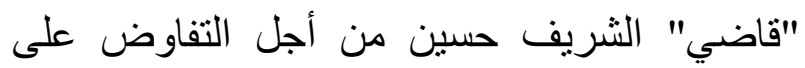
شر اء عقار (313) يملكه السيد عبد الستار الميمني(314) وبحضور كلٍ من الثيخ سي أحمد أفندي باناجه(315) وكيل المالية في ولاية الحجاز، وقاضي القضاة ومفتى الأقطار الحجازية بمكة الثيخ عبد الله بن

${ }^{(308) " L e ~ P r e s i d e n t ~ d u ~ C o n s e i l ~ M i n i s t r e . . . ", ~ d u ~} 24$ Octobre 1916. ${ }^{(309)}$ Ibid.

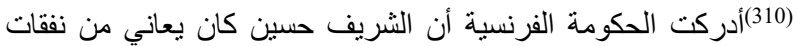

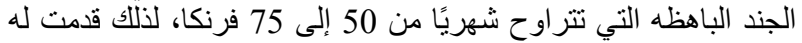
المعونة، ينظر الياهن "Le President du Conseil Ministre...", du 24 Octobre 1916.

${ }^{(311)}$ Ibid.

(312)تجدر الإشارة إلى أن الوفد الفرنسي قد حمل رسائل من حكام شمال

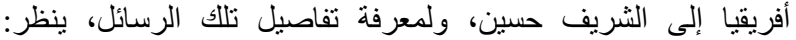

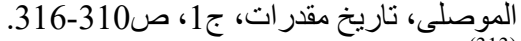

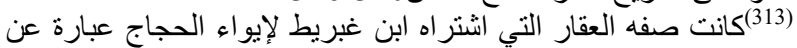

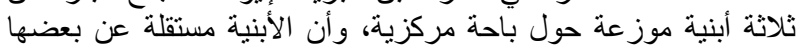

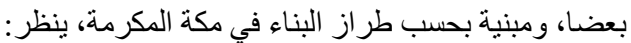

"Rapport Medical sur...", Carton 310. Dossier 2, p. 11.

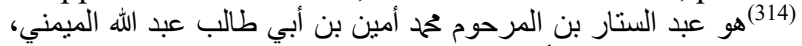

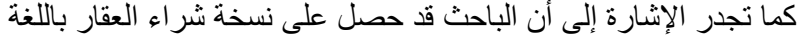

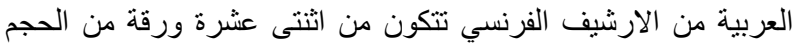
المتوسط، ينظر : الأرن

"Àmbassadeur Francais au Caire". Ministere des Àffaires Étrangeres Lr, Carton, 529, P. 1.

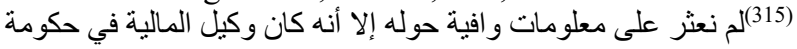

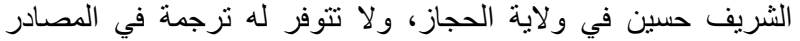
و المر اجع المتاحة. 
و الغربية(329). عند ذلك اقتنع الثريف حسين وثُرجم إلى خطوة عملية وتمت كتابة عقد البيع(330) باسم ابن غبريط(331)؛ لكن ساد خملاف مرة ونم أخرى حول تسمية العقار في مكة، عندها اقترح الثريف حسين تسميتة "رباط المغاربة في الحجاز" وكان هدف الثريف حسين من ذلك هو إكسابه الصفه الدينية الجهادية(332)، عندها وافقت الحكومة الفرنسية على هون إلى مقترح الثريف حسين؛ لأن هنالك ميزات كثيرة في جعل ملكيتة لمسلمي شمال وغرب أفريقيا التي تخدم

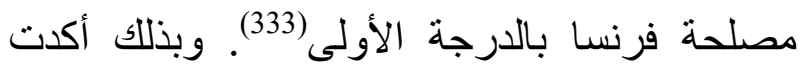
المعلومات الفرنسية أنه قد جرى توقيع العقد لاحقًا بتاريخ: 1335-3-29هـ/23-1-1917م وتم دفع المبلغ المتبقى وهو مائة وثلاثنة وعشرون ألف(334) فرنك(335). و عليه وبسرعة فائقه أعطت الحكومة ماته ونيه الفرنسية تعليماتها لمبعوثها الرسمي سي وبر الحاج

(329)"Traduction en Francais de Constitution...", Carton 310. Dossier 2, P. 18.

(330) جرت المبايعة لدى قاضي مكة المكرمة مستوفيه شرائط الشرعيه

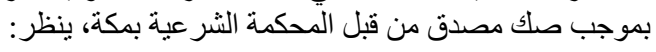

"Àmbassadeur Francais au...", Carton, 529, p. 11.

(331)"Telegramme du Quai d'Orsay au Resident General du Maroc a l'intention..." (Decembre 1916Avril, 1918), (Paris), vol. 1710.

(332) هو اري، مسألة الحج، ص 77؛ الحناشي، "جمعية أحباس..."، ص

(333)"Lettre de President du...", le 1mai, 1917, Carton 310. Dossier 2. p. 47.

(334)تجدر الإشارة إلى أن القوانين المطبقة في مصر لم تسمح بتحويل

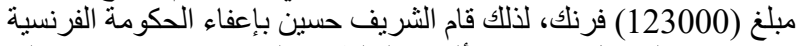

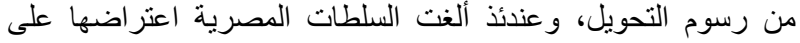
إخر اج العملة الذهبية، ينظر الخونة

"Lettre de President du...", le 1mai, 1917, Carton 310.

Dossier 2. p. 46.

(335)"Telegramme Ministre des Affaires Etrangeres", Paris, le 21 Jànviér 1917. Service Historique de la Defence. No "2837".
ذللك كادوا أن يتراجعوا عن البيع(323)، و عندما وصلت تللك المعلومات إلى بريموند "Bremond" أسرع إلى طمأنة الثريف حسين ومعه وزير ماليته بخصوص هويّة المشتري(324)، لتفادي الإساءة للثريف حسين أمام الرأي العام الإسلامي، إذ لن يكن المشتري هو الحكومة الفرنسية بِكُل تأكيد بل

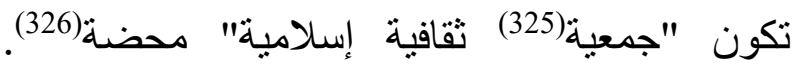
وسيمثل تللك الجمعية رسميا ابن غبريط(327) وهو رئيسها وستحمل مسمى "جمعية أحباس الحرمين الشريفين" (328) و غايتها هو امتلاك البناء في مكة وتحويله إلى "وقف" لصالح الحجاج الفقراء المحتاجين للمأوى، والقادمين من أفريقيا الثمالية

(323)"Proces-Verbal de la Seance...", du 14 Decembre, 1915, Carton, 2 Mi 101, vol, 6e.

(324)"Telegramme du Quài d'Orsay au Resident General du Màroc à l'intention de Ben Ghabrit". Cite in Le Pautremat Ministere de Àffaires Étrangeres, Guerre 1914-1918, Hedjaz, Mi P 1462, Hotelleries de La Mecque (Decembre 1916-Avril, 1918), (Paris), vol. 1710.

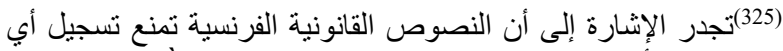

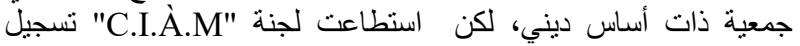

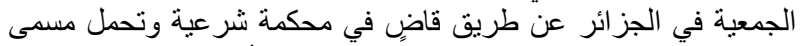

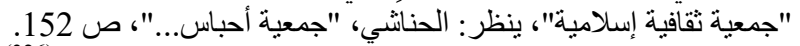
(326)"Lettre de President du...", le 1mai, 1917, Carton 310. Dossier 2. p. 48.

(327)(قل أعطت الحكومة الفرنسية ابن غبريط كامل الصناحيات لتمثيل

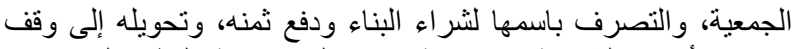

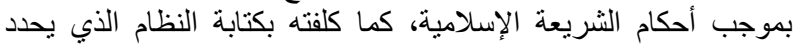

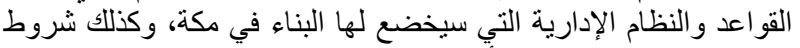
قبول الحجاج الملتجئين إليه أنثناء موسم الحج، لينظر:

"Traduction en Francais de Constitution...", Carton 310. Dossier 2, P. 17.

(328) تجدر الإشارة إلى أن قرار إحداث "جمعية أحباس الحرمين

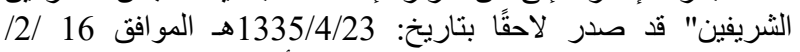

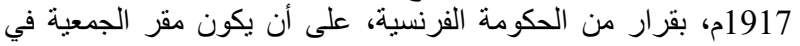

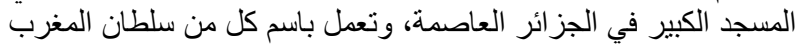
وباب تونس ومفتي الجز ائر، ينظر العاري

"Notes on the Mission of French to Sherif Husein ruled Mecca", Arab Bureau, 16 Febrory 1917, F.O. 6075. 
1335-8-19هـ/ 1917-6-10م أكد فيها أن عليه أن يقوم بالعمل الآتي: 1ـ العمل مع الثريف حسين على

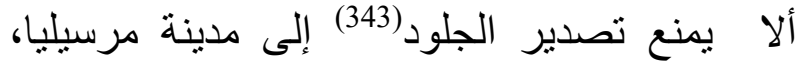
و إقناعه بكل قوة بأن رفع الحظر عن تصدير الجلود(344) إلى فرنسا هو دليل صدان رفعة الثة الثريف

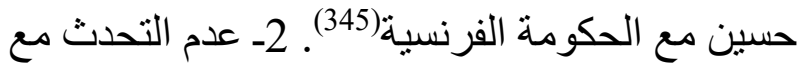
الثريف حسين في قضية البنك العثماني(346) حتى

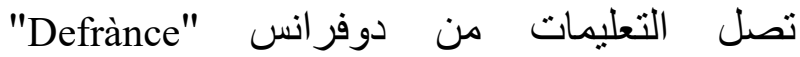
بالقاهرة(347). 3- يجب التعات من التفاهم مع الثريف حوفين على كيفية حساب الرسوم الجمركية(348) وهذا بلفئ

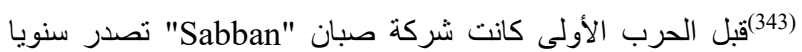

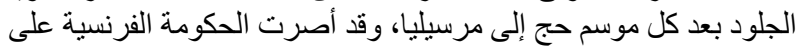

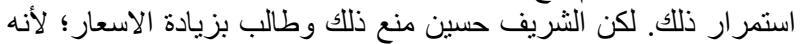
كان يمر بظروف ماليه صعبة ينظر : "Lettre de President du...", le 1mai, 1917, Carton 310. Dossier 2. p. 46.

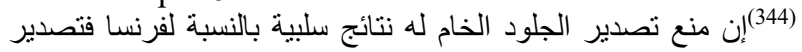

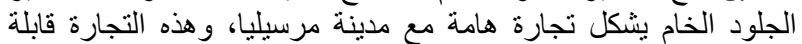
للتوسع نظر النقص الجلود في بقية أنحاء العالم، ينظر : "Lettre de President du...", le 1mai, 1917, Carton 310. Dossier 2. p. 53.

(345)"Lettre de Colonel Bremond, Chef de la Mission...", 10 Juin 1917, Carton 310. Dossier 2.

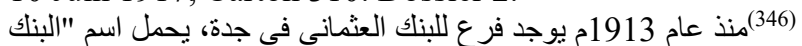

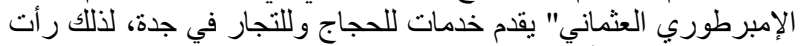

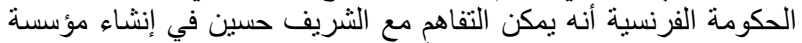

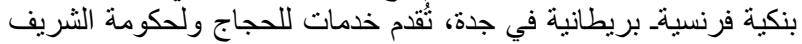

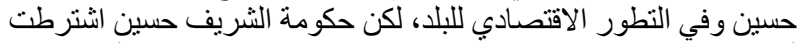

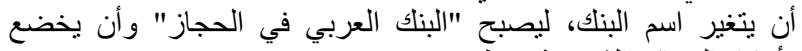
لأحكام المحاكم الثرعية، ينظر :

"Lettre de President du...", le 1mai, 1917, Carton 310. Dossier 2. p. 51.

(347)"Lettre de Colonel Bremond, Chef de la Mission...", 10 Juin 1917, Carton 310. Dossier 2.

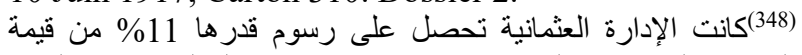

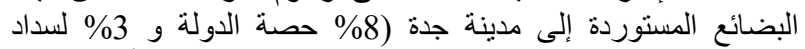

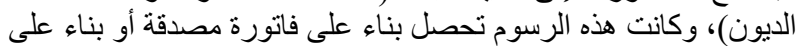

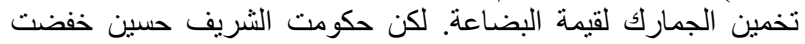

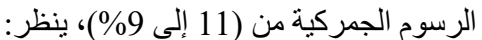

"Lettre de President du...", le 1mai, 1917, Carton 310. Dossier 2. p. 54.
مصطفى بن أحمد شرشالي(336) (نظرا لمغادرة بريموند "Bremond" ولاية الحجاز لعدة أسابيع) للقيام بمهمة خلمة تخدم تهلحة الحكومة الفرنسية(337)، وكذلك لسفر ابن غبريط إلى الى باريس(338) وكانت على النحو الآتي: 1- المحافظة على التناغم مع الحكومة البريطانية. 2- إكمال الإجراءات القانونية اللازمة لتملك ملكية نهائية عقار (339) مكة باسم "جمعية أحباس الحرمين الشريفين"(340). 3- تحويل ذلك العقار إلى وقف. 4تجهيز العقار لاستخدامه نزلاً "خاناً" أثناء موسم حج إسى وله 1335هـ/ 1917م. 5- التجهيز و الإشر اف على حج

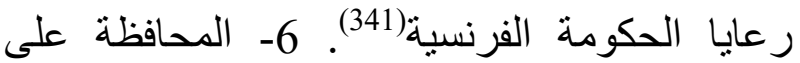
سلامة و استقلال و لاية الحجاز (342). وعلى إثر ذللك وصلت رسالة من بريموند "Bremond" إلى مبعوثها الرسمي شرشالي بتاريخ:

وانه (336) أصبح شرشالي يحمل صفة المبعوث الرسمي للحكومة الفرنسية.

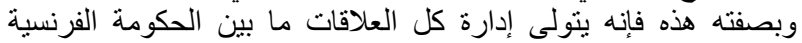

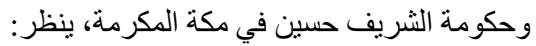
"Lettre de Colonel Bremond, Chef de la Mission Francaise" M. Cherchali. Djeddah, Dossier, le 10 Juin 1917. Ministere de Àffaires Étrangeres, 1918-1919. "Àrabie-Hejaz", 18. Mission de M. Cherchali. Serie É. Carton 310. Dossiér 2.

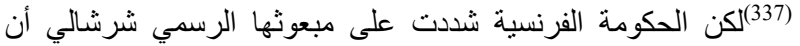

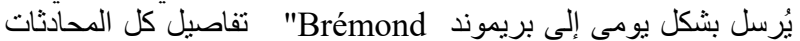
التي ستجرى مع الثنريف حسين؛ لأن بيده الإدارة العليا، ينظر : لئل

"Lettre de President du...", le 1mai, 1917, Carton 310. Dossier 2. p. 54.

${ }^{(338)}$ Ibid.

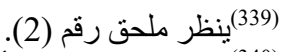

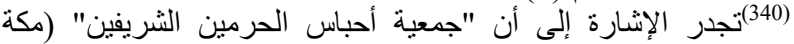

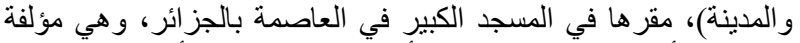

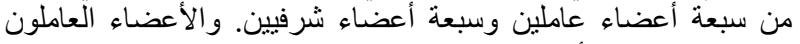

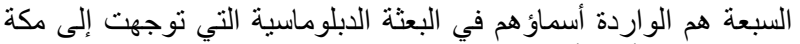

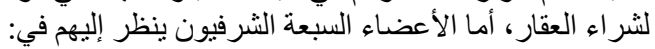
"Traduction en Francais de Constitution...", Carton 310. Dossier 2, P. 17.

(341)"Lettre de President du...", le 1mai, 1917, Carton 310. Dossier 2. p. 46.

${ }^{(342)}$ Ibid, p. 48. 
وقفا، وتحويله إلى مأوى للمحتاجين من حجاج شمال وغرب أفريقيا(355). وعلى أية حال، وصلت البعثة إلى مصر وعند وصولها أرسل السفير الفرنسي في القاهرة دوفرانس "Defrance" رسالة إلى وزير الحرب الفرنسي يخبره فيها بأنه كانت هناك نتائج عدة نوصلت لهائ البعثة الفرنسية بقيادة ابن غبريط (356)؛ لأن البعثة فئة فئن في الأصل صمدت على طريقة الحكومة الفرنسية، لذللك فإنها عرفت كيف تُرى وكيف تُفهم، وفُتحت الاصن

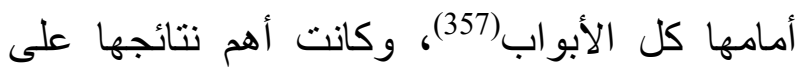

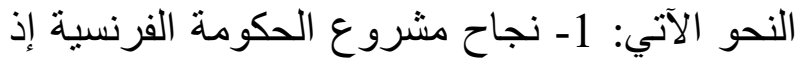

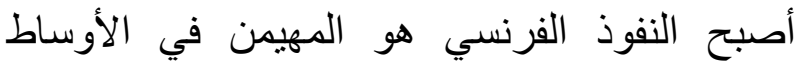
السياسية في مكة(358). 2- أعطت سلوكيات حجاج المستعمر ات الفرنسية في شمال أفريقيا، سمعة طيبة عن الحكومة الفرنسية لكل المسلمين في أنحاء المعمورة(359). 3- حصلت الحكومة الفرنسية فجأة بعد موسم حج 1334هـ/ 1916م على مكانة عظيمة

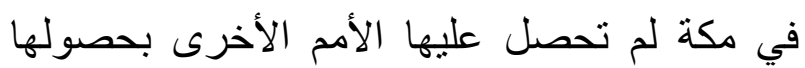
على الاهتمام و الرعاية من حكومة الثريف حسين

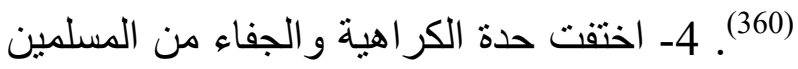
تجاه الحكومة الفرنسية وخاصة الذين كانوا يكنّون لها الكره و الجفاء، كما جنبت الحكومة الفرنسية مشكلات الانتفاضات و المقاومة المسلحة(361).

(355)"Traduction en Francais de Constitution...", Carton 310. Dossier 2, P. 17.

(356)"Le President du Conseil Ministre...", du 26 Octobre 1916.

${ }^{(357)}$ Journal Le Matin, N 11946,11 Novembre 1916, P, 1.

${ }^{(358) " L e ~ P r e s i d e n t ~ d u ~ C o n s e i l ~ M i n i s t r e . . . ", ~ d u ~} 27$ Octobre 1916.

${ }^{(359)}$ Ibid.

${ }^{(360)}$ Ibid.

${ }^{(361)}$ Ibid؛
سيكون عند عقد معاهدات تجارية(349) معه(350.) يجب التفاهم مع الثريف حسين على الأبعاد الدولية لقضيتي الجمارك و التجارة(351). ولذلك وجهت الحكومة الفرنسية إلى بعثتها رسالة مضمونها كالآتي: إن المهمة التي تقوم بها البعثة

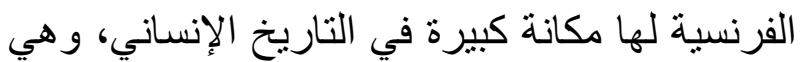
مهمة عظيمة وجليلة، وعلى الجميع أن يتشاركوا فيها، وأن يكونوا على تفاهم تام، كما يجب أن يبذل

\section{كل واحد منهم كل جهة لإنجاح البعثة(352) 10- مغادرة البعثة، ونتائجها:} غادرت البعثة الفرنسية بصحبة الحجاج المغاربة مدينة جدة يوم الأربعاء بتاريخ: 20-12-1334هـ/ 1916-10-18 الفرنسية إلى مبعوثها شرشالي أن ينوب عن ابن إنائ غبريط(354) الذي غادر مكة في إكمال الإجراءات

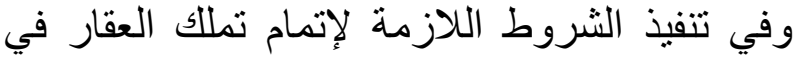
مكة، كما أوكلت إلى شرشالي بمهمة جعل العقار

إدارته في لفت نظر الثريف حسين إلى مساوئ المبادرات التي تتخذها

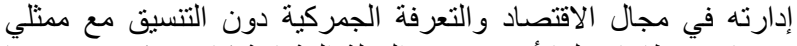

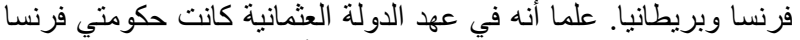

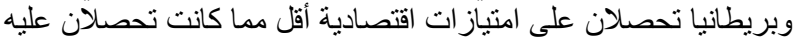

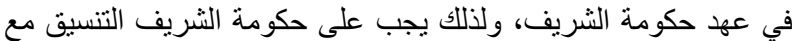

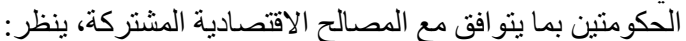

"Lettre de President du...", le 1mai, 1917, Carton 310. Dossier 2. p, 54.

${ }^{(350)}$ Ibid.

${ }^{(351)}$ Ibid.

(352)"Lettre de Colonel Bremond, Chef de la Mission francaise au Capitaine Saad", 5 Juin 1917. Carton 310. Dossier 2.

(353)"Le President du Conseil Ministre...", du 25 Octobre 1916.

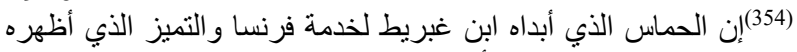

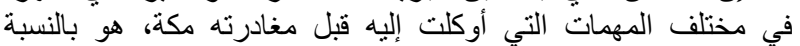

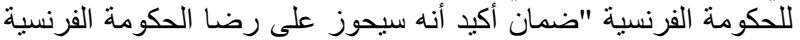
التام في المهمة التي شرفتكم بها"، ينظر : النهان "Lettre de President du...", le 1mai, 1917, Carton 310. Dossier 2. p, 54. 
ونتيجةً لما سبق حصل بريموند "Bremond" مباشرة بتاريخ: 1334-12-22 هـ/ 1916-10-20م على موافقة وزارة الخارجية الفرنسية بإحداث تمثيل دبلوماسي في مكة؛ لأن ذلك سيكون مفيدا لها عندما يصبح الثريف حسين مجاور ا لها في سوريا(370). و على إثر ذلك تم تعيين المترجم السابق في قنصلية

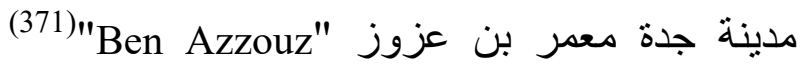
بإدارة شؤون الحجاج المسلمين(372)؛ لكنه في الحقيقة كان يعمل بصفة نائب قنصل في مكة(373) وكان يقوم بلدور صلة الوصل ما بين بريموند "Bremond"

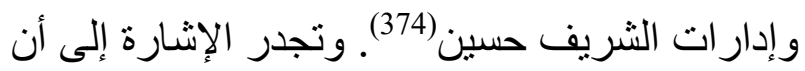
الحكومة الفرنسية قد استخدمت أسلوب الحكومة البريطانية بالتستر خلف مصالح ولاية الحجاز لإحداث مركز نفوذ لها هنالك من أجل المحافظة على بلى استمرار استعمار ها لبلاد شمال أفريقيا من خلهن هلادل السيطرة على الثريف حسين (375). 11- 11

وفي ختام هذا البحث يتضح أن الحكومة الفرنسية لم تتوان عن إرسال بعثتها إلى ولاية الحجاز من أجل هل أن تخوض معها في شؤون سياسية تهم مصالحها

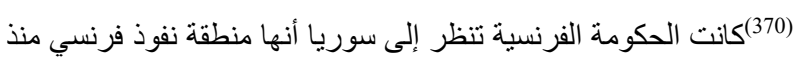

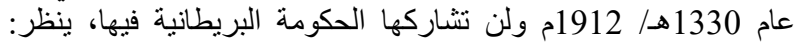
حجار، بلاد الثام، ص 19. (371)"Lettre de President du...", le 1mai, 1917, Carton 310. Dossier 2. p, 84.

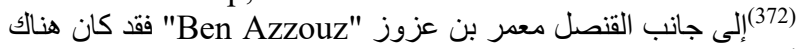

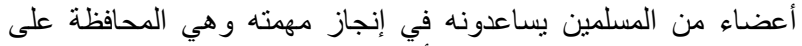
استقلال الثريف حسين وسلامة الأر اضي المين المقدة، ينظر:

"Lettre Ministre des Affaires...", du 2 Octoper 1916, "Londres, Ambassade Fonds K, 378Po/K 382".

(373)"Proces-Verbal de la Seance...", du 14 Decembre, 1915, Carton, 2 Mi 101, vol, 6e; "Lettre de President du...", le 1mai, 1917, Carton 310. Dossier 2. p, 54.

(374) Ibid.

(375)"Proces-Verbal de la Seance...", du 15 Decembre, 1915, Carton, 2 Mi 101, vol, 7e.
أوجدت البعثة للحكومة الفرنسية مكانة سياسية مرموقه في شبه الجزيرة العربية، إذ كان اسم فرنسا

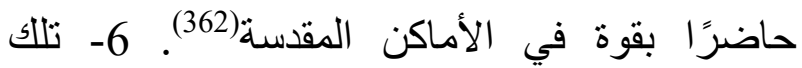
المكانة التي حظيت بها الحكومة الفرنسية في مكة كانت صمام أمان لفرنسا في مستعمر اتها الإسلامية المنتشرة في القارة الأفريقية(363). 7 ـ كسبت الحكومة الفرنسية مكانة عظيمة لدى المسلمين في بلاد الثام(364) مما سهل لها احتو اءها سياسيا لاحقان(365). 8- مكنت الحكومة الفرنسية من ازدهار تجارتها بين

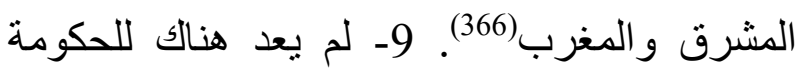
الفرنسية ما يسمى إسلاما منغلقا و عدائيا؛ لأن شريف مكة يدعو ها إلى تقديم دعمها ومساعيها(367). 10بروز نجم ابن غبريط الذي أدى مهمته ببالغ الإتقان؛ لأنه قد حاز على ثقة شريف مكة، و على إثز ذللك عمل على تتظيم الدعاية في مكة بحنكة ونشاط

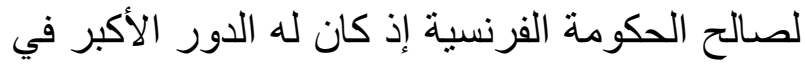
الوصول إلى تلك النتائج التي يمكن وصفها بأنها نتائج عظيمة(368). 11- يجب أن تستغل الحكومة الفرنسية تللك النتائج العظيمة و أثنار ها الإيجابية على الأمة الفرنسية(369).

(362)"Le President du Conseil Ministre...", du 28 Octobre 1916.; Journàl Lé Màtin, N 11946, 11 Novémbré 1916, $\mathrm{P}, 1$.

${ }^{(363)}$ Ibid.

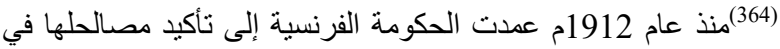

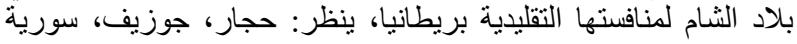
بلاد الثام تجزئه وطن (دمشق: دار طلاس، 1999م)، ص19 صنارئ ${ }^{(365)}$ Meynier, L Algerie Revellee, p. 539.

(366)"Le President du Conseil Ministre...", du 23 Octobre 1916.

${ }^{(367)}$ Ibid.

${ }^{(368)}$ Ibid.

${ }^{(369)}$ Ibid. 
الاستعمارية، لما لها من مكانة دينية في نفوس شركاتها البحرية من جني الكثير من الأرباح التجارية من (خلال نقل الحجاج إلى من الأماكن المقسة).

أثبت البحث نجاح البعثة فقد حسّنت العلاقة بين فرنسا وولاية الحجاز، كما عكست مردودا إيجابيا

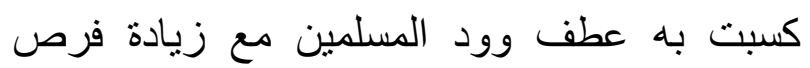
الدولة الفرنسية في السيطرة على تلك البلدان من زئن

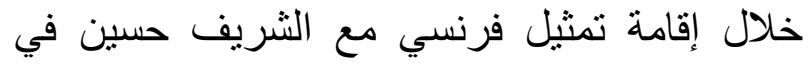
مكة، وقد لعبت البعثة بقيادة ابن غبريط والوند

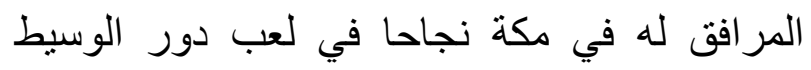

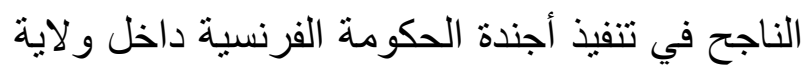

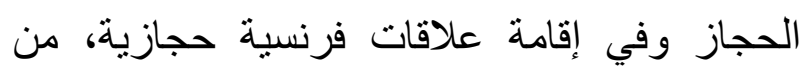
خلال تسيير حملات للحج عندما فتحت الحكومة الفرنسية باب حج موسم 1334 هـ/ 1916م، وأكدت فئل للشعوب الإسلامية أنها لا تقف في وجها ممارسة

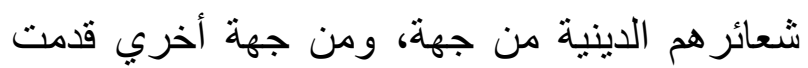
لهم الخدمات الصحية؛ لأن الحكومة الفرنسية كانت ومن التهن

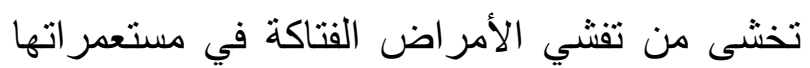
الإسلامية.

كما أن مشروع البعثة يكثف عن طبيعة السياسة

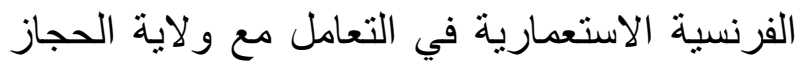

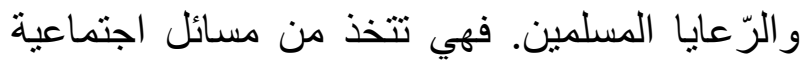

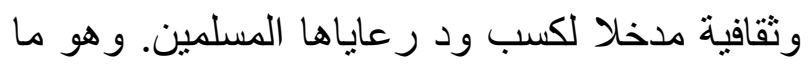

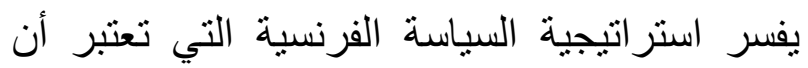

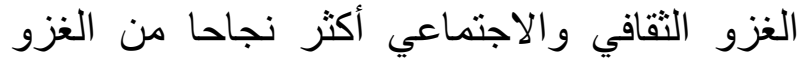

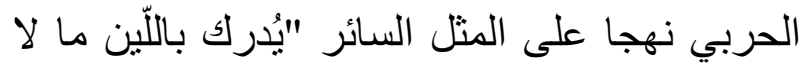
يُدرك بالقُوة.

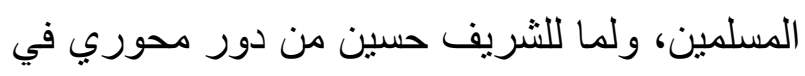
الحرب العالمية الأولى لكونه يسيطر على الأماكن

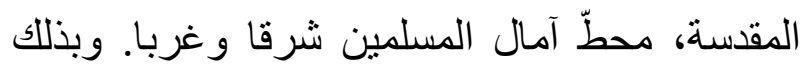
أصبحت مكة مسرحا للتنافس بين فرنسا وبريطانيا؛ لأن الأخيرة كان لها قصب السبق لاى حكومة الثريف حسين وفي أجزاء شاسعة من شبه الجزيرة العربية، وبذللك كثفت الدراسة عن وجود تنافس

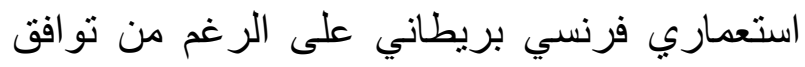
المصالح حول و لاية الحجاز من خلال محاولة فرنسا عرقلة هيمنة الحكومة البريطانية على شبه الجزيرة

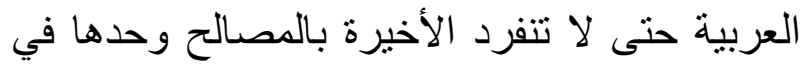
و لاية الحجاز ؛ لأن للحكومة الفرنسية مصالح خاصة في تعزيز علاقتها مع الثريف حسين كان في لإنهان لهان مقدمتها إز الة الدولة العثمانية من الخارطة العالمية. وبالرغم من أن الحكومة البريطانية لم تغير موقفها من الحكومة الفرنسية من (خلال معارضتها للبعثة

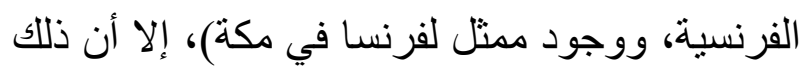
لم يمنعها من التعاون معها. وبذللك نجحت البعثة الفرنسية في دعم الثريف حسين في مواجهة العثمانيين. مثّل مشروع شراء نُزل "خان" في مكة مسألة سياسية واجتماعية إذ كانت مدخلا لتوطيد العلاقات بين الحكومة الفرنسية والثريف حسين لعام 1334هـ/ 1916م؛ إذ كان الهدف من ور ائه استمالة المسلمين وتقديم كل العون لرعاياها الحجاج القادمين من مستعمر اتها في شمال و غرب أفريقيا وتقديم كل ما يحتاجون إليه حتى لا تضيع هيبتها أو تخسر 
ملحق رقم (1): صورة من الورقة الأولى لموقع العقار الذي اشترته الحكومة الفرنسية في مكة باسم ابن غبريط، عام 1334 هـ/ 1916م.

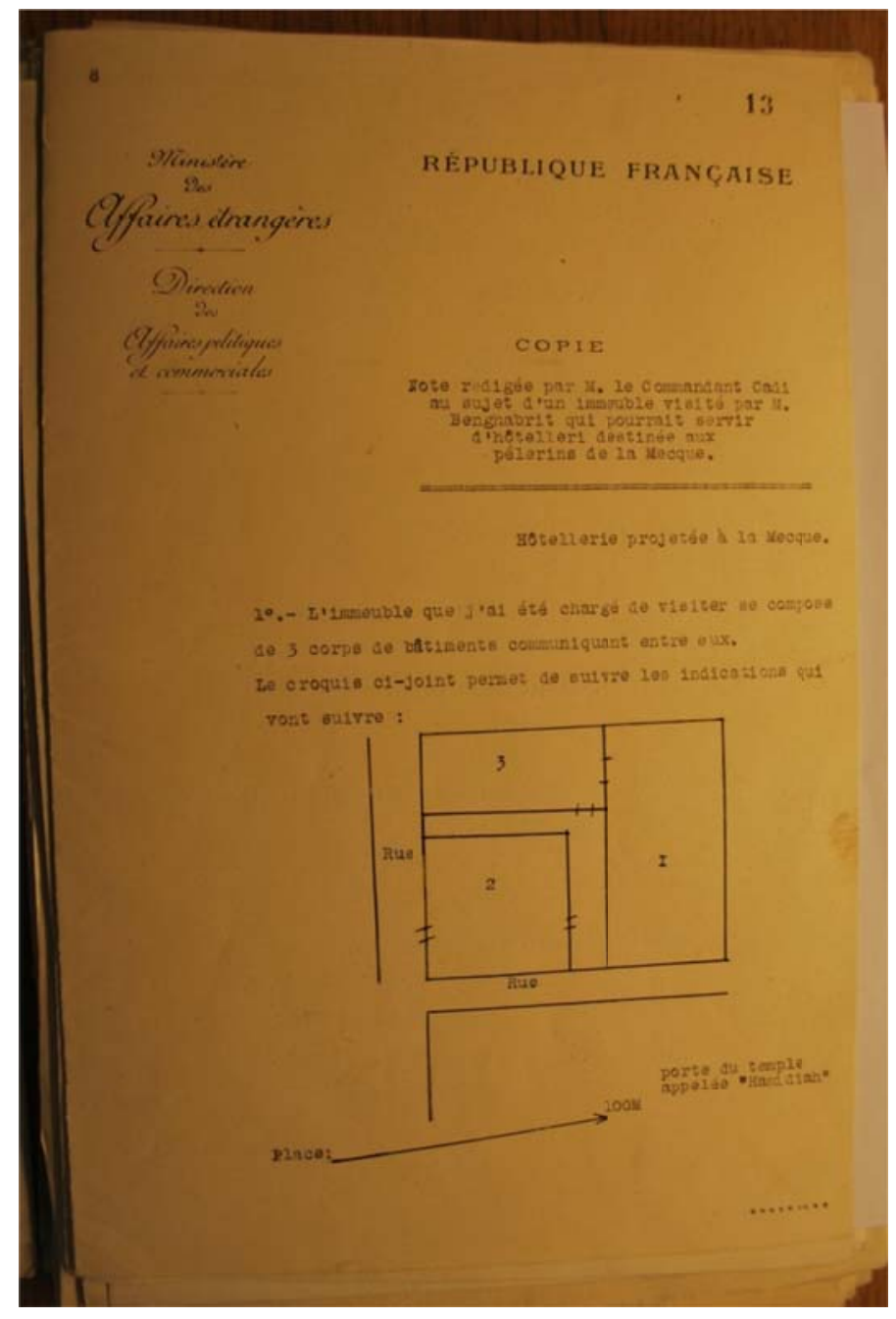


"Note Redigee p ar M. le Commandant Cadi...", 1916, "Àrabie-Hejaz", 18. Mission de M. Cherchali. Serie É. Carton 310. Dossier 2.

ملحق رقم (2): صورة من الورقة الأولى لصك العقار الذي اشترته الحكومة الفرنسية في مكة باسم ابن غبريط، عام 1334 هـ/ 1916م.

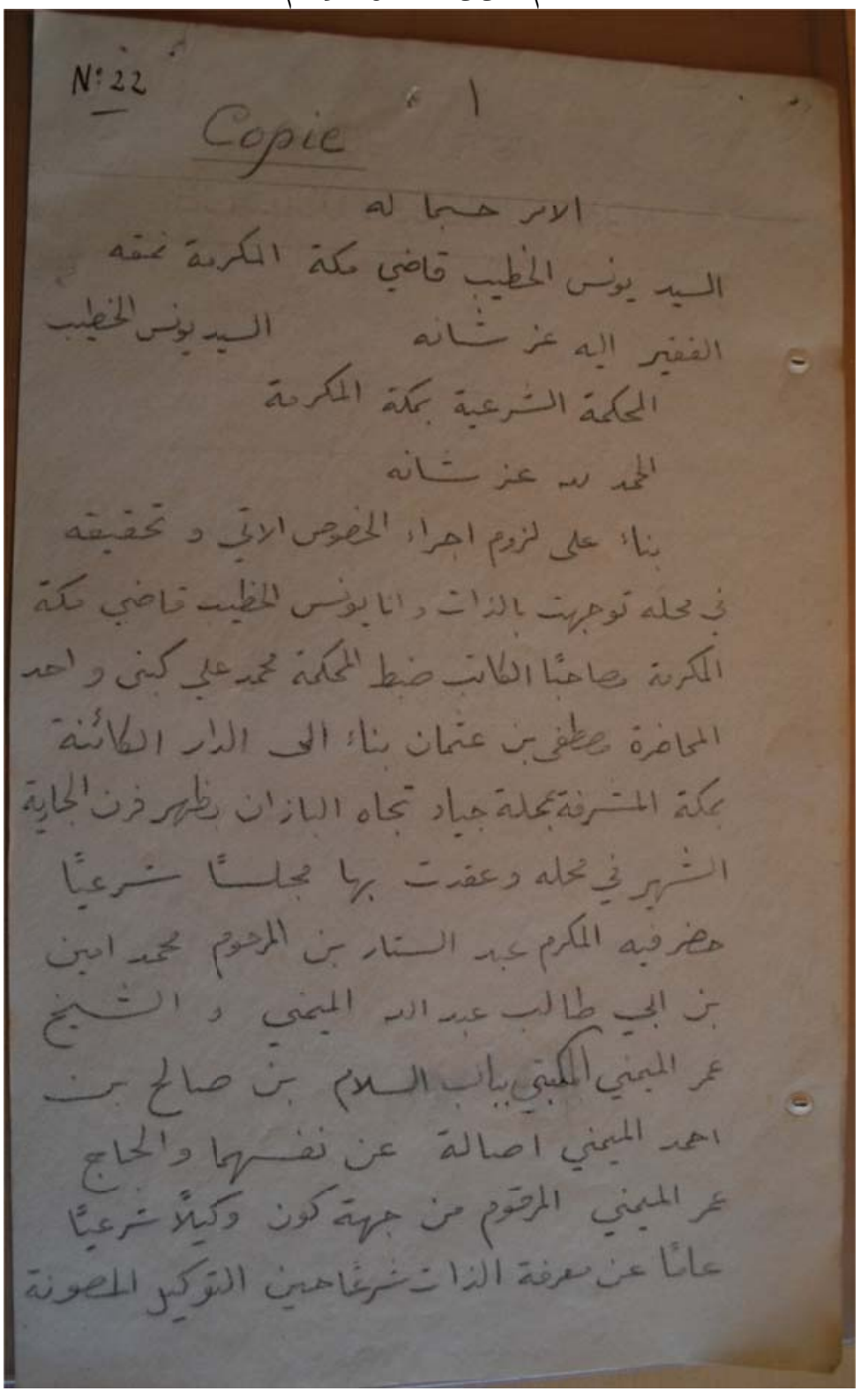




$$
\text { سعيد بن مشبب بن سعيد القحطانى }
$$

"Àmbassadeur Francais au Caire". Ministere des Àffaires Étrangeres Lr, Carton, 529, P. 1.

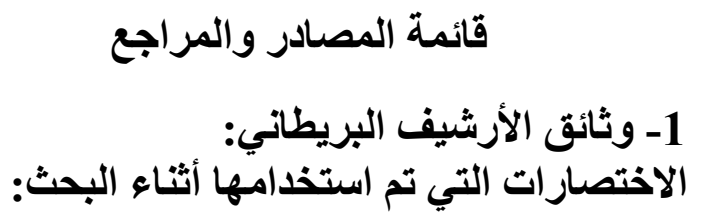

Abbreviations;

1- F. O: Records Created or inherited by the Foreign Office.

- "Arabian Report" N. S, 16 July 1916, F.O.17/177.

- "Arabian Report" N. S, 10 August, 1916, F.O.17/178.

- Foreign Office Memorandum, 14 August, 1916, F.O. 371/6074.

- Telegram from the Resident, Cairo to the Secretary of State for the Colonies, 28 Augest 1916, F.O. 882/10.

- Telegramme from Political Resident to the Secretary to the Government

of India in the Foreign and Political Department, 29 Augest 1916, F.O. 371/6096.

- "Arabian Report" N. S, 23 September 1916, F.O.17/177.

- Political Resident to the Secretary to the Government of India in the Foreign and Political Department, 24 Septembre 1916, F.O. 371/2476.

- Telegram from Resident Aden to Sir Mcmahon Cairo, 15 October 1916, F.O. 2487.

- "Notes on the Mission of French to Sherif Husein ruled Mecca", Arab Bureau, 16 Octobre 1916, F.O. 6074.

- Statement of Lord Grey Regarding Mission to Mecca, 1916, F.O. 371/2479.
- Italian War Aims and Claims in regard to Arabia, 1916, F.O. 371/11448.

- Political Eastern Arabia, 1916, F.O. 371/11447.

- Under Secretary of State Foreign Office to India Office, Political Turkey, 1916, F.O. 371/2799.

- "Notes on the Mission of French to Sherif Husein ruled Mecca", Arab Bureau, 16 Febrory 1917, F.O. 6075.

- Telegram Secret From Resident Jedda to High Commissioner Cairo "Arabie Report", 12 July 1917, F.O. 371/6075.

- Telegram Secret From Resident Jedda to High Commissioner Cairo "Arabie Report", 11 August 1918, F.O. 371/6075.

\section{2- Oriental and India Office ( $\mathrm{L} / \mathrm{P} / \mathrm{S} /)$.}

- Telegram from the Secretary to the Government of India in the Foreign and Political Department, 1916, L/PS/10/1175.

- Memorandum on British Commitments to Cairo, Political Intelligence Department, F.O. 1916, L/PS/10/1089.

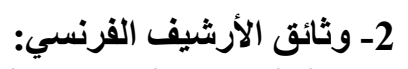

- "Àmbassadeur Francais au Caire". Ministere des Àffaires Étrangeres Lr, Carton, 529, P. 112.

- "Commissaire Resident General, Relative a la Creation Hotolleries la Mecque", Rabat, le 23 Juin 1916, Àrchives Diplomàtique de Nantes. Commission Interministerielle aux Àffaires Musulmanes, Carton, 2 Mi 101, vol, $5 \mathrm{e}$. 
- "La Depeche le Consul de France a Djeddah a Son Excellence Poincare Prisident du Conseil" Service Historiqué de la Defence, 20 Fevrier 1912, Dossier, 57. 13 Fevrier 1912, Dossier, 58. 14 Fevrier 1912, Dossier, 59. 20 Fevrier 1912, Dossier, 60.

- "La Depeche Direction des Affaires Politiques et Commerciales, Sous-Diriction Déuropes", du 14 Juin, 1916. Àrchives Dipiomatique de Nantes, Maroc, Dossier, No, 660. du 13 Juin, 10, 24, 25,1916, Rabat No, 977.

- "La Depeche Ministre des Affaires Etrangeres", Paris, du 5, 9, 12, Aout, 1916, Archives Diplomatiques de Nantes, "Londres, Ambassade Fonds K, 378Po/K 381".

- "La Depeche, Sairt Aulaire, Ministre Plenipotentiaire Delegues", du 9 Octoper 1916. Àrchives du Ministere des Àffàires Étrangeres, Àfrica II, 169-1.

- Étrangeres, Guerre 1914-1918, Hedjaz, Mi P 1462, Hotelleries de La Mecque (Decembre 1916-Avril, 1918), (Paris), vol. 1710.

-"Lettre de Colonel Bremond, Chef de la Mission francaise au Capitaine Saad", 5 Juin 1917. Carton 310. Dossier 2.

- "Lettre de Colonel Bremond, Chef de la Mission Francaise" M. Cherchali. Djeddah, Dossier, le 10 Juin 1917. Ministere de Âffaires Étrangeres, 1918-1919. "Àrabie-Hejaz", 18. Mission de M. Cherchali. Serie É. Carton 310. Dossiér 2.

- "Lettre Ministre des Affaires Etrangeres", Paris, du 4, 6 Septembre, 2 Octoper 1916, Àrchives Diplomatiques de Nantes, "Londres, Ambassade Fonds K, 378Po/K 382".

- "Lettre de President du Conseil", Ministre des Àffaires Étrangeres a Monsieur Mustapha Cherchali Charge de Mission au Hedjaz. Paris, lelmai, 1917. Ministere de Àffaires Étrangeres , 1918- 1919. "Arabie-Hejaz", 18. Mission de M. Cherchali. Serie É. Carton 310. Dossier 2. p. 46. p. 47 p. 48 . p. 49 . p. 50. p. 51. p. 53, p. 54. $\mathrm{p}, 84$.
- "Note Redigee p ar M. le Commandant Cadi au Sujet" d'un Immeuble Visite par $M$. Benghabrit qui Pourrait Servir d'hotellerie Destinee aux Perlerins de la Mecque Ministere de Àffaires Étrangeres, 1918- 1919, "ÀrabieHejaz", 18. Mission de M. Cherchali. Serie É. Carton 310. Dossier 2.

- "Le President du Conseil Ministre des Affaires Etrangeres a Monsieur de Fleuriau Charge d Affaires de la Republique Francaise a Londres", Paris, Service Historique de là Defence, du 22, 23, 27, 28 Octobre 1916.

- "Proces-Verbal de la Seance de la Commission Interministerielle des Àffaires Musulmanes", Àrchives Diplomatique de Nantes, du 2, 3, 14, 15, Decembre, 1915, Carton, 2 Mi 101, vol, 6e vol, 7e, 8e.

- "Rapport Médical sur le local Propose". Mecque, le 11 Octobre, 1916. Ministere de Àffaires Étrangeres, 1915- 1919, "ÀrabieHejaz", 18. Mission dé M. Cherchali. Serie É. Carton 310. Dossier 2, p. 11, 12.

- "Telegramme Affaire Etrangeres, Reponse a letter", No, 878, du 15 Juin, 1916. Àrchives Dipiomatique de Nantes, Arab-Hedj, ELev.18-40.

- Tiegramme du Conseil Ministres dés Àffaires Étrangeres Francais, No, 39, du 17 Octoper, 1916, Àrchives du Ministere des Àffaires Étrangeres: Àrabie-Hedjaz. Càrton, 77.

- Telegramme de Francais au Ministere des Àffaires Étrangeres Francais, No, 40, du 4 Octoper, 1916, Àrchives du Ministere des Àffaires Étrangeres: Àrabie-Hedjaz. Carton, 78.

- "Telegramme, Ministre des Affàires Etrangeres", Paris, du 3, 4, Septembre 1916. Àrchives Diplomatiques de Nantes, "Londres, Ambassade Fonds K, 378Po/K 382".

- "Telegramme Ministre des Affaires Etrangeres", Paris, le 21 Jànviér 1917. Service Historique de la Defence. No "2837".

- "Telegramme du Quài d'Orsay au Resident General du Màroc à l'intention de Ben 
سعيد بن مشبب بن سعيد القحطانى

Ghabrit". Cite in Le Pautremat Ministere de Àffaires

- "Traduction en Francais de Constitution de Societe Civile". Ministere des Àffaires Étrangeres, 1918- 1919. "Àrabie - Hejaz", 18. Serie É. Carton 310. Dossier 2, P. 18.Carton

ـ السدحان، عبد الله ناصر، (2014م)، الأوقاف على الحرمين الثريفين، خارج المثلكة العربية السعودية، الرياض: مركز تاريخ مكة المكرمة.

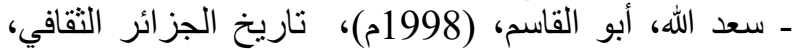

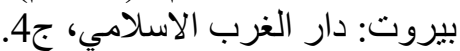
ـ سعيد، أمين، (د.ت)، أسرار الثتورة العربية الكبرى ومأساة الثريف حسين، بيروت: دار الكتاب. الكئ.

- سعيد، أمين، (د.ت)، الثثرة العربية الكبرى تاريخ مفصل

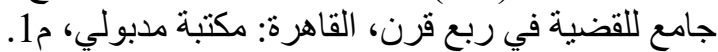

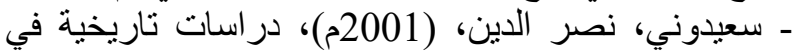

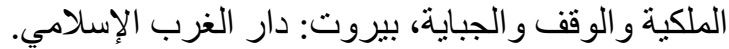

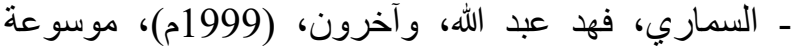
تاريخ الملك عبد العزيز الدبلوماسي، الرياض: مكنبة الملك

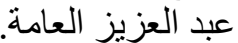
الطويل، توفيق، (1988م)، التصوف في مصر في العصر

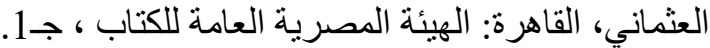

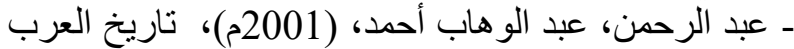
الحديث 1798-1920م، دبي: دار القلم للنشر والتوزيع. ـ عطية الله، أحمد، (1968م)، القامئ، القاموس السياسي، القاهرة: دار النهضة العربية.

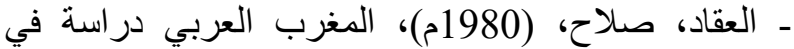

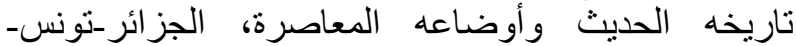
المغرب الأقصى، القاهرة: مكتبة الأنجلو الدصرية.

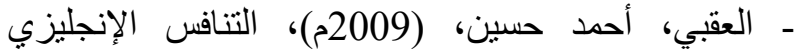

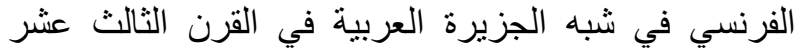

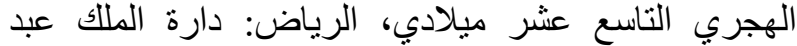
العزيز. - العزي. ـ أبو عليه، عبد الفتاح حسن، (1991م)، تاريخ الدولة السعودية الثانية، الرياض: دار الثريخ.

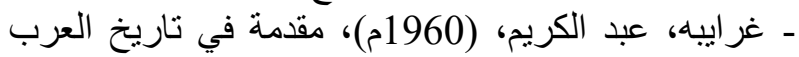
الحديث 1500-1919م، العراق والجزيرة العربية، دمشقي:

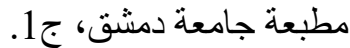
ـ فريد، مححد، (2012م)، تاريخ الدولة العثمانية، هنداوي، ط2. ـ فريحات، حكت عبد الكريم، (1987م)، السياسة الفرنسية تجاه الثورة العربية الكبرى 1916-1920م، عمان: دار الكرئ

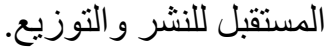

310. Dossier 2, P. 16. Carton 310. Dossier 2, P. 17.

\section{المراجع العربية والمعربية}

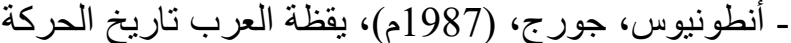

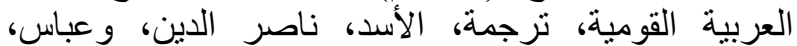

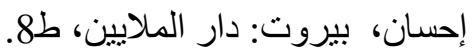

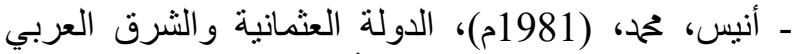
-1514-1914م، القاهرة: مكتبة الأنجلو المصرية.

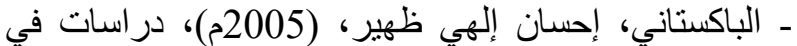

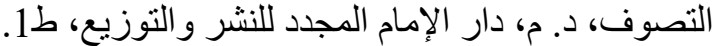

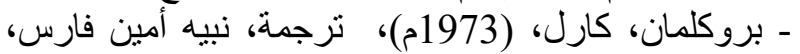
ومنير البعلبكي، تاريخ الثعوب الإسلامية، بيروت: دارئ دار العلم

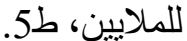
ـ البعلبكي، منير، معجم أعلام المورد، (1992م)، لبنان: دار

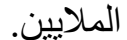
ـ التميمي، عبد الجليل، (1994م)، دراسات في التاريخ العربي العثماني 1453-1918 "سياسة الاتحاديين ببلاد الثام و الثورة العربية سنة 1916م محاولة جديدة للفهم"، ز زواني: منشور ات مركز الدراسات و البحوث العثمانية.

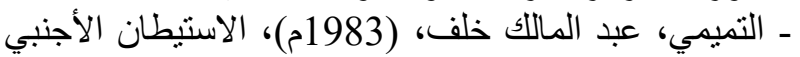
في الوطن العربي دراسة تاريخية مقارنة، الكويت: عالم الألم

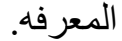
- حجار، جوزيف، (1999م)، سورية بلاد الثشام تجزئه وطن، دمشق: دار طلاس.

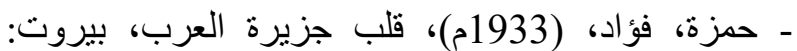

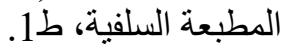
ـ الحميد، عبد اللطيف لمحيد، (1995م)، البحر الأحمر

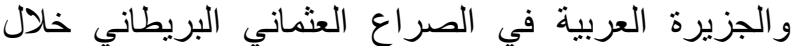

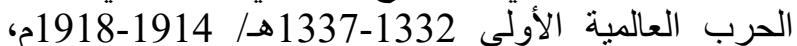

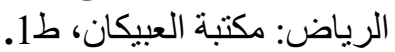

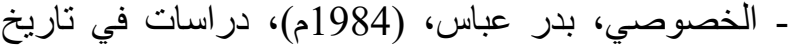
الخليج العربي الحديث والمعاصر، الكويت: منشورات ذات ذات

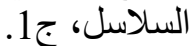
ـ الدقن، (1985م)، سكة حديد الحجاز الحميدية، دراسة و وثائقية (د. م، د. ن). - زين، نور الدين، (1987م)، الصراع الدونة الدولي في الثرق الأوسط وولادة دولتي سوريا ولبنان، بيروت: دار النهار النهار

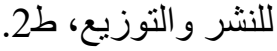


2- صحيفة العرب: (1435هـ الموافق 2014م)، العدد:

3- المدينة: ( 1436 هـ الموافق 2015م)، العدد: (18947).

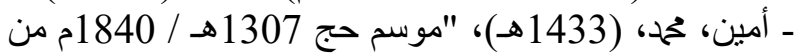
خلال تقرير دبلوماسي فرنسي" (38) مجلة الدارة، ع (4)، سنة

ـ التميمي، عبد الجليل، (1992م)، "سياسة الاتحاديين ببلاد

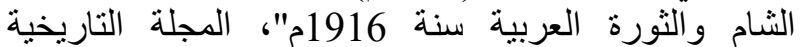

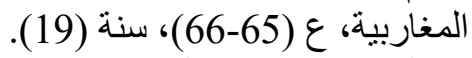

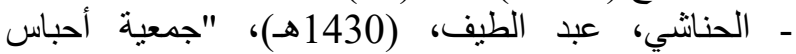
الحرمين الثريفين" مجلة الدارة، ع (3)، سنة (35).

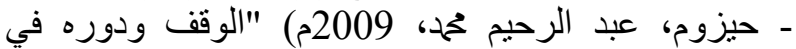

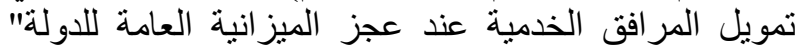

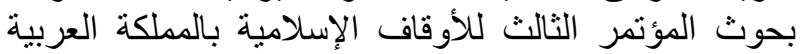
السعودية (المدينة المنورة: الجامعة الإسلامية. - سوقير ، النمذر، (1422هـ)، "العلاقات السعودية الفرنية العندية

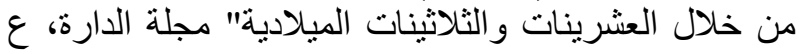

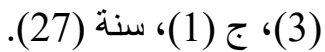
- الثيياني، جحمح عبد الهادي، (27) (2009م)، "أوقاف المدينة

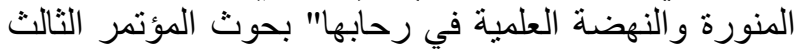
للأوقاف الإسلامية بالمملكة العربية السعودية، المدينة المنورة: الجامعة الإسلامية. ـ القليبي، محيى الدين، (1966م)، الإندة، الرباط في سبيل الله كيف

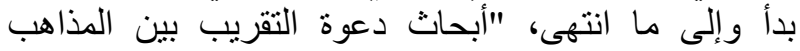

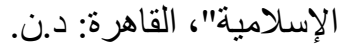

\section{المراجع الاجنبية}

- The Arab Builetin of The Arab Bureau in Cairo, 1916-1919, (London: Archive Editions, 1986) Vol, 2.

Arnoulet, Francois, (1995) Residents generaux de France en Tunisie ces mal-aimes, ed. (Marseille: Narration).

-Baker, Randel, (1979) King Husain and the Kingdom of Hejaz (Cambridge:Oleander Press).

- Bellon, (2016) Christophe: Àristide Briand, (Paris: Edition CNRS,

- Berneron-Couvenhes, Marie-Françoise, (2006) La Compagnie des Messageries Maritimes: Initiatives privees et subventions publiques a l'origine d'un grand Armement Commercial Français au XIXe siecle, (in Revue d'histoire maritime, no 5.
ـ قدري، أحمد، (1956م)، مذكراتي عن الثورة العربية، دمثق: مطابع ابن زيدون. ـ كوثراني، وجياه، (1980م)، التاريخ الاجتماعي: بلاد الثام:

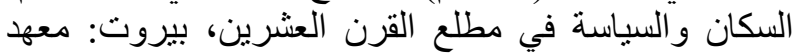
الاعتماد العربي. - مححد عفيفي، (1991م)، الأوقاف والحياة الاقتصادية في العصر العثماني، القاهرة: العيئة المصرية العامة للكتاب.

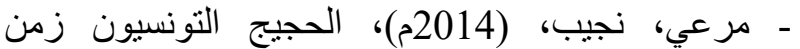

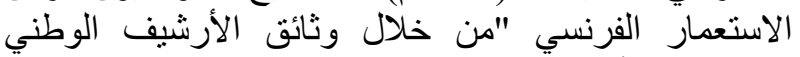

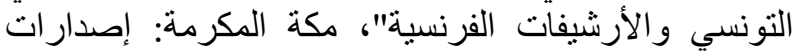
مركز تاريخ مكة المكرمة.

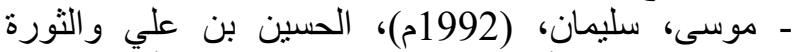

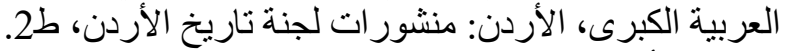

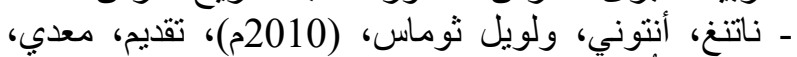
الحسيني، لُورنس لغز الجزيرة العربية، دمشقي: دار الكتاب

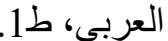
ـ الأنصاري، طدي، عبد القدوس، (1982م)، موسو عة تاريخ مدينة

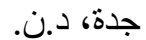
ـ نصيف، حسين ححمد، (1930م)، ماضي الحجاز وحاضره،

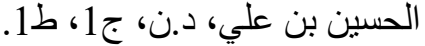

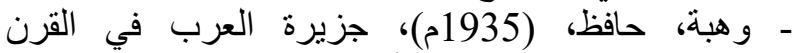

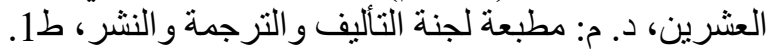

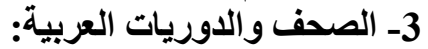

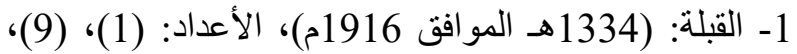

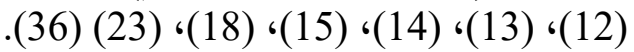

- Bertrand-Cadi, Jean-Yves (2005) Le Colonel Cherif Cadi: Serviteur de l'Islam et de la République. [Colonel Sharif Cadi: Servant of Islam and the Republic], (Paris: Maisonneuve \& Larose).

- Busch, Briton Cooper, (1971) Britain India and the Arabs 1914-1921(London: University of California Press).

- Chauvin, Jacques, Doumer, Paul, (1994) le Président Àssassine, (Paris: Les Editions du Pantheon).

- Clayton, Gilbert Falkingham, (1969) An Arabian Diary, (Press: University of California).

- Commandement de la IvmeArmée (Tanine, 1916).

- Denechere, Yves, (2005) Femmes et Diplomatie: France au XXe Siecle. (Presse: Universitaires Europeennes Bruxelles). 
- Elder, Dan, "French Policy Towards Hussyn Sharif of Mecca", An Annual Publishe by Frank Cass, Middel Eastern Studies, London, Vol, 26, No, 3 (July 1990).

- Gouvion, Edmond, (1920) Kitab Àayane elMarhariba, Tome,1, (Paris: Fontana Freres.

- Hoisington, William, (1995) Lyautey and the French Conquest of Morocco (Palgrave, Macmillan).

- Guler, Mustafa, (2002) Osmanli Devetinde Haremeyn Vakhflari, Xvii (Istanbul).

- Hurewitz, J. C, Diplomacy in the Near and Middle East: A Documentary Record: 19141956, (London: D.Van Nostrand Company, 1956).vol. 2.

- Hurbert Lucien, (1918) L Islam et Guerre (Paris: Chcllamel Editeur).

- Hubert, lucien, (1918) Une Politique Colonel, le Salut par les Colonel, Une Politique Colonel: le salut par les Colonel / Lucien Hubert (Paris: Librairie Felix Alcan).

- Julien, Charles Àndres, (2010) Histoire de Lalgrie Contemporàine (Alger: Edition Casbah).

- The King of Hedjeaz and Arab Independence, (London: Hayman Lilly Ltd, 1917).

- Leclerc, C, Àvec (1998) T.E. Lawrence en Arabie. La Mission Militaire Francaise au Hedjaz 1916-1920 (Paris: Lharmattan).

- هواري، قبايلي، (2014م)، مسألة الحج في السياسة

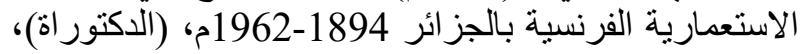

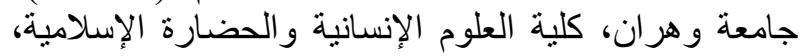

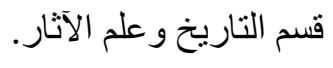

\section{الصحف الاجنبية}

- Éxcelsior, Paris, (10 Novembre 1916), Ànnee 7, N 2191.

- "Journal Officiel (28 December 1915. 20 January 1916. 28 December 1915), de la Republique Française, Debats Parlementaires". Chambre des Deputes.
- Malcolm, Edward Yapp's, (1990) The Making of the Modern Near East 1792-1923 (London: Forth Impression).

- Meynier, Gilbert, (1981) L Algerie Revellee, Là Guerre de 1914-1918 et le Premier Quàrt du Xxe (Geneva: Publications Libràirue Droze).

- Pascal, Pautremat, (2006)"La Mission du Lieutenant-colonel Brémond au Hedjaz, 19161917",Dans Guerresmondiales et Conflitscontemporains / $1\left(\mathrm{n}^{\circ} 221\right)$.

- Pautremat, Pascal, (2003) La Politique Musulmane de la France au xxe siecle. De l'Hexagone aux Terresd' Islam. Espoirs, Réussites, échecs (Paris: Maisonneuve et Larose).

-Records of the Hashimite Dynastics, Atwentieth Century Docuementary History (1995) "The Hashimite Leadership of the Arab Revolt" (London: Archive Editions) vol, 5.

- Riley, Carroll, (1972) Historical and Cultural Dictionary of Saudi Arabia (New Jersey: Scarecrow Press).

- Sellam, Sadak, (2006) La France et ses Muslmans (Alger: Casbah).

- Sbai, Jalila, (2012) Ben Ghabrit Abdelqader (Sidi Bel Abbes, Algerie, 1868-1954) Dictionnàire des Orientàlistes de Làngue Francaise (Paris: Editions Karthala).

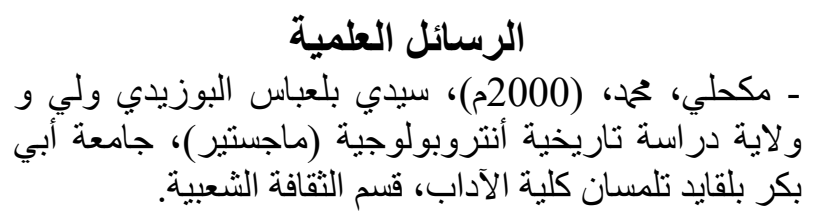

- "Journal Officiel (14 November 1916), de la Republique Française", Lois Decrets.

- Journal Le Matin, (11 Novembre 1916), N 11946.

\section{الروابط الإكترونية}

-Http://www.Assemblee-

Nationale.fr/Decouvrir-1-assemblee/role-etpouvoirs-de-1-assemblee-nationale. 
-Http://www. elysee.fr/Presidence/PaulDeschanel.

-Http://www.elysee.fr/la-presidence/pauldoumer.

-Http://data.bnf.fr/12951347/paul_bluysen. -Http://fresques.ina.fr/rhone-alpes/fichemedia/Rhonal00368/justin-godart.html.

-Http://gw.geneanet.org/deverdiere?lang.fr\&p-louis\&n-malvy.

-Http://orientxxi.info/l-orient-dans-la-guerre1914-1918.
Https://en.wikipedia.org/wiki/Charles_Lutaud.

Https://fr.wikipedia.org/wiki/Charles_Harding

e.

-Https://fr.wikipedia.org/wiki/Paul_Cambon. -Https://ar.wikipedia.org/wiki/HenryMcMahon.

-Https://ar.wikipedia.org/wiki/Arnold-TalbotWilson.

\title{
The Project of the French Government Mission to Mecca During the Reign of Sharif Hussein Bin Ali in 1334 AH / 1916 (A Historical and Documentary Study)
}

\author{
Saeed Mushabbab Saeed Alqahtani \\ King Khalid University
}

\begin{abstract}
This study aimed to study the what was called the project or the strategic plan of the French government mission to Mecca during the reign of Sharif Hussein Ben Ali in $1334 \mathrm{AH} /$ 1916. This study was a kind of a historical and documentary study. Its importance lied in trying to highlight the role played by the French government during World War I in an attempt to control the state of Hejaz through the head of its mission Ibn Ghabrit, who was entrusted with the tasks of the mission that was sent to Sharif Hussein in order to establish the bases of communication with Hussein. As the study showed, Ibn Ghabrit played a great role in buying a real estate (Khan / Inn) in Mecca to attract the attention of Muslims who were under the French control and colonization.This study was significant when put in its historical context, and when we are trying to understand the goal behind the mission which was to search for real estates in Mecca. However, there was another goal for the mission and that was to compete with British over the control of the state of the Hijaz due to the importance of this state to Muslims. This study gained even more importance as it relied on authentic documents and in making use of the historical context of criticism and analysis. This happened within the framework of the available texts and documents relied upon to produce a thorough and in depth study.
\end{abstract}


سعيد بن مشبب بن سعيد القحطانى

Keywords: French government Mission- Sharif Hussein bin Ali. 